\title{
Currency hedging strategies, strategic benchmarks and the Global and Euro Sovereign financial crises ${ }^{1}$
}

\author{
Massimiliano Caporin ${ }^{2}$, Juan-Angel Jimenez-Martin ${ }^{3}$ and Lydia Gonzalez-Serrano ${ }^{4}$
}

\author{
October 2013
}

\begin{abstract}
This paper investigates dynamic currency hedging benefits, with a further focus on the impact of currency hedging before and during the recent financial crises originated from the subprime and the Euro sovereign bonds. We take the point of view of a Euro-based institutional investor who considers passive investment strategies in portfolios holding European, British and US assets. We analyze the impact of the model specification to improve the risk-return tradeoff when currency risk is hedged. Hedging strategies of currency risk, using exchange rates futures and driven by several multivariate GARCH models, depend on the portfolio composition and period analyzed. Dynamic covariance models provide limited evidences of a decrease in hedging rations compared to naïve hedging strategies based on linear regressions or variance smoothing. Nevertheless, those results are coupled with better performances of dynamic covariance models in terms of hedging effectiveness an improved Sharpe ratios. The empirical evidences are observed both in-sample as well as in an out-of-sample exercise.
\end{abstract}

Keywords: Multivariate GARCH, conditional correlations, currency futures, optimal hedge ratios, hedging strategies.

JEL codes: C32, C53, C58, , G01, G11, G15, G17, G23, G32.

\footnotetext{
${ }^{1}$ The first author acknowledges financial support from MIUR PRIN project MISURA - Multivariate Statistical Models for Risk Assessment and from the European Union, Seventh Framework Programme FP7/2007-2013 under grant agreement SYRTO-SSH-2012-320270. The second author acknowledges financial support of the Ministerio de Ciencia y Tecnología of Spain through the research project ECO2012-31941.

2 University of Padova, Department of Economics and Management "Marco Fanno", e-mail: massimiliano.caporin@unipd.it

${ }^{3}$ Complutense University of Madrid, Department of Quantitative Economics, e-mail: juanangel@ccee.ucm.es. Corresponding author

${ }^{4}$ Rey Juan Carlos University, Department of Business Administration.
} 


\section{Introduction}

The global financial crisis (GFC) has had a tremendous impact on global financial markets and has been particularly severe in the Euro zone. The subsequent Euro sovereign crisis (ESC) further exacerbated the effects of the GFC and led to high levels of uncertainty regarding the future of the Euro currency. Taking the point of view of a Euro-based investor, under previous circumstances, the investment in international (non-Euro) traded stocks and bonds became especially attractive for two reasons. On the one hand, international diversification resulted in lower risk than purely domestic diversification. On the other hand, there were more possibilities in taking advantage of countries with different levels of growth, and consequently, with different opportunities for successful investment. However, international investment leads to the inclusion of exchange rate volatility, and thus, currency risk in a portfolio. In this framework, investors faced the choice of maintaining exposure to currency fluctuations, or to hedge the currency risk exposure in order to further improve the returns-risk performance of their (globally) diversified portfolio. These issues have received some attention in the financial economics literature.

De Roon et al. (2011) point out that risk hedging is just one of the two motivations for internationally diversifying portfolios. They show the manner in which speculative benefits can be achieved for both bond and equity portfolios when currency positions are included as a further asset class. Overall, they also provide supporting evidence to show that currency hedging reduces risk in multi-currency portfolios. Moreover, portfolio performance improves with hedging when the comparison is made in-sample, while out-of-sample results show evidence of benefits for bond portfolios but not for equity portfolios. Campbell et al. (2010) show further evidence of hedging benefits for bond portfolios and the potential positive impact of currency investing (as opposite to hedging) in equity portfolios. Schmittmann (2010) analyses four different strategies: no hedging, half hedging, full hedging of currency risk, and the minimum-variance hedging ratio. In the cited paper, these strategies are applied to different investment horizons ranging from one-quarter to five years. Moreover, the paper examines the currency hedging benefits of single- and multi-country portfolios. The results show significant risk reduction for the hedged portfolios but no statistically significant differences in returns. We note that the first three strategies are purely naïve, and risk-minimizing hedging ratios account for the movements and comovements of portfolios and the currencies forward returns within a static framework.

In the present paper, we do not follow De Roon et al. (2011) or Campbell et al. (2010), and we do not consider the issue of direct investment in currencies. Instead, we focus on hedging decisions with respect to currency risk. A relatively inexpensive and reliable strategy for hedging foreign exchange risk involves the use of currency futures markets. Hedging with 
futures contracts is perhaps the simplest method of managing market risk arising from movements in foreign exchange markets. Hedgers usually short an amount of futures contracts if they hold a long position in international portfolios. In that case, optimal hedging ratios (OHR), namely, how many futures contracts should be held for each unit of the underlying portfolio, can be determined by minimizing the variance of the hedged portfolio returns or, equivalently, within a linear regression framework. Key inputs to obtain hedging ratios are the time series of portfolio and currency futures returns from which conditional and unconditional covariance matrices can be estimated with different approaches. In static or unconditional hedging, hedge ratios are estimated on a historical basis without taking into account the dynamic evolution of the returns (for both the investment assets and the currency) or of their risk. Implicitly, static hedging approaches assume that the covariance matrix is time-invariant, so that the OHR is constant over time, even if derived within a risk minimization approach. One way of moving toward dynamic hedging might involve the fundamental link between currencies and interest rates, as in de Roon et al. (2003), and Campbell et al. (2010). In these cases, dynamic hedges outperform static ones. A different approach for deriving dynamic hedge ratios comes from the time-varying nature of financial returns distribution. In fact, an extensive literature shows evidence of the presence of dynamic in the second and higher order moments of returns. Here, dynamic hedges are derived within a risk-minimization framework, thus making use of econometric models belonging to the multivariate GARCH class (see Caporin and McAleer 2010). The commonly adopted specifications allow for dynamic in variances, and covariance or correlations, following the taxonomy outlined in Bauwens et al. (2005), McAleer (2005), and Silvennoinen and Terasvirta (2009).

Multivariate conditional variance models have already been used within a currency hedging framework. Kroner and Sultan (1993) show the overperformance of dynamic hedging strategies based on a simple bivariate GARCH model compared to static hedging derived by a regression framework. Similar, though less strong, evidence has been provided by Chakraborty and Barkoulas (1999). Ku et al. (2007) evaluate the benefits of dynamically modeling correlations, as in Engle (2002), compared to specifications where only the conditional variance is dynamic. They verify the improvement in the hedge ratios with dynamic correlations. Chang et al. (2013) analyze the in-sample hedging effectiveness of alternative multivariate GARCH models when using two different currency futures maturities. Even though no significant differences among models are found, hedging leads to noticeable volatility reduction. Brown et al. (2012) examine dynamic hedging strategies for international portfolios of bonds and equities using the dynamic conditional correlation model (DCC) developed by Engle (2002). They compare their dynamic strategy with static hedging strategies (hedging ratios 0, 0.5, 1 and OLS estimates) and conclude that dynamic strategies, based on conditional variance matrices, outperform other strategies in terms of risk portfolio reduction during the in-sample period. 
Similar results were found in the out-of-sample analysis and were especially evident for the period covering the global financial crisis.

When dealing with out-of-sample hedging effectiveness, further elements must be considered, for instance, the forecast performances of alternative models. An example is given in Hakim and McAleer (2009) that analyze whether multivariate GARCH models incorporating volatility spillovers and asymmetric effects of negative and positive shocks on the conditional variance provide different forecasts. Using three multivariate GARCH models - the CCC of Bollerslev (1990), the VARMA-GARCH of Ling and McAleer (2003), and the VARMAAGARCH of McAleer et al. (2009) - they forecast conditional correlations between three classes of international financial assets (stocks, bonds, and foreign exchange rates). They suggest that incorporating volatility spillovers and asymmetric effects of negative and positive shocks on conditional variance does not affect the forecasts of conditional correlations.

Our paper belongs to the strand of literature which analyses dynamic currency hedging benefits, with a further focus on the impact of currency hedging before and during a period of financial turmoil. Consequently, we take the point of view of a Euro-based institutional investor and consider passive investment strategies. These might take the form of pure, passively managed portfolios or might represent the benchmark for an actively managed portfolio. In both cases, the institutional investor is willing to evaluate the potential improvements in the riskreturn trade-off when currency risk is hedged. We stress that we will not consider the case of direct investment in currencies as in de Roon et al. (2011). We further assume that our reference investor is willing to allocate a fraction of his wealth in non-Euro denominated assets, namely in the UK and the US. The passive portfolios we consider differ in terms of their composition by asset classes (full bond, full equity, or balanced portfolios investing both in bonds and equities), and country weight (equally weighted across the selected investment areas or home biased toward Euro-denominated assets). Finally, with respect to the bond asset class, we consider bond investments with different maturities (a generic all-maturity allocation, and 1-3-year and 10+-year maturity allocations) to highlight the potential heterogeneity in currency risk hedging depending on the bond maturity.

Our implementations and results are novel in several aspects. We first analyze the impact of the model specification on the evaluation of the currency hedging effectiveness. To this end, we consider a wider selection of models compared to previous studies. Our empirical analyses include the following specifications: the well-known exponential weighted moving average filter; the DCC model of Engle (2002); the BEKK model of Engle and Kroner (1995); and finally, we use the OLS static hedging ratios as a benchmarks. In addition, we use US dollar and British pound futures, instead of forwards, to build our hedging strategies. While futures are similar to forward contracts, they also solve some of the shortcomings of forward markets: in a forward contract, we need to find a counterparty; futures are much more liquid because they are 
traded in an organized exchange market; futures provide greater flexibility because they are more easily offset than forwards; and finally, futures have the benefit of not being exposed to further counterparty risks for hedgers. The choice of taking the Euro-based point of view will allow us to focus on the impact of the GFC and ESC crises on passively managed strategies and currency hedging, a novel contribution to the literature. Our analyses will include both insample evaluations as well as out-of-sample analyses. The latter will be based on daily data with a rolling evaluation scheme.

An in-sample analysis shows that bearing currency risk using exchange rate futures improves the performance of international portfolios. Apparently, risk hedging not only reduces portfolio risk, it also enables improvements in the risk-returns trade-off. In line with previous studies, our findings suggest that currency exposure should be hedged and hedging ratios vary over time and currency. Therefore, there is evidence of the consistent dominance of risk minimizing strategies against static naïve ones. Optimal hedging ratios are similar across models. In terms of total hedging, namely, the sum of hedging ratios for each portfolio, OLS and EWMA seem to show higher averages. As in Schmittmann (2010), hedging effectiveness is higher for full bond portfolios than for portfolios that include equities; however, improved Sharpe ratios for full bond hedged portfolios are lower than for EMU portfolios for the fullsample and before crisis periods. This result confirms the idea that for European bond investors, holding foreign bonds during calm periods might not be a good strategy. Both hedging effectiveness and improved Sharpe ratios for EWMA, and especially for the DCC and BEKK procedures, are higher than for the OLS case, thereby confirming the advantages of using conditional hedging strategies over static ones.

The out-of-sample analysis produces slightly lower total hedging ratios than the insample study for all models and, as in the previous case, OLS seems to require, on average, higher short positions in currency futures. As expected, hedging effectiveness is lower than for the in-sample analysis. Differences between in- and out-of-sample hedging effectiveness are especially significant for OLS cases with an average reduction of 37\%. On average, OLS provides the lowest improved Sharpe ratios, while BEKK provides the highest. Therefore, OLS requires higher hedging ratios, on average, but it does not imply a better return-risk trade-off.

The remainder of the paper is organized as follows. In Section 2, we describe the kinds of portfolios we are analyzing, risk minimizing hedging strategies as well as a hedging effectiveness measurement. In Section 3, four different models used to estimate optimal hedging ratios are described. Section 4 presents the data, including a preliminary statistical analysis of bonds, equities, and spot and currency futures. Sections 5 and 6 report on the results and Section 7 presents the conclusions. 


\section{A Simplified Multi-currency Portfolio}

As discussed in the introduction, we analyze the perspective of a European (Euro-based) institutional investor managing a multi-currency portfolio. The allocation strategy we adopt is, by construction, passive, but might also represent the benchmark of an actively managed portfolio. As a consequence, the allocations we consider can be associated with strategic reference portfolios or strategic asset allocations. In this framework, the institutional investor is willing to evaluate the benefits of currency hedging from a strategic perspective. Therefore, we partially deviate from previous studies as our allocations are not optimal in a mean-variance framework as, for instance, in de Roon et al. (2003 and 2011), and Campbell et al. (2010). The portfolio designs defined here are reasonable for institutional investors who are willing to introduce foreign assets (bonds and equities) in their asset allocation. They thus face the strategic decision of exposing, or not, the overall portfolio to the currency risk. To simplify the analyses, we consider a three-currency portfolio in which the investor is holding EMU, British and US stocks and/or bonds. We restrict the portfolio design to selected developed markets for a simple reason: institutional portfolios, in particular, those largely invested in bonds, normally include a limited fraction of foreign assets in order to indirectly control the currency risk. As foreign investment areas, we select a standard world reference, given by the US market, and a European alternative with non-Euro issues. Our analyses are limited to selected financial markets, but they can be easily generalized to include additional non-Euro denominated markets such as Switzerland, Nordic countries, or Asian markets. As a consequence of our choices, the results we provide are dependent on the selected foreign markets, and the costs/benefits of hedging might turn out to be different for additional markets not considered in the present paper. Nevertheless, the approach provided would represent a methodology for evaluating the possible introduction of currency hedging strategies. We finally stress that the analyses we pursue pertain to potential improvements in a passive portfolio management framework. The central role here is assigned to the management of the currency risk, the only active element we consider. The investor compares the benefits of currency hedging in terms of the risk-return profiles of hedged and un-hedged passive portfolios.

In our generic framework, the nominal unhedged portfolio return at time, $r_{t}^{U H}$, is given as:

$$
r_{t}^{U H}=w^{E M U}\left(w^{E M U, B} r_{t}^{E M U, B}+w^{E M U, S} r_{t}^{E M U, S}\right)+w^{U K}\left(w^{U K, B} r_{t}^{U K, B}+w^{E M U, S} r_{t}^{U K, S}\right)+w^{U S}\left(w^{U S, B} r_{t}^{U S, B}+w^{U S, S} r_{t}^{U S, S}\right)
$$

where $r^{\text {country,B }}$, with country equal to either EMU, UK or US, is the return in Euro for a European investor holding EMU, UK or US bonds; $r^{\text {country,S }}$ is the return in Euro for a European 
investor investing in EMU, UK or US stocks; and $w^{\text {country }}$ is the weight of EMU, UK or US assets in the portfolio; and $w^{\text {country,S }}$ and $w^{\text {country,B }}$ are the weights of bonds and equities at the country level. Note that, $w^{\text {country, }}+w^{\text {country }, B}=1$, and that $w^{E M U}+w^{U K}+w^{U S}=1$.

Portfolio returns are weighted averages of the country portfolio returns of the two asset classes we consider (bonds and equities). Note that all returns are expressed in Euro. As a consequence, the returns of the UK- and US-based portfolios are influenced by local currency returns as well as by the exchange rate of the Euro, that is $r^{U K, B}=\left(1+r^{U K, B, l o c a l}\right)\left(1+r^{G B P / E u r o}\right)-1$, and similarly, for equity and US-based investments.

Moreover, when we focus on risk, the variance of the three-currency portfolio depends on the covariances among the stock and bond market returns, the covariances among the exchange rate fluctuations changes and the cross-covariances among the stock and bond market returns and the exchange rate. For instance, the total risk of a bond position in the US is equal to $\sigma_{U S, B}^{2}=\sigma_{U S, B, l o c a l}^{2}+\sigma_{U S D, E U R}^{2}+2 \sigma_{U S, B, l o c a l} \sigma_{U S D / E U R} \rho_{U S D, B, l o c a l ; U S D / E U R}$. As a consequence, the institutional investor has to decide whether the currency risk should be completely hedged in order to obtain portfolio returns in (1) with local currency returns instead of Euro-based returns from UK and US assets. As an alternative, the use of hedging strategies for currency risks might be considered as an additional tool provided to the managers to generate superior returns.

In the following, we analyze four different investments strategies:

(1) An equally weighted three-currency full bond portfolio with $w^{\text {country }}=0.33, w^{\text {country,S }}=0$ and $w^{\text {country,B }}=1$, for the three countries, EMU, the UK and the US.

(2) An equally weighted three-currency full stock portfolio, with $w^{\text {country }}=0.33, w^{\text {country,S }}=1$ and $w^{\text {country,B }}=0$, for the three countries, EMU, the UK and the US.

(3) An equally weighted three-currency $50 \%$ bond and $50 \%$ stock portfolio where $w^{\text {country }}=$ $0.33, w^{\text {country,S }}=0.5$ and $w^{\text {country,B}}=0.5$, for the three countries, EMU, the UK and the US.

(4) And finally, a home biased three-currency portfolio, i.e., $w^{E M U} .=0.60$ and $w^{\text {country }} .=0.20$ for the UK and the US, $50 \%$ bond and $50 \%$ stock portfolio ( $w^{\text {country,S }}=0.5$ and $w^{\text {country,B }}=0.5$ ).

These four cases will allow an evaluation of the benefits of currency hedging when focusing on full bond and full equity portfolios (cases 1 and 2). Conversely, the third case focuses on balanced portfolios equally weighted between bonds and equities. Finally, the last case is introduced to evaluate the effects of some home bias for a Euro-based investor willing to partially reduce currency risk exposure by appropriately designing the strategic benchmark. Clearly, the choice of the combination weights is merely subjective and can be easily generalized to other designs. 


\subsection{Optimal hedging ratios}

The unhedged portfolio defined in (1) has a currency exposure to both GBP and USD exchange rate changes. The investor could hedge the currency exposure of the unhedged portfolio by selling an appropriate number of future currency contracts denominated in GBP and USD. In order to find an optimal hedging strategy, we follow Cecchetti et al. (1988) and Kroner and Sultan (1993), among others. We thus focus on the investor problem, that is, the need to minimize the variance of a hedged portfolio return given by:

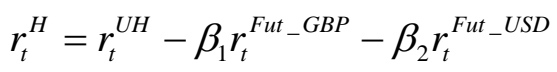

where $r^{U H}$ is the portfolio return in (1), and $r^{\text {Fut_GBP }}$ and $r^{\text {Fut_USD }}$ are the changes in the GBP and USD futures prices, respectively. In this framework, $\beta_{1}$ and $\beta_{2}$, the optimal hedging ratios (OHR) would be the optimal number of futures contracts in GBP and USD, respectively, that the investor should sell for each Euro invested in the international portfolio. A positive value of $\beta_{i}$, for $i=1,2$, means that the investor could reduce the volatility of the unhedged portfolio by holding a short position in such a future currency. On the contrary, a negative value would mean that the investor should hold a long position in futures contracts. A future short position implies that the future currency tends to appreciate against the Euro when the unhedged returns, denominated in Euros, increase, while a future currency long position would mean that that future currency would tend to depreciate as the unhedged returns increased. To identify the optimal values of $\beta_{1}$ and $\beta_{2}$, the standard practice focuses on the variance of the hedged portfolio.

We follow the same approach, but we consider a more general framework for a multicurrency portfolio whose returns are defined as follows

$r_{t}^{H}=r_{t}^{U H}-\boldsymbol{\beta}^{\prime} \mathbf{r}_{t}^{\text {Fut }}$

where $\mathbf{r}_{t}^{\text {Fut }}$ is a k-dimensional vector of currency futures, which are included/affecting the returns of the unhedged portfolio, and $\boldsymbol{\beta}$ is the vector of the corresponding number of futures contracts required for the hedge. The evaluation of the vector $\boldsymbol{\beta}$ comes from a minimum problem, i.e., we search for the vector that minimizes the variance of the hedged portfolio returns. The minimum problem is the following:

$\min _{\beta} \operatorname{Var}\left[r_{t}^{H}\right]$ 
The hedged portfolio variance can be represented as a function of the variance-covariance matrix of the unhedged portfolio returns and currency future returns defined as

$\operatorname{Var}\left[\begin{array}{c}r_{t}^{U H} \\ \mathbf{r}_{t}^{\text {Fut }}\end{array}\right]=\left[\begin{array}{cc}\sigma_{U H}^{2} & \boldsymbol{\sigma}_{U H, \text { Fut }} \\ \boldsymbol{\sigma}_{U H, \text { Fut }} & \Sigma_{\text {Fut }}\end{array}\right]=\Sigma$

where $\sigma_{U H}^{2}$ is the variance of the unhedged portfolio returns, $\Sigma_{F u t}$ is the covariance matrix of the currency futures returns, $\boldsymbol{\sigma}_{U H, F u t}$ is the k-dimensional vector of the covariances between the currency futures and unhedged portfolio returns, and $\Sigma$ is the full covariance matrix (of dimension $\mathrm{k}+1$ ). The hedged portfolio variance is thus

$\operatorname{Var}\left[r_{t}^{H}\right]=\left[\begin{array}{ll}1 & -\boldsymbol{\beta}^{\prime}\end{array}\right]\left[\begin{array}{cc}\sigma_{U H}^{2} & \boldsymbol{\sigma}_{U H, F u t}^{\prime} \\ \boldsymbol{\sigma}_{U H, F u t} & \Sigma_{F u t}\end{array}\right]\left[\begin{array}{c}1 \\ -\boldsymbol{\beta}\end{array}\right]=\sigma_{U H}^{2}+\boldsymbol{\beta}^{\prime} \Sigma_{F u t} \boldsymbol{\beta}-2 \boldsymbol{\beta}^{\prime} \boldsymbol{\sigma}_{U H, F u t}$

The solution of the minimum problem comes by equating the $k$ first-order conditions to zero

$$
\begin{aligned}
& \min _{\boldsymbol{\beta}} \sigma_{U H}^{2}+\boldsymbol{\beta}^{\prime} \Sigma_{F u t} \boldsymbol{\beta}-2 \boldsymbol{\beta}^{\prime} \boldsymbol{\sigma}_{U H, F u t} \\
& \frac{\partial}{\partial \boldsymbol{\beta}^{\prime}}\left(\sigma_{U H}^{2}+\boldsymbol{\beta}^{\prime} \Sigma_{F u t} \boldsymbol{\beta}-2 \boldsymbol{\beta}^{\prime} \boldsymbol{\sigma}_{U H, F u t}\right)=2 \Sigma_{F u t} \boldsymbol{\beta}-2 \boldsymbol{\sigma}_{U H, F u t}=0
\end{aligned}
$$

The optimal vector $\boldsymbol{\beta}$ is then equal to

$\hat{\boldsymbol{\beta}}=\Sigma_{F u t}^{-1} \boldsymbol{\sigma}_{U H, F u t}$

In the two-currency case of equation (2), the optimal hedge ratios are equal to

$$
\begin{aligned}
& \beta_{1}=\frac{\sigma_{12} \sigma_{33}^{2}-\sigma_{13} \sigma_{23}}{\sigma_{22}^{2} \sigma_{33}^{2}-\sigma_{23}^{2}} \\
& \beta_{2}=\frac{\sigma_{13} \sigma_{22}^{2}-\sigma_{12} \sigma_{23}}{\sigma_{22}^{2} \sigma_{33}^{2}-\sigma_{23}^{2}}
\end{aligned}
$$

where 


$$
\begin{aligned}
\sigma_{22}^{2} & =\operatorname{Var}\left[r_{t}^{\text {Fut_GBP }}\right] ; \quad \sigma_{33}^{2}=\operatorname{Var}\left[r_{t}^{\text {Fut_USD }}\right] \\
\sigma_{12} & =\operatorname{Cov}\left(r_{t}^{\text {UH }}, r_{t}^{\text {Fut_GBP }}\right) ; \quad \sigma_{13}=\operatorname{Cov}\left(r_{t}^{U H}, r_{t}^{\text {Fut_USD }}\right) \\
\sigma_{23} & =\operatorname{Cov}\left(r_{t}^{\text {Fut_GBP }}, r_{t}^{\text {Fut_USD }}\right)
\end{aligned}
$$

The approach we follow resemble that of Brown et al. (2012) and leads to highly similar optimal hedge ratios. However, our result differs in one fundamental relevant aspect: future positions are not multiplied by the corresponding weights of the foreign currency positions in the portfolio. As a result, our approach is more general as we consider the covariance between the un-hedged portfolios and the un-weighted future positions. The optimal hedge ratios we provide differ from those of Brown et al. (2012) by a scale factor, the weight of foreign currency positions. The latter optimal hedge ratios refer to single foreign currency positions, while our optimal hedge ratios refer to the full un-hedged portfolio.

\subsection{Hedging effectiveness}

In order to compare the performance of the OHRs obtained from different multivariate conditional volatility models, Ku et al. (2007) suggest that a more accurate model of conditional volatility should also be superior in terms of hedging effectiveness, as measured by the variance reduction for any hedged portfolio compared with the unhedged portfolio. Thus, a hedging effective index (HE) is given as:

$$
H E=\left[\frac{\sigma_{U H}^{2}-\sigma_{H}^{2}}{\sigma_{U H}^{2}}\right],
$$

where $\sigma_{H}^{2}$ denotes the variances of the hedged portfolio returns $r_{t}^{H}$ (see, for example, Ripple and Moosa, 2007). A higher HE indicates a higher hedging effectiveness and a larger risk reduction, such that the hedging method with a higher HE is regarded as a superior hedging strategy. When variances become dynamic, as will be highlighted in the following section, the evaluation of the hedging effectiveness becomes more complicated. In that case, the evaluation of HE would require the use of both descriptive tools and graphics (additional details will be provided in the empirical section). Moreover, the evaluation of the benefits of hedging will also be based on the analysis of hedged and unhedged portfolio returns and risk.

\section{Multivariate Conditional Volatility Models}


In order to estimate the conditional variances and covariances so as to find optimal hedging ratios, this paper uses three multivariate models, the exponential weighted moving average (EWMA), the DCC model of Engle (2002) and the diagonal BEKK model of Engle and Kroner (1995). The three modeling approaches will be, in all cases, fitted on three returns sequences: that of an unhedged portfolio and those of two currencies. Additionally, in order to compare our results with a benchmark, we estimate, by ordinary least squares, the following equation:

$$
r_{t}^{U H}=\beta_{0}+\beta_{1} r_{t}^{\text {Fut_GBP }}+\beta_{2} r_{t}^{\text {Fut_USD }}+u_{t}
$$

The estimated betas will provide a static OHR. In the following, we briefly describe the three conditional covariance models we consider to estimate the hedge ratios in (3). In that case, the hedge ratios will be dynamic and will be based on the estimated conditional variances and covariances/correlations patterns.

\subsection{Exponential weighted moving average}

Consider the 3-dimensional vector or returns $r_{t}=r_{t}^{U H}, r_{t}^{\text {Fut_GBP }}, r_{t}^{\text {Fut_USD }}$ with a conditional mean, zero, and a conditional covariance matrix, $H_{t}$ :

$$
r_{t}=\varepsilon_{t}=\Sigma_{t}^{1 / 2} \eta_{t}
$$

where $\eta_{t}$ is i.i.d with $E\left(\eta_{t}\right)=0$ and $\operatorname{var}\left(\eta_{t}\right)=I_{n}$. Following the RiskMetrics approach, we consider the class of conditional covariance matrices that are the weighted sum of the cross products of past returns and the elements of the variance and covariance matrix:

$$
\Sigma_{t}=(1-\lambda) r_{t-1} r_{t-1}^{\prime}+\lambda \Sigma_{t-1}
$$

The decay factor $\lambda$ is set to 0.97 . An important consequence of using an exponential weighting scheme is that regardless of the actual number of historical returns used in the volatility calculation, the effective number of days used is limited by the size of the decay factor. In other words, $99.9 \%$ of the information is contained in the last $\log (0.001) / \log (\lambda)$ days. As we use $\lambda=0.9799 .9 \%$ of the information is contained in the last 227 days. The EWMA one-day volatility estimate changes everyday as we incorporate new information and discard old observations. Note that this approach, despite being naïve compared to the following, allows 
obtaining time-varying conditional variances, covariances, and indirectly, time-varying conditional correlations.

\subsection{BEKK}

The EWMA described above is, however, a calibrated model. More appropriate model specifications are available in the literature (see the surveys by Bauwens et al., 2006; Silvennoinen and Terasvirta, 2011). Among the large number of available specifications, we consider the BEKK model of Engle and Kroner (1995). Such a specification has the attractive property that the conditional covariance matrices are positive definite by construction without the need of imposing too much structure on model parameters. This comes at a cost. In fact, the BEKK, as many other specifications, suffers from the so-called "curse of dimensionality" (see McAleer et al., 2009, and Caporin and Paruolo, 2013 for a comparison of the number of parameters in various multivariate conditional volatility models). The simplest BEKK model is given as follows:

$$
\Sigma_{t}=C C^{\prime}+A^{\prime} \varepsilon_{t-1} \varepsilon_{t-1}^{\prime} A+B^{\prime} \Sigma_{t-1} B,
$$

where the matrix $C$ is a lower triangular, and the parameter matrices $A$ and $B$ are full. In the BEKK model, the conditional variances and covariances are linear functions of past variances and covariances and past cross-products of return shocks. Note that the BEKK model has been used in several variants, including restricted specifications where the matrices $A$ and $B$ have been set diagonally or replaced with scalars. In our framework, such a general economically unjustified restriction is not needed. In fact, with just three variables included in the model, the parameter estimation is feasible. Note also that the BEKK formulation guarantees the conditional covariance to be positive definite for all $t$ due to the dynamic equation involving the quadratic form, and under the condition that the recurrence equation is initialized with a positive definite matrix. Moreover, to avoid observationally equivalent outcomes, the upper left element of the matrices $A$ and $B$ is constrained to be positive (see Engle and Kroner for further details).

Similar to the EWMA, the BEKK model provides indirect dynamic conditional correlations (see Caporin and McAleer, 2008), whereby the scalar, diagonal and full versions of BEKK are also discussed and compared to the dynamic conditional correlation model, the subject of the next subsection.

\subsection{Dynamic conditional correlation (DCC)}

The dynamic conditional correlation model differs from EWMA and BEKK in the manner in which the dynamic of the conditional covariance is described. In fact, the present 
model takes off from the decomposition of the covariance matrix in its constituent elements, variances and correlations. Moreover, it also tries to give an answer to the unrealistic assumption of constant correlations proposed by Bollerslev (1990). Engle (2002) suggests a dynamic conditional correlation (DCC) model, which is defined as follows:

$$
\Sigma_{t}=D_{t} R_{t} D_{t}
$$

where $D_{t}=\operatorname{diag}\left(\sigma_{1, t}, \ldots, \sigma_{k, t}\right)$ is a diagonal matrix of conditional standard deviations, and $R_{t}$ is the conditional correlation matrix. The conditional variance can be described by univariate GARCH models as follows:

$$
\sigma_{i, t}^{2}=\omega+\sum_{k=1}^{p} \alpha_{i, k} \varepsilon_{i, t-k}+\sum_{l=1}^{q} \beta_{i, l} \sigma_{j, t-l}^{2}
$$

And model orders $p$ and $q$ are, in most cases, restricted to 1 . Note that the univariate specifications need not be equal across the variables included in the model.

If we define the variance standardized innovations $\eta_{i, t}=r_{i, t} \sigma_{i, t}^{-1}$, the conditional correlation matrix is driven by the following equations:

$$
R_{t}=\left\{( \operatorname { d i a g } ( Q _ { t } ) ^ { - 1 / 2 } \} Q _ { t } \left\{\left(\operatorname{diag}\left(Q_{t}\right)^{-1 / 2}\right\}\right.\right.
$$

where the $k \times k$ symmetric positive definitive matrix $Q_{t}$ is given by

$$
Q_{t}=\left(1-\theta_{1}-\theta_{2}\right) \bar{Q}+\theta_{1} \eta_{t-1} \eta_{t-1}^{\prime}+\theta_{2} Q_{t-1}
$$

In the previous equation, $\theta_{1}$ and $\theta_{2}$ are non-negative scalar parameters capturing the effects of previous shocks and of a past $Q_{t}$ matrix on the current $Q_{t}$ matrix. Moreover, $\bar{Q}$ is a positive definite matrix with unit elements on the main diagonal. When $\theta_{1}=\theta_{2}=0, \bar{Q}$ in (12) is equivalent to the constant conditional correlations (CCC), the DCC collapses to the model of Bollerslev (1990). Note that the DCC model obtains a dynamic conditional correlation as a byproduct of the dynamic of variance standardized residuals. The equation (12) is nothing more than a scalar BEKK specification for those residuals (for further discussion on the DCC model, see Engle, 2002; and Caporin and McAleer, 2012). We also observe Aielli’s (2013) note on an inconsistency problem in the DCC estimation approach commonly considered. We are not 
exposed to this inconsistency bias given that the parameters $\theta_{1}$ and $\theta_{2}$ are, in sum, close to 1 and the parameter $\theta_{2}$ is larger than 0.95 in most cases.

Comparing our approach to that of Brown et al. (2012), we differ on the choice of covariance models, analyzing the impact of model complexity on currency hedging. Several authors have included a mean dynamic in the construction of optimal hedge ratios (see Brooks et al., 2002; Caporin, 2013; Hammoudeh et al., 2010, among others. We do not consider a mean dynamic in this work as we focus on the benefits of multi-currency hedging and we prefer to exclude the impact of model and parameter uncertainty related to the mean.

\section{Data Description}

Our empirical analysis utilized equity indices from Morgan Stanley Capital International (MSCI), and government bond indices, both provided by Thomson Reuters-Datastream. Spot exchange rates and currency futures prices from the Chicago Mercantile Exchange (CME) were provided by the Thomson Reuters-Ecowin Financial Database.

We used the MSCI Price Index (MSPI) that measures the price performance of markets without including dividends. For bonds, we considered the bond Price Index (PI), which reflects the total value of the holdings (that is, price plus accrued interest) for each date, and hence, it is equivalent to how much it would cost to purchase the bonds, ignoring expenses for settlement on the index date. We considered three alternative maturity buckets for the bond indices: allmaturity, 1-3-year and 10+-year maturities.

The Thomson Reuters-Ecowin Financial Database provided continuous time series of currency futures prices. They are perpetual series of futures prices formed from individual futures prices. It starts with the nearest contract month, which forms the first value of the continuous series, with a switchover following the last trading day using traditional months (March, June, September and December).

For all time series of interest, we downloaded data in the range, January of 1999 to October of 2012, at the daily frequency with a total of 3593 observations. We also split the sample into the 'before crisis' period (BC) and the 'during crisis' (DC) period. The second subsample started on 16 September 2008 after Lehman Brothers declared bankruptcy.

Table 1A reports averages and standard deviations of returns for the stock, bond and currency markets for three different cases: the whole period, January 03, 1999 to October 12, 2012; the BC period, spanning January 03, 1999 to September 15, 2008, and includes 2531 observations; and finally, the DC period, starting from the Lehman Brothers' bankruptcy to the end of the sample and has 1060 observations. 
Table 1A shows that from a European perspective, before the crisis, domestic and foreign bond and stock returns tended to perform badly, while the Euro was appreciating against the GBP and USD, magnifying negative foreign stock and bond market movements. While negative EMU stock market returns were found in the DC period, the EMU bond market returns were positive. In addition, foreign markets showed positive average returns when the Euro was appreciating against the GBP and depreciating against the USD; therefore, the EUR/GBP exchange rate movement reduced the positive British yields, but the increasing EUR/USD exchange rate boosted the US stock and bond returns. A falling European stock market and an increasing bond market in the DC period should have driven European investors to hold domestic bonds and foreign stocks and bonds, thereby increasing their exposure to currency risk. However, the peculiar signs of average returns were associated with the presence of the technology market bubble in the 'before crisis' period, which negatively affected equity returns. Conversely, for the bond case, the BC period includes 2007 when the first symptoms of the GFC were identified, with possible impacts on returns. The bond market average returns also showed a dependence on the bond maturity. While the longer-term bonds provided higher returns during the crisis, shorter maturity instruments were always associated with negative average returns. If we compared the standard deviations, we would note that the crisis period was characterized, as expected, by higher risk for all asset classes, including currencies. Notably, the US bond market was characterized by a decrease in the volatility of shorter maturity bonds. This was expected and was associated with the flattening of the interest rate curve for short maturities.

In order to shed some light on the crisis impact in terms of average returns and risk, we analyzed a different partition of the sample, comparing a stable period, ranging from January of 2003 to December of 2006 (1042 observations), with the crisis period. The latter was further divided into two sub-samples, from the Lehman bankruptcy up to the end of November of 2011 (838 observations), and from the first of December 2011 to the end of the sample (223 observations). This second sub-sample identifies the period of ECB interventions. The results are reported in Table $1 \mathrm{~B}$.

A first interesting observation has to do with the risk level: during the ECB interventions, the risk returned to levels comparable to those of the 2003-2006 period, or sensibly decreased compared to the period from Lehman to November, 2011. This highlights the importance of the ECB intervention, which had a positive impact on equity returns, compared to the September, 2008 - November, 2011 period, and that contributed to the stabilization of bond risks. A second relevant finding comes from the comparison of the US bond returns in USD and Euro. We observed that USD-based US bond returns had a smaller dispersion after the ECB intervention compared to the 2003-2006 and 2008-2011 periods. This is associated with the true limited movement in US bond returns rather than an effect of ECB intervention. On the contrary, the 
USD bond returns, expressed in Euro, suggest an increase in risk up to the BC, or stable periods, due to the inclusion of the currency risk. Such relevant differences support the potential impact of an appropriate hedging strategy on both the portfolio return and the portfolio risk.

In general, for the full period and for the different sub-samples, we observed that the local currency returns were characterized by lower risk levels compared to Euro returns. Such differences were more pronounced in the bond case than in that of equity. This empirical evidence supports the need to verify the impact of hedging strategies as a tool to control the impact of currency risk in managed portfolios. In fact, appropriate hedging approaches, focused, for instance, only on bonds, might allow the reduction of risk, but at the same time, they could allow for maintaining the benefit of currency exposure that, in some cases, induces an increase in the average returns level. This last point refers, for instance, to the comparison of local currency average returns to Euro-based returns in the DC period for US assets, noting that the latter are generally higher for equities and lower for bonds. Noteworthy, local currency returns are associated with the introduction of a perfect currency hedging strategy, while Euro-based returns are given as an aggregation of local market returns and foreign exchange returns.

\section{In-Sample Results}

We first compared the model and strategy performances in-sample using the estimated paths of conditional variances and covariances. For the OLS model, estimates were based on a full-sample evaluation, thus hedge ratios were constant. Tables 2 to 4 show the averages of the estimated optimal hedge ratios $\left(\beta_{1}\right.$ and $\left.\beta_{2}\right)$, hedging effectiveness and Sharpe ratios, respectively, for all estimation approaches (OLS, EWMA, DCC and BEKK), three periods (whole sample (ALL), before crisis (BC), and during crisis (DC)) and each analyzed investment strategy: full bond portfolio (Full Bond), full equity portfolio (Full Equity), bond and equity portfolio (equally weighted, $50 \%$ bonds, $50 \%$ assets), home biased bond and equity portfolio (60\% EMU, 20\% the UK and 20\% the US). For portfolios, including bonds, Tables 2-4 show results based on the all-maturities bond index. Additional tables with results for short-term (1-3 years) and long-term (+10 years) bond indices are included in the Appendix.

Table 3 displays the hede ratios that minimized the risk of the portfolio analyzed. A long (buy) position of one Euro in a portfolio should be hedged by a short (sell) position of $\beta_{1}$ Euros in British pound futures and $\beta_{2}$ Euros in US dollar futures. For example, based on the OLS approach, for each Euro invested in a full bond three-currency portfolio, to minimize the volatility of the portfolio a European investor should hold, on average, 0.2625 and 0.3195 Euro short positions in GBP and USD futures, respectively. We observe that $\beta_{1}$ is greater than $\beta_{2}$ for the ALL and DC periods, except for the full bond case in which we find the opposite behavior, 
$\beta_{2}$ is greater than $\beta_{1}$, for the ALL and DC periods and lower before the crisis. This result held for all estimation approaches (OLS, EWMA, DCC and BEKK). For the full bond portfolio, this was because the positive correlation between Euroland portfolio and USD future returns was higher than for the GBP futures during high volatility periods

Consider now $\beta_{1}$ and $\beta_{2}$ separately. Again, with the exception of the full bond portfolio, $\beta_{1}$ is always higher for the DC period than for the whole and BC periods. For the DC period, dynamic correlations between the international unhedged portfolio and GBP future returns were positive, as well as between GBP and USD futures returns, but negative for the international unhedged portfolio and USD futures returns. Based on equation (3), this would explain why during the crisis period it was optimal for a European investor to over-hedge the British pound exposure implicit in his/her portfolio and hold long exposure to the USD currency. Different patterns appear for the full bond portfolio where the $\beta_{1}$ value was somewhat stable across periods. The optimal hedging ratio $\beta_{2}$ was positive for the $\mathrm{BC}$ period and turned negative during the crisis except for the full bond case. A negative $\beta_{2}$ implies that a risk minimizing strategy would be to hold a long position in USD futures.

Using estimated hedge ratios, we computed simulated portfolio returns with (hedged portfolios, denoted by $\mathrm{H}$ ) and without (unhedged portfolios, denoted by $\mathrm{UH}$ ) currency hedging. Moreover, we recovered the returns and reported some information of a portfolio based only on Euro denominated assets (EMU). We computed unhedged portfolio average returns $\left(R_{U H}\right)$ and volatility $\left(\sigma_{U H}\right)$, hedged portfolio average returns $\left(R_{H}\right)$ and volatility $\left(\sigma_{H}\right)$, and EMU portfolio average returns $\left(R_{E M U}\right)$ and volatility $\left(\sigma_{E M U}\right)$. These statistics allowed us to obtain hedging effectiveness (HE), shown in Table 3, and improved Sharpe ratios (SHR), found in Table 4, for the all-maturity bond index case. Note that due to the presence of negative average returns, the traditional Sharpe ratio turned out to be inappropriate for comparisons across allocation strategies, models, periods and hedging presence. In fact, given two assets, A and B, with the same negative average return, say $-1 \%$, and the volatility of A twice the volatility of B, $20 \%$ and $10 \%$, respectively, the Sharpe ratio of A would be higher than that of $B,-0.05$ versus -0.1 (see Caporin et al., 2012 for additional comments). To overcome this limitation, we considered the modified Sharpe of Israelsen (2005) where the average returns are multiplied by the volatility if it is negative, thus restoring the appropriate ordering. Additional information for the 1-3 and 10+-year bond indices can be found in the Appendix. All data referring to returns and volatilities are reported in annualized terms.

The patterns observed for the average optimal hedge ratios were common across estimation strategies. Some difference should have appeared when we considered the portfolio variance and hedging effectiveness. The highest portfolio variances appeared for the full equity portfolio and the lowest for the full bond portfolio, as expected. Hedged portfolio variances 
always remained smaller than unhedged portfolio variances (in every portfolio, period and model used), confirming the correctness of the analyses. Moreover, the highest variance values were observed in the DC period and were due to the instability of financial markets.

Table 3 shows that the full bond portfolio reported the highest hedging effectiveness (HE), and the full equity portfolio, the lowest. For the full bond case, portfolio volatility was dominated by exchange rate volatility hedged by using futures contracts, thereby explaining why HE was higher for portfolios holding bonds. For the equity and bond portfolios, the higher the weight of domestic bonds and equity, the lower was the HE. This result was also expected as increasing the share of domestic equity in the portfolio reduced the exchange rate contribution to the variance of the unhedged portfolio through its variance and covariance with the foreign asset. Noteworthy, the sub-period analysis suggests some changes in risk reduction strategies. Hedging effectiveness was higher before the Lehman crisis for all portfolios except for the full bond portfolio. Currency risk turned out to be more difficult and hedged in the DC period, and the only way to improve the hedging strategy was to develop more conservative investments (full bond portfolios).

Table 4 provides the improved Sharpe ratios of Israelsen (2005) for three portfolios (UH, $\mathrm{H}$ and EMU). Average returns were, in general, negative across periods, investment strategies and models. Most of the positive returns could be found in the DC period. The full equity portfolios reported the highest returns (or less negative). Risky environments (DC periods) and the higher weight of the equity in the portfolio increased returns but was usually combined with a drop in HE. Average returns appeared higher for hedged portfolios. The modified Sharpe ratios were higher in most cases for the hedged portfolios. The only exceptions were given by the full bond investment strategy when the comparison was made on the full sample. If we contrasted the performances of portfolios with foreign assets to those of the Euro denominated portfolio, we would observe that the vast majority of modified Sharpe ratios would suggest a preference of investment strategies with foreign currencies and hedging. Such a result held across periods and models, and it was more evident when equities were included in the portfolio.

Comparing EWMA, DCC and BEKK models, we can only perceive that $\beta_{1}$ and $\beta_{2}$ values were closer in EWMA and DCC models and somewhat higher (lower) for the $\beta_{1}\left(\beta_{2}\right)$ full asset portfolio in BEKK. $\beta_{2}$ was negative for the full asset and bond+equity portfolios during the crisis period. A noteworthy result is that the OLS model reported the lowest hedging effectiveness for every portfolio except for the DC period; DCC did a very good job in obtaining the lowest HE in 6 out of 12 cases and the second lowest in 5 out of 6 remaining left; finally the BEKK procedure obtained slightly lower HE values. If we analyzed the difference across models in terms of portfolio returns and volatility, such differences would not emerge in a clear manner. We thus focused on the modified Sharpe ratios and noted that the Sharpe of the 
hedged portfolio (the only quantity influenced by the model choice) was highest for the BEKK model in many cases, 5 out of 12 considered: full sample and BC for the equally weighted and home biased bond and equity portfolios; BC for the full equity portfolio. The DCC model was the preferred choice in only three cases (during the crisis for the full bond, full equity and home biased bond and equity portfolio), and the EWMA was preferred in two instances. Finally, the static OLS hedging strategy turned out to be the optimal choice in the full bond portfolio for the full sample. These results have different explanations: first, the OLS approach provided static hedge ratios and thus the introduction of variance dynamic can sensibly affect the results; second, the models differed in terms of the number of parameters, the EWMA was calibrated, while DCC and BEKK had a similar number of parameters (the estimated parameters are reported in the appendix); third, the BEKK might be more stable than the DCC in small systems (see Caporin and McAleer, 2008); finally, the previous comments are related to average hedge ratios and to the volatility and returns of the Euro, unhedged and hedged portfolios over the selected periods. As a consequence, differences across models might not appear clearly. To this end, we graphically analyzed the optimal hedge ratios. Figure 2 reports an example of the time evolution of the hedged ratios for the three models. It clearly emerges that the ratios are very close to each other, with some local deviations. To appreciate the differences across models, Figures 3 to 5 provide the box plots for the full bond, full equity and equally weighted portfolios, and for the three periods and all models. These graphs refer to the all-maturity bond index; those with different bond indices are reported in the appendix. The box plots show further evidence of the closeness of the average hedge ratios across models. There were some differences when we focused on the dispersion of the hedge ratios. These were more volatile for the EWMA case and less volatile for the DCC model. Nevertheless, these differences were not very relevant. As a preliminary conclusion, we can state that the introduction of dynamic hedging is, at least in principle, beneficial. However, alternative dynamic covariance models are equally good as tools for the derivation of optimal hedge ratios.

Finally, we were interested in evaluating whether the previous observations could be preserved when the maturity of the underlying benchmark bond index was modified. We thus considered the short-term (1-3 years) or long-term ( +10 years) bond indices as an alternative to the all-maturities bond index previously used. All tables and figures are reported in the appendix. If we considered the longer maturity bonds, the introduction of foreign currencies and dynamic hedging would be beneficial compared to the Euro-only portfolio case in most cases; few exceptions were given by the full bond portfolio and by the balanced portfolios in the BC period. Moreover, the introduction of hedging provided better, modified Sharpe ratios (again, with the exception of the full bond portfolio strategy). For the short maturity bond, similar results appeared. In particular, the full bond portfolio was always characterized by opposite results to the portfolios, including equities. We can thus draw a general conclusion that on the 
basis of our results, it appears that the introduction of foreign bonds does not improve the riskadjusted performances of a Euro-denominated bond portfolio. Such a result is stronger for shortterm bonds. Other comments reported for the all-maturity bond indices were also confirmed with short- and long-term bond indices.

We can conclude that international portfolios for European investors holding domestic and foreign assets showed higher improved Sharpe ratios than portfolios holding only domestic assets in 8 out of 12 cases analyzed (the EMU portfolio produced higher Sharpe ratios for full bond in the All and BC periods, and for bond+equity portfolios during the BC period). Therefore, international investment led to an improvement in portfolio performance, especially during crisis periods, but at the same time, this strategy increased the impact of currency risk. The in-sample analysis demonstrated that bearing this risk using exchange rate futures improved the performance of international portfolios. Apparently, risk hedging not only reduces portfolio risk; it also provides improvements in the risk-returns trade-off.

Our findings suggests that currency exposure should be hedged, and that the optimal hedging ratios should be dynamic and, obviously, defined on a single asset base. Contrary to Campbell et al. (2010), risk-minimizing hedging strategies are far from full currency hedging. Moreover, optimal hedging ratios were similar across models, thus suggesting that simpler specifications might be considered. Nevertheless, hedging effectiveness was higher for EWMA, DCC and BEKK procedures than for the OLS case, which confirms the advantages of using conditional hedging strategies over static ones. Furthermore, our historical analysis recommends holding a short position in GBP and USD futures as these currencies tended to move in line with the portfolio returns for the All and BC periods. However, during the crisis we found that overhedging the pound risk exposure, and holding a long position in USD would have been optimal as a result of increasing EUR/USD exchange that boosted US bond and equity returns. In addition, hedging effectiveness was higher for full bond portfolios than for other portfolios including equities. However, the improved Sharpe ratios for full bond hedged portfolios were lower than EMU portfolios for the All and BC periods. This finding supports that of de Roon et al. (2003), in that, this might not be a good strategy for European bond investors holding foreign bonds during calm periods. Finally, we stress that the in-sample evidence does not guarantee identical out-of-sample behavior. This is analyzed in the following section.

\section{Out-of-Sample Evaluation}

To further analyze the benefits of hedging and dynamic covariance modeling, we performed an out-of sample analysis. In this case, we estimated the various models on a 1-day 
rolling basis, keeping the estimation window size fixed and equal to five years of data (roughly, 1500 observations). In each estimation window, the various models, including the OLS case, were used to provide optimal one-step-ahead hedging ratios. We then assumed that the optimal hedges were constructed and updated on a daily basis according to the model forecasts. This gave rise to an out-of-sample period ranging from 01 September 2004 to 12 October 2012. Note that the first five years of data were needed to initialize the forecasting procedure. The out-ofsample range was then divided into before and during crisis sub-periods, similar to what we did in the previous section. However, due to the different sample sizes the before crises period (BC) began 01 September 2004 and ended 15 September 2008. We then replicated the in-sample analysis across periods and models. Tables 5 to 7 show out-sample optimal hedging ratios, hedging effectiveness and improved Sharpe ratios, respectively. Additional results are included in the Appendix. For the in-sample period, we started from the comparison across models when the all-maturity bond index was used to build the passive portfolios.

In Table 5, we see that even in the out-of-sample analyses, excluding the DCC model case, $\beta_{1}$ was larger than $\beta_{2}$ for both the whole and DC periods, while for the BC period $\beta_{2}$ dominated. In the DCC case, $\beta_{1}$ was always higher, suggesting that heterogeneity across models increased in the out-of-sample exercise. We also note that the dispersion of the hedge ratios was smallest for the OLS, followed by the DCC case, and then higher for the BEKK and EWMA. Separately considering the hedge ratios, we found confirmation of higher values for $\beta_{1}$ and smaller values for $\beta_{2}$ during the crises, with the exception of the full bond portfolio where the result was reversed. Notably, hedging ratios were still negative for the Euro against the USD during the crisis. For the full bond portfolio during the crisis period, $\beta_{2}$ was not only positive but also higher than $\beta_{1}$. The intuition behind this fact is that the correlation between unhedged full bond portfolio returns and EUR/USD and EUR/GBP future returns moved in the same direction during this period. Looking again at Table 1A, the behavior in EMU bonds (1.23\%) along with positive returns in the British (3.66\%) and American (4.11\%) bond returns were boosted by the Euro depreciation against both the GBP and USD, inducing investors to hold short positions in both currency futures to minimize portfolio risk. As in the in-sample analysis during the crisis, for portfolios holding equities, $\beta_{2}$ was always negative or close to zero.

Table 6 presents the results on out-of-sample hedging effectiveness (the HE was evaluated ex-post). These quantities were computed on the realized portfolio returns, and for that reason, EMU and unhedged results were constant across estimation methods (no hedge ratios, and thus no impact from the model as the portfolio allocation was calibrated). The hedged portfolios always recorded a lower variance than the unhedged ones, and when equity was included, hedged portfolios recorded a lower variance than the full EMU portfolios. Higher variances were associated with the crisis period, as expected. The results were substantially similar across models, thus showing limited differences across the ex-post realized hedged 
portfolio variances. Hedging effectiveness was higher for the full bond portfolio and decreased when equity indices entered the portfolio, as in the in-sample analysis. Hedging effectiveness was especially low for the OLS procedure and full equity case during the crisis. The OLS did not provide the highest HE, and the EWMA did a very good job, with 7 out of 12 cases providing the highest HE.

In Table 7, we focus on hedging performance, as monitored by the modified Sharpe ratios. Comparing the Sharpe ratios of the hedged portfolios versus the unhedged ones, as markets experienced turbulence, we observed that hedging and foreign investments improved performance compared to the simple Euro-based portfolios. On the contrary, during stable market phases, Euro-based portfolios resulted in better performance than unhedged international portfolios. In general (except for the full bond case before the crisis), hedging improved remuneration per unit of risk. OLS hedging worsened during the crises. We related this finding to the limited flexibility of the model. When conditional variance models are used, even if they are naive (like the EWMA), they provide a greater flexibility than simple linear regression, with relevant effects on the estimation of the optimal hedge ratios during market turbulence. On the contrary, when markets are somewhat stable, the use of time series models for the estimation of hedge ratios becomes suboptimal. In fact, in the BC period the OLS model provided the highest modified Sharpe ratios. This might have been due to the impact of estimation and model errors which turned out to be more severe for conditional variance specifications compared to linear regression. Notably, the out-of-sample performance of the BEKK model worsened compared to the in-sample case. The BEKK model was frequently outperformed by the DCC and EWMA models. This might have been an effect of the limited flexibility of the BEKK compared to the DCC, and of the higher impact of estimation error with respect to the EWMA. Further differences across models appeared on the box-plots of the hedging ratios, presented in Figures 6-8. As for the in-sample case, we provided the analysis for the full bond, full equity and equally weighted portfolios. We observed that the DCC model (columns 2, 5 and 8) provided ratios with smaller dispersions across portfolios and periods, and this might explain the somewhat higher preference for this specification.

Finally, we evaluated the results with respect to the different maturities of the bond index. Previous findings were substantially confirmed. With respect to the advantages associated with the introduction of both foreign investments and hedging, in particular, we noted the following: hedging always improved portfolio performance; for BEKK, EWMA and DCC models, results suggest that hedging and foreign investments were most beneficial to performance during market turbulence; results for the OLS case were less clear and indicated a higher preference for portfolios with foreign investments, irrespective of the phase of the market. 
To conclude, similar to the in-sample analysis and contrary to static strategies that do not take correlation among assets into account, or the universal hedge ratio of 0.77 popularized by Black (1990), we found that optimal hedging ratios changed depending on the portfolios and periods, but were relatively stable along the models. A short position in British pound futures was shown to be the optimal strategy for every period, model, and portfolio. A long position in dollar futures was optimal for portfolios holding equities during the financial crisis. Looking at total hedging, namely, the sum of hedging ratios for each portfolio, we found that for each Euro invested in an international portfolio, on average, for all models, portfolios and periods, around 60 cents should be used for hedging, going from 1.43 cents for the full equity portfolio during the crisis to 23 cents for the home biased portfolio in the EWMA model. Total hedging was lower for the home biased portfolios; the lower the international risk exposure, the lower the risk to be hedged by currency futures. Finally, on average, OLS and EWMA provided the highest total hedging ratios per Euro invested in an international portfolio with an average short position in futures of 61 cents against 52 and 58 cents of the DCC and BEKK models, respectively. The average short position was higher for the in-sample analysis than for the outof-sample case.

As expected, HE was lower than for the in-sample analysis. Differences between in- and out-of-sample HE results were especially significant for the OLS case, with an average reduction of $37 \%$. OLS recorded the lowest average hedging effectiveness, around $20 \%$ against 25\%, 23\% and 25\% of the EWMA, DCC and BEKK procedures, respectively.

On average, for all portfolios and periods OLS resulted in the lowest improved Sharpe ratios (-2.49). EWMA, DCC and BEKK produced lower averages, -0.49, -0.25 and -0.19, respectively. Therefore, OLS required higher hedging ratios on average, but it did not imply a better return-risk trade-off.

\section{Conclusions}

This paper investigated dynamic currency hedging benefits, with a further focus on the impact of currency hedging before and during a period of financial turmoil. From the point of view of a Euro-based institutional investor who considers passive investment strategies in portfolios holding European, British and US assets, we analyzed the impact of the model specification to improve the risk-return trade-off when currency risk is hedged.

The empirical study, which involved both in-sample evaluations as well as out-ofsample analyses, included three main contributions: (1) we analyzed the impact of model specification, that is, why we used three models, EWMA, DCC, and BEKK, and OLS static hedging ratios as a benchmark; (2) we used US dollar and British pound futures, instead of forwards, to build our hedging strategies. While futures are similar to forward contracts, they 
also solve some of the shortcomings of forward markets; and (3) the choice of taking the Eurobased point of view allowed us to focus on the impact of the GFC and ESC crises on passively managed strategies and currency hedging, a novel contribution to the literature.

We found that for the portfolios, models and periods analyzed, international investment improved the risk-return trade-off in almost all cases. Therefore, international investment led to improvements in portfolio performance, especially during crisis periods, but at the same time, this strategy increased exposure to currency risk. An in-sample analysis showed that bearing this risk using exchange rate futures improved the performance of international portfolios. Apparently, risk hedging not only reduces portfolio risk, but also provides improvements in the risk-returns trade-off. Our finding suggests that currency exposure should be hedged, but hedging ratios vary over time and currency. Therefore, there was evidence of the consistent dominance of risk minimizing strategies against static naïve policies (constant hedging ratios of 0, 0.5 and 1). Optimal hedging ratios were similar across models. In terms of total hedging, the OLS and EWMA seemed to show higher averages. Hedging effectiveness was higher for full bond portfolios than for portfolios including equities, however, improved Sharpe ratios for full bond hedged portfolios were lower than for EMU portfolios for the All and BC periods. This result confirmed the idea that holding foreign bonds during calm periods might not be a good strategy for European bond investors. Both hedging effectiveness and improved Sharpe ratios for EWMA, and especially for the DCC and BEKK procedures, were higher than for the OLS case, thereby confirming the advantage of using conditional hedging strategies over static ones.

The out-of-sample analysis produced slightly lower total hedging ratios than the insample study for all the models, and as in the previous case, OLS seemed to require, on average, higher short positions in currency futures. As expected, hedging effectiveness was lower than for the in-sample analysis. Differences between in- and out-of-sample HE were especially significant for the OLS cases, with an average reduction of $37 \%$. On average, OLS provided the lowest improved Sharpe ratios, while BEKK provided the highest. Therefore, OLS required higher hedging ratios on average, but it did not imply a better return-risk trade-off. The analysis utilized several models, in-sample and out-sample studies, and currency futures for hedging, and confirmed that hedging strategies depend on the portfolio composition and period. The DCC and BEKK models seemed to recommend, on average, slightly lower hedging ratios than OLS and EWMA and better results in terms of improved Sharpe ratios. This fact stood out in the outsample study.

Finally, it is noteworthy to point out that: (1) as we provided an analysis based on theoretically hedged portfolio returns where hedging was dynamic and updated daily, and where hedging was implemented in a real framework, we must consider the effect on liquidity and margin requirements for daily adjustments; (2) our analyses were limited to selected financial markets, but they can easily be generalized to include additional non-Euro denominated markets 
such as Switzerland, Nordic countries, or Asian markets. The results obtained were dependent on selected foreign markets, and the costs/benefits of hedging might turn out to be different for additional markets not considered in the present paper. Nevertheless, the approach provided represents a methodology for evaluating the possible introduction of currency hedging strategies; and (3) the analyses we pursued referred to potential improvements in a passive portfolio management framework. The central role here was assigned to the management of the currency risk, the only active element we considered. The investor compared the benefits of currency hedging in terms of the risk-return profiles of hedged and unhedged passive portfolios.

\section{References:}

Aielli, G.P., 2013, Dynamic conditional correlations: on properties and estimation, Journal of Business and Economic Statistics, 31, 282-299.

Bauwens, L., S. Laurent and J.V.K. Rombouts, 2005, Multivariate GARCH models: a survey, Journal of Applied Econometrics, 21, 79-109.

Black, F., 1990, Equilibrium exchange rate hedging, Journal of Finance 45, 899-907.

Bollerslev, T., 1990, Modelling the coherence in short-run nominal exchange rates: a multivariate generalized ARCH model, Review of Economics and Statistics, 72, 498505.

Brooks, C., O.T. Henry, and G. Persand, 2002, The effect of asymmetries on optimal hedge ratios, The Journal of Business, 75, 333-352.

Campbell, J. Y., K. Serfaty-de Medeiros, and L. M. Viceira, 2010, Global Currency Hedging, The Journal of Finance, 65, 87-122.

Caporin, M., 2013, Equity and CDS sector indices: dynamic models and risk hedging, North American Review of Economics and Finance, 25, 261-275.

Caporin, M., G. Jannin, F. Lisi and B. Maillet, 2012, A survey on the four families of performance measures, Journal of Economic Surveys, forthcoming.

Caporin, M., and M. McAleer, 2008, Scalar BEKK and indirect DCC, Journal of Forecasting, 27, 537-549.

Caporin, M., and M. McAleer, 2010, A scientific classification of volatility models, Journal of Economic Surveys, 24, 192-195.

Caporin, M., and P. Paruolo, 2013, Proximity-structures multivariate volatility models, Econometric Reviews, forthcoming.

Cecchetti, S.G., R.E. Cumby, and S. Figlewski, 1988, Estimation of optimal futures hedge, Review of Economics and Statistics, 70, 623-630. 
Chang, C., L. Gonzalez-Serrano and J-A. Jiménez-Martin, 2013, Currency hedging strategies using dynamic multivariate GARCH, forthcoming, Mathematics and Computer in Simulation.

Chakraborty, A., J.T. Barkoulas, 1999, Dynamic futures hedging in currency markets, The European Journal of Finance, 5, 299-314.

De Roon, F., T.E. Nijman, and B. Werker, 2003, Currency hedging for international stock portfolios: the usefulness of mean-variance analysis, Journal of Banking and Finance, 27, 327-349.

De Roon, F., E. Eiling, B. Gerard and P. Hillion, 2011, Speculative profits or hedging benefits? Currency investing in Global Portfolios, available at SSRN.

Engle, R.F., 2002, Dynamic conditional correlation: A simple class of multivariate generalized autoregressive conditional heteroskedasticity models, Journal of Business and Economic Statistics, 20, 339-350.

Engle, R.F., and K.F. Kroner, 1995, Multivariate simultaneous generalized ARCH, Econometric Theory, 11, 122-150.

Hakim, A., M. McAleer, 2009, Forecasting conditional correlations in stock, bond and foreign exchange markets, Mathematics and Computers in Simulation, 79, 2830-2846

Hammoudeh, S., Y. Yuan, M. McAleer, M. Thompson, 2010, Precious Metals Exchange Rate Volatility Transmissions and Hedging Strategies, International Review of Economics and Finance, 20, 633-647.

Israelsen, C.L., 2005, A refinement to the Sharpe ratio and information ratio, Journal of Asset Management, 5, 423-427.

Kroner, K.F., J. Sultan, 1993, Time-varying distributions and dynamic hedging with foreign currency futures, Journal of Financial and Quantitative Analysis, 28, 535-551.

Ku, Y.H., H.C. Chen, K.H. Chen, 2007, On the application of the dynamic conditional correlation model in estimating optimal time-varying hedge ratios, Applied Economics Letters, 14, 503-509.

Ling, S. and M. McAleer, 2003, Asymptotic theory for a vector ARMA-GARCH model, Econometric Theory, 18, 280-310.

McAleer, M., 2005, Automated inference and learning in modelling financial volatility, Econometric Theory, 21, 232-261.

McAleer, M., S. Hoti, and F. Chan, 2009, Structure and asymptotic theory for multivariate asymmetric conditional volatility, Econometric Reviews, 28, 422-440.

Opie, W., C. Brown, and J. Dark, 2012, Dynamic currency hedging for international stock portfolios, Review of futures markets, 20, 419-455.

Ripple, R.D., and I.A. Moosa, 2007, Hedging effectiveness and futures contract maturity: the case of NYMEX crude oil futures, Applied Financial Economics, 17, 683-689. 
Schmittmann, J., 2010, Currency hedging for international portfolios, IMF working papers, $\mathrm{WP} / 10 / 151$

Silvennoinen, A., and Terasvirta, T., 2009, Multivariate GARCH models, in Andersen, T., Davis, R., Kreiss, J., and Mikosch, T., eds., Handbook of financial time series, Springer, 201-229. 
Table 1A. Descriptive Statistics of Returns (annualized)

Whole

January 03, 1999

-October 12, 2012

$\mathrm{N}=3591$

BC

January 03, 1999

September 15, 2008

$\mathrm{N}=2531$
DC

September 16, 2008

October 12, 2012 $\mathrm{N}=1060$

Ave.

Std

Ave.

Std

Ave.

Std

\begin{tabular}{|c|c|c|c|c|c|c|c|c|}
\hline \multirow{5}{*}{ 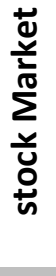 } & & EMU (EUR) & -1.8821 & 22.4917 & -0.6727 & 20.1263 & -4.2810 & 27.3221 \\
\hline & & U.K. (GBP) & -0.1249 & 19.9366 & -1.1682 & 17.9523 & 3.2515 & 23.9732 \\
\hline & & U.S. (USD) & 0.9293 & 20.8963 & -0.5236 & 17.7783 & 4.0807 & 26.9126 \\
\hline & & U.K. (EUR) & -0.9455 & 21.3596 & -2.2005 & 19.5033 & 2.8394 & 25.2113 \\
\hline & & U.S. (EUR) & 0.3506 & 22.2862 & -2.3471 & 21.6663 & 6.3688 & 23.6760 \\
\hline \multirow{15}{*}{ 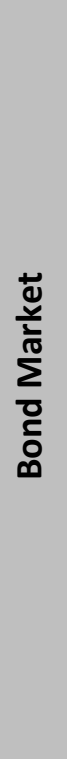 } & \multirow{5}{*}{ 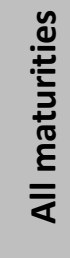 } & EMU (EUR) & -0.1998 & 3.5591 & -0.8216 & 3.2508 & 1.2325 & 4.2027 \\
\hline & & U.K. (GBP) & 0.3506 & 6.1111 & -1.2423 & 5.4881 & 4.1068 & 7.3839 \\
\hline & & U.S. (USD) & 0.7780 & 5.1118 & 0.3255 & 4.9964 & 1.8671 & 5.3806 \\
\hline & & U.K. (EUR) & -0.4988 & 9.7999 & -2.2739 & 8.5160 & 3.6653 & 12.3297 \\
\hline & & U.S. (EUR) & 0.1752 & 11.3289 & -1.5135 & 9.8979 & 4.1068 & 14.1702 \\
\hline & \multirow{6}{*}{. } & EMU (EUR) & -1.2423 & 1.5464 & -1.4889 & 1.4230 & -0.6231 & 1.8057 \\
\hline & & U.K. (GBP) & -1.2669 & 3.2366 & -1.5135 & 3.3994 & -0.6479 & 2.8128 \\
\hline & & U.S. (USD) & -0.1998 & 1.8736 & -0.1499 & 2.0302 & -0.2746 & 1.4293 \\
\hline & & U.K. (EUR) & -2.0782 & 8.6409 & -2.5423 & 7.8345 & -1.0693 & 10.3169 \\
\hline & & U.S. (EUR) & -0.7968 & 10.4497 & -1.9802 & 9.4805 & 1.9181 & 12.4610 \\
\hline & & EMU (EUR) & 0.5012 & 7.0013 & -0.4988 & 6.5475 & 2.7110 & 7.9705 \\
\hline & \multirow{4}{*}{$\begin{array}{l}\frac{1}{0} \\
\stackrel{0}{0} \\
0 \\
\stackrel{1}{+}\end{array}$} & U.K. (GBP) & 0.9797 & 9.2339 & -1.1187 & 7.9626 & 5.9443 & 11.7162 \\
\hline & & U.S. (USD) & 1.8926 & 11.1249 & 0.6773 & 9.4394 & 4.7855 & 14.3757 \\
\hline & & U.K. (EUR) & 0.1251 & 11.8680 & -2.1516 & 10.0972 & 5.4951 & 15.2801 \\
\hline & & U.S. (EUR) & 1.2831 & 15.1821 & -1.1682 & 12.1495 & 7.0891 & 20.6860 \\
\hline \multirow{4}{*}{\multicolumn{2}{|c|}{ 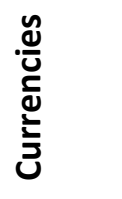 }} & EUR/GBP (Spot) & -0.8464 & 8.2282 & -1.0445 & 7.3001 & -0.3992 & 10.1082 \\
\hline & & EUR/USD(Spot) & -0.5982 & 10.4861 & -1.8331 & 9.6370 & 2.1987 & 12.2744 \\
\hline & & EUR/GBP(Fut) & -0.7720 & 8.1492 & -0.8712 & 7.3112 & -0.4739 & 9.8710 \\
\hline & & EUR/USD(Fut) & -0.5485 & 10.1762 & -1.6611 & 9.4489 & 1.9691 & 11.7336 \\
\hline
\end{tabular}

Note: mean and standard deviations across periods and assets. The first column identifies the asset type, the second column reports the country and in parenthesis the currency or the type of exchange. 
Table 1B. Descriptive Statistics of Returns (annualized)

January 2003/

December 2006

$\mathrm{N}=1042$
September 15, 2008/

November 30, 2011

$$
\mathrm{N}=838
$$

December 1, 2011/

October 12, 2012 $\mathrm{N}=223$
Ave.

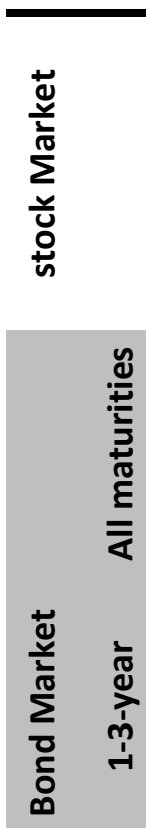

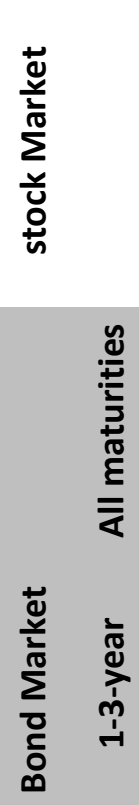

EMU (EUR)

U.K. (GBP)

U.S. (USD)

U.K. (EUR)

U.S. (EUR)

Std

EMU (EUR)

$-0.4988$

U.K. (GBP)

$-1.1682 \quad 4.9332$

U.S. (USD)

$-1.5873 \quad 4.4446$

U.K. (EUR)

$\begin{array}{ll}-1.9557 & 7.0740\end{array}$

U.S. (EUR)

$-6.8780$

EMU (EUR)

$-1.9312$

U.K. (GBP)

$-2.2739$

U.S. (USD)

$\begin{array}{ll}-1.5873 & 1.6997\end{array}$

U.K. (EUR)

$-3.0526$

U.S. (EUR)

$-6.8548$

9.0552

Ave.

Std

Ave.

Std

$\begin{array}{rr}16.1202 & 15.4983 \\ 11.6251 & 12.8942 \\ 12.2685 & 12.2285 \\ 10.7084 & 14.2540 \\ 6.2625 & 16.2177\end{array}$

$-9.0643$

28.5743

7.3302

20.5564

$0.8788 \quad 25.5338$

4.2891

14.4801

$-0.1249 \quad 29.2985$

15.6569

13.1345

3.2903

$-1.5873 \quad 26.9837$

11.8764

14.6919

2.0456

25.6919

21.0069

11.2846

$-0.7720$

4.2295

9.1971

4.0778

$\begin{array}{ll}4.9166 & 7.4567\end{array}$

2.3265

$1.9436 \quad 5.7459$

0.9545

7.1167

2.4801

12.9606

10.2115

3.6888

8.9872

3.7172

5.6006

9.6102

1.2270

$-1.3903$

14.9908

2.2754

10.5636

3.3188

0.1000

1.7898

$-3.1980$

1.8594

$-0.1499$

2.5694

-3.1980
-0.9703

3.5892

6.6771

$-2.2250$

1.5938

4.2370

0.4791

1.5620

11.0111

3.5876

7.1467

EMU (EUR)

$1.5366 \quad 6.6186$

$-0.2996$

3.2831

15.5125

8.7548

๙

U.K. (GBP)

$-0.4490 \quad 7.2543$

6.9286

8.1397

4.6024

7.3191

U.S. (USD)

$-1.0940$

8.6947

4.7332

11.8348

3.7690

11.2435

U.K. (EUR)

$-1.2423 \quad 8.6204$

12.6338

12.8072

U.S. (EUR)

$-6.4111 \quad 10.6932$

$8.5441 \quad 18.0092$

EUR/GBP (Spot)

$-0.8216$

6.1000

$6.5551 \quad 21.3406$

7.2766

6.2060

EUR/USD(Spot)

$-5.3521$

9.3667

2.1732

10.9383

4.6285

8.7358

EUR/GBP(Fut)

$-0.9703$

6.2076

$-2.5666$

13.0634

6.9821

5.7680

EUR/USD(Fut)

$-5.7064$

9.1564

$1.9946 \quad 12.4309$

4.2891

8.5555

Note: mean and standard deviations across periods and assets. The first column identifies the asset type, the second column reports the country and in parenthesis the currency or the type of exchange. 
Table 2: in-sample optimal hedge ratios for alternative models

\begin{tabular}{|c|c|c|c|c|c|c|c|c|c|}
\hline & & \multicolumn{2}{|c|}{ OLS } & \multicolumn{2}{|c|}{ EWMA } & \multicolumn{2}{|c|}{ DCC } & \multicolumn{2}{|c|}{ BEKK } \\
\hline & & $\beta_{1}$ & $\beta_{2}$ & $\beta_{1}$ & $\beta_{2}$ & $\beta_{1}$ & $\boldsymbol{\beta}_{2}$ & $\beta_{1}$ & $\boldsymbol{\beta}_{2}$ \\
\hline \multirow{3}{*}{ Full Bond } & ALL & 0.2625 & 0.3195 & 0.2782 & 0.3026 & 0.2766 & 0.3021 & 0.2781 & 0.3009 \\
\hline & BC & 0.2766 & 0.2466 & 0.2885 & 0.2476 & 0.2845 & 0.2500 & 0.2871 & 0.2474 \\
\hline & DC & 0.2575 & 0.4236 & 0.2543 & 0.4338 & 0.2667 & 0.4344 & 0.2546 & 0.4329 \\
\hline \multirow{3}{*}{ Full Equity } & ALL & 0.5448 & 0.0580 & 0.3358 & 0.2699 & 0.3532 & 0.2700 & 0.3370 & 0.2661 \\
\hline & BC & 0.2667 & 0.6405 & 0.1603 & 0.6722 & 0.2143 & 0.6481 & 0.1862 & 0.6373 \\
\hline & DC & 0.7884 & -0.7475 & 0.7570 & -0.7106 & 0.7105 & -0.6468 & 0.7259 & -0.6783 \\
\hline \multirow{3}{*}{$\begin{array}{c}\text { Bond }+ \text { Equity } \\
(0.33 \text { each country })\end{array}$} & ALL & 0.4036 & 0.1888 & 0.3070 & 0.2863 & 0.3227 & 0.2782 & 0.3145 & 0.2755 \\
\hline & BC & 0.2716 & 0.4436 & 0.2244 & 0.4599 & 0.2528 & 0.4486 & 0.2431 & 0.4384 \\
\hline & $\mathrm{DC}$ & 0.5230 & -0.1619 & 0.5057 & -0.1384 & 0.4902 & -0.1135 & 0.4889 & -0.1158 \\
\hline \multirow{3}{*}{$\begin{array}{l}\text { Bond + Equity } \\
\text { (0.60 EMU) }\end{array}$} & ALL & 0.3024 & 0.0486 & 0.2033 & 0.1527 & 0.2186 & 0.1486 & 0.2119 & 0.1319 \\
\hline & BC & 0.1586 & 0.3341 & 0.1118 & 0.3513 & 0.1488 & 0.3324 & 0.1472 & 0.2888 \\
\hline & DC & 0.4307 & -0.3446 & 0.4234 & -0.3324 & 0.4000 & -0.3004 & 0.3710 & -0.2547 \\
\hline
\end{tabular}

Portfolio composition is reported in the first column: Full bond portfolio (Full Bond), Full equity Portfolio (Full Equity), Bond and equity portfolio (equally 33\% country weight, 50\% bonds, 50\% equities), home biased Bond and equity portfolio, (60\% EMU, 20\% the UK and 20\% the US). The second column reports the reference period: whole period (ALL), Before Crisis (BC), During Crisis (DC). The other columns are model-specific and include Euro units of British Pound future sold $\left(\boldsymbol{\beta}_{1}\right)$ and Euro units of US dollar future sold $\left(\boldsymbol{\beta}_{2}\right)$ per Euro invested in an international portfolio. Bond portfolio results are based on the all-maturities bond index.

Table 3: in-sample hedging effectiveness

\begin{tabular}{ccrccc}
\hline & & \multicolumn{1}{c}{ OLS } & EWMA & DCC & BEKK \\
\hline \multirow{3}{*}{ Full Bond } & ALL & 54.2271 & 55.9783 & 56.4614 & 56.2802 \\
& BC & 48.0645 & 48.6290 & 49.1129 & 49.1935 \\
& DC & 64.7259 & 64.5369 & 64.6881 & 64.4991 \\
\hline \multirow{3}{*}{ Full Equity } & ALL & 6.3218 & 17.3255 & 17.1643 & 16.8419 \\
& BC & 17.8482 & 19.9368 & 21.2931 & 20.3778 \\
& DC & 14.8817 & 14.9784 & 15.7008 & 13.2536 \\
\hline \multirow{2}{*}{ Bond + Equity } & ALL & 21.9506 & 29.3108 & 28.6606 & 28.9987 \\
(0.33 each country) & BC & 34.4463 & 35.5593 & 36.5888 & 35.9210 \\
& DC & 18.8174 & 18.5926 & 18.5926 & 16.9739 \\
\hline \multirow{2}{*}{ Bond + Equity } & ALL & 7.9051 & 17.6812 & 17.2069 & 14.7019 \\
(0.60 EMU) & BC & 18.5955 & 20.1025 & 21.5190 & 17.7134 \\
& DC & 14.7541 & 15.2196 & 16.3327 & 11.7418 \\
\hline
\end{tabular}

Portfolio composition is reported in the first column: Full bond portfolio (Full Bond), Full equity Portfolio (Full Equity), Bond and equity portfolio (equally 33\% country weight, 50\% bonds, 50\% equities), home biased Bond and equity portfolio, (60\% EMU, 20\% the UK and 20\% the US). The second column reports the reference period: whole period (ALL), Before Crisis (BC), During Crisis (DC). The other columns are model-specific and include the hedging effectiveness in percentage points. Bond portfolio results are based on the all-maturities bond index. 
Table 4: in-sample improved Sharpe ratios

\begin{tabular}{ccrrrrrr}
\hline & & UH & OLS & EWMA & DCC & \multicolumn{1}{c}{ BEKK } & \multicolumn{1}{c}{ EMU } \\
\hline & ALL & -1.1250 & 0.0517 & -1.7042 & -1.2718 & -1.4865 & -0.7113 \\
Full Bond & BC & -8.4267 & -3.4957 & -5.9460 & -5.3222 & -5.1260 & -2.6718 \\
& DC & 0.3650 & 0.4658 & 0.4584 & 0.4863 & 0.4169 & 0.2932 \\
\hline \multirow{3}{*}{ Full Equity } & ALL & -15.4869 & -6.8421 & 0.0821 & 0.0465 & -6.8393 & -42.3323 \\
& BC & -29.9870 & -6.6629 & 0.0084 & -10.7644 & 0.0243 & -13.5394 \\
& DC & 0.0695 & 0.1678 & 0.2701 & 0.2776 & 0.2179 & -116.969 \\
\hline \multirow{2}{*}{ Bond + Equity } & ALL & -4.9022 & -0.6494 & 0.0607 & -0.1656 & 0.0698 & -11.4112 \\
(0.33 each country) & BC & -15.5454 & -4.9724 & -5.3264 & -8.0766 & -3.0291 & -7.2155 \\
& DC & 0.2134 & 0.2988 & 0.4067 & 0.3500 & 0.3089 & -21.0662 \\
\hline \multirow{2}{*}{ Bond + Equity } & ALL & -7.0131 & -4.1969 & 0.0317 & -0.4431 & 0.0339 & -11.4112 \\
(0.60 EMU) & BC & -28.9056 & -4.9157 & -4.4775 & -7.8264 & -3.0385 & -7.2155 \\
& DC & 0.0655 & 0.1572 & 0.2746 & 0.2921 & 0.2182 & -21.0662 \\
\hline
\end{tabular}

Portfolio composition is reported in the first column: Full bond portfolio (Full Bond), Full equity Portfolio (Full Equity), Bond and equity portfolio (equally 33\% country weight, 50\% bonds, 50\% equities), home biased Bond and equity portfolio, (60\% EMU, 20\% the UK and 20\% the US). The second column reports the reference period: whole period (ALL), Before Crisis (BC), During Crisis (DC). The other columns report the improved Sharpe Ratio of Israelsen (2005) (when average returns are negative those are multiplied by the standard deviation rather than divided) for the unhedged portfolio (UH), for the hedged portfolios where hedge ratios are model-dependent, and for the portfolio containing only assets denominated in Euro (composition by asset class is here consistent to that in the first column). Bond portfolio results are based on the all-maturities bond index.

Table 5: out-of-sample optimal hedge ratios for alternative models

\begin{tabular}{cccccccccc}
\hline & & \multicolumn{2}{c}{ OLS } & \multicolumn{2}{c}{ EWMA } & \multicolumn{2}{c}{ DCC } & \multicolumn{2}{c}{ BEKK } \\
\hline & & $\boldsymbol{\beta}_{\mathbf{1}}$ & $\boldsymbol{\beta}_{\mathbf{2}}$ & $\boldsymbol{\beta}_{\mathbf{1}}$ & $\boldsymbol{\beta}_{\mathbf{2}}$ & $\boldsymbol{\beta}_{\mathbf{1}}$ & $\boldsymbol{\beta}_{\mathbf{2}}$ & $\boldsymbol{\beta}_{\mathbf{1}}$ & $\boldsymbol{\beta}_{\mathbf{2}}$ \\
\hline \multirow{4}{*}{ Full Bond } & ALL & 0.2644 & 0.2814 & 0.2678 & 0.3611 & 0.3782 & 0.2321 & 0.2701 & 0.3490 \\
& BC & 0.2794 & 0.2115 & 0.2820 & 0.2879 & 0.3594 & 0.1785 & 0.2761 & 0.2806 \\
& DC & 0.2495 & 0.3509 & 0.2536 & 0.4339 & 0.3969 & 0.2853 & 0.2642 & 0.4170 \\
\hline \multirow{4}{*}{ Full Equity } & ALL & 0.4495 & 0.2230 & 0.5132 & -0.1862 & 0.4311 & -0.0015 & 0.4394 & -0.0277 \\
& BC & 0.2228 & 0.7077 & 0.2709 & 0.3203 & 0.4053 & 0.2868 & 0.2401 & 0.4526 \\
& DC & 0.6748 & -0.2585 & 0.7540 & -0.6894 & 0.4568 & -0.2878 & 0.6375 & -0.5048 \\
\hline \multirow{3}{*}{ Bond + Equity } & ALL & 0.3570 & 0.2522 & 0.3905 & 0.0875 & 0.3936 & 0.1082 & 0.3532 & 0.1517 \\
& BC & 0.2511 & 0.4596 & 0.2765 & 0.3041 & 0.3737 & 0.2250 & 0.2579 & 0.3655 \\
& DC & 0.4621 & 0.0462 & 0.5038 & -0.1278 & 0.4134 & -0.0079 & 0.4480 & -0.0607 \\
\hline \multirow{2}{*}{ Bond + Equity } & ALL & 0.2580 & 0.1273 & 0.3034 & -0.0742 & 0.2609 & 0.0138 & 0.2636 & 0.0082 \\
& BC & 0.1454 & 0.3592 & 0.1846 & 0.1744 & 0.2511 & 0.1469 & 0.1665 & 0.2444 \\
& DC & 0.3699 & -0.1031 & 0.4214 & -0.3210 & 0.2707 & -0.1185 & 0.3601 & -0.2265 \\
\hline
\end{tabular}

Portfolio composition is reported in the first column: Full bond portfolio (Full Bond), Full equity Portfolio (Full Equity), Bond and equity portfolio (equally 33\% country weight, 50\% bonds, 50\% equities), home biased Bond and equity portfolio, (60\% EMU, 20\% the UK and 20\% the US). The second column reports the reference period: whole period (ALL), Before Crisis (BC), During Crisis (DC). The other columns are model-specific and include Euro units of British Pound future sold $\left(\boldsymbol{\beta}_{1}\right)$ and Euro units 
of US dollar future sold $\left(\boldsymbol{\beta}_{2}\right)$ per Euro invested in an international portfolio. Bond portfolio results are based on the all-maturities bond index.

Table 6: out-of-sample hedging effectiveness

\begin{tabular}{cccccc}
\hline & & OLS & EWMA & DCC & BEKK \\
\hline & ALL & 57.4547 & 58.4404 & 54.6875 & 58.5361 \\
Full Bond & BC & 41.6089 & 42.9759 & 39.3177 & 43.3117 \\
& DC & 63.4246 & 64.2737 & 60.4934 & 64.2709 \\
\hline \multirow{3}{*}{ Full Equity } & ALL & 4.2412 & 12.1629 & 10.1212 & 11.0508 \\
& BC & 5.4192 & 8.5194 & 9.1866 & 8.9343 \\
& DC & 3.8049 & 13.5258 & 10.4710 & 11.8421 \\
\hline \multirow{2}{*}{ Bond + Equity } & ALL & 14.2884 & 20.0723 & 18.9343 & 19.3880 \\
(0.33 each country) & BC & 25.0534 & 26.3492 & 25.6997 & 26.6090 \\
& DC & 9.3884 & 17.2353 & 15.8632 & 16.1128 \\
\hline \multirow{2}{*}{ Bond + Equity } & ALL & 5.7603 & 13.1157 & 10.8842 & 12.2160 \\
(0.60 EMU) & BC & 9.0645 & 11.1853 & 11.7767 & 11.5658 \\
& DC & 4.5082 & 13.8568 & 10.5483 & 12.4666
\end{tabular}

Portfolio composition is reported in the first column: Full bond portfolio (Full Bond), Full equity Portfolio (Full Equity), Bond and equity portfolio (equally 33\% country weight, 50\% bonds, 50\% equities), home biased Bond and equity portfolio, (60\% EMU, 20\% the UK and 20\% the US). The second column reports the reference period: whole period (ALL), Before Crisis (BC), During Crisis (DC). The other columns are model-specific and include the hedging effectiveness in percentage points. Bond portfolio results are based on the all-maturities bond index.

Table 7: out-of-sample improved Sharpe ratios

\begin{tabular}{cccccccc}
\hline & & UH & OLS & EWMA & DCC & BEKK & EMU \\
\hline & ALL & 0.0300 & 0.1500 & 0.0800 & 0.1600 & 0.1300 & 0.0300 \\
Full Bond & BC & -12.4600 & -3.5200 & -5.3200 & -5.0700 & -3.7900 & -3.5000 \\
& DC & 0.3600 & -10.3200 & 0.4300 & 0.5400 & 0.4300 & 0.2900 \\
\hline \multirow{3}{*}{ Full Equity } & ALL & 0.0600 & 0.1600 & 0.1600 & 0.1700 & 0.1500 & -3.0600 \\
& BC & 0.0300 & 0.3300 & 0.0500 & 0.1400 & 0.0800 & 0.2900 \\
& DC & 0.0700 & 0.0200 & 0.2400 & 0.2000 & 0.2000 & -113.670 \\
\hline \multirow{2}{*}{ Bond + Equity } & ALL & 0.0700 & 0.2200 & 0.1900 & 0.1800 & 0.1817 & -0.0700 \\
(0.33 each country) & BC & -7.3300 & 0.2700 & -2.4300 & 0.0100 & -0.3199 & 0.2300 \\
& DC & 0.2200 & -8.9500 & 0.3600 & 0.3000 & 0.3109 & -20.290 \\
\hline \multirow{2}{*}{ Bond + Equity } & ALL & 0.0400 & 0.1500 & 0.1400 & 0.1500 & 0.1312 & -0.0700 \\
(0.60 EMU) & BC & -0.1400 & 0.3100 & -0.0600 & 0.0800 & 0.0418 & 0.2300 \\
& DC & 0.0700 & -8.7000 & 0.2400 & 0.2000 & 0.1927 & -20.290 \\
\hline
\end{tabular}

Portfolio composition is reported in the first column: Full bond portfolio (Full Bond), Full equity Portfolio (Full Equity), Bond and equity portfolio (equally 33\% country weight, 50\% bonds, 50\% equities), home biased Bond and equity portfolio, (60\% EMU, 20\% the UK and 20\% the US). The second column reports the reference period: whole period (ALL), Before Crisis (BC), During Crisis (DC). The other columns report the improved Sharpe Ratio of Israelsen (2005) (when average returns are negative those are multiplied by the standard deviation rather than divided) for the unhedged portfolio (UH), for the hedged portfolios where hedge ratios are model-dependent, and for the portfolio containing only assets denominated in Euro (composition by asset class is here consistent to that in the first column). Bond portfolio results are based on the all-maturities bond index. 
Figure 1: future prices of British Pound and US Dollar against the Euro.

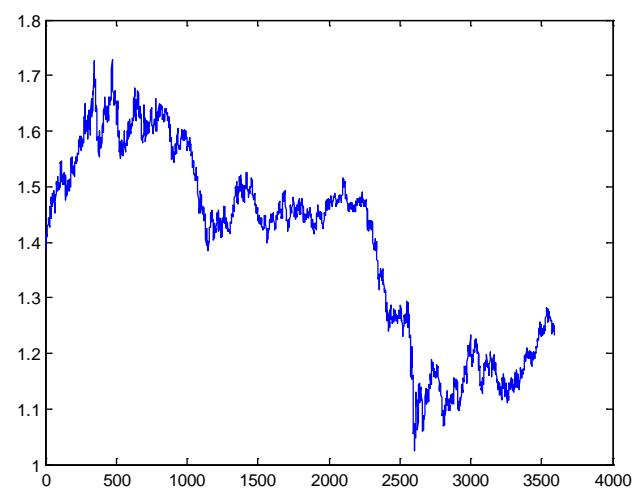

GBP Future prices

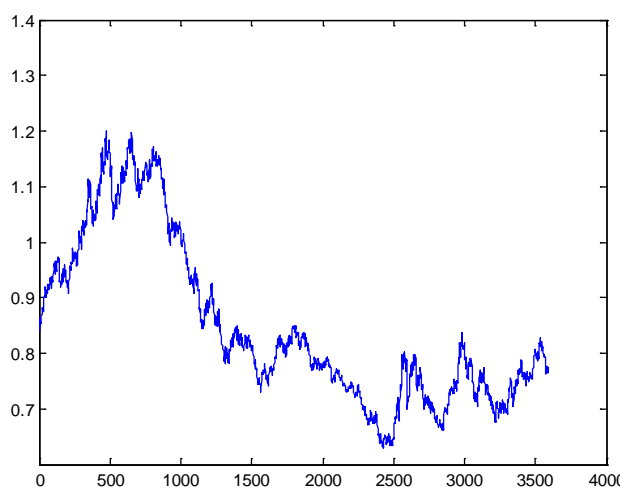

USD Future prices

Figure 2: Time path of hedge ratios (Full bond portfolio with All-maturities bond index)
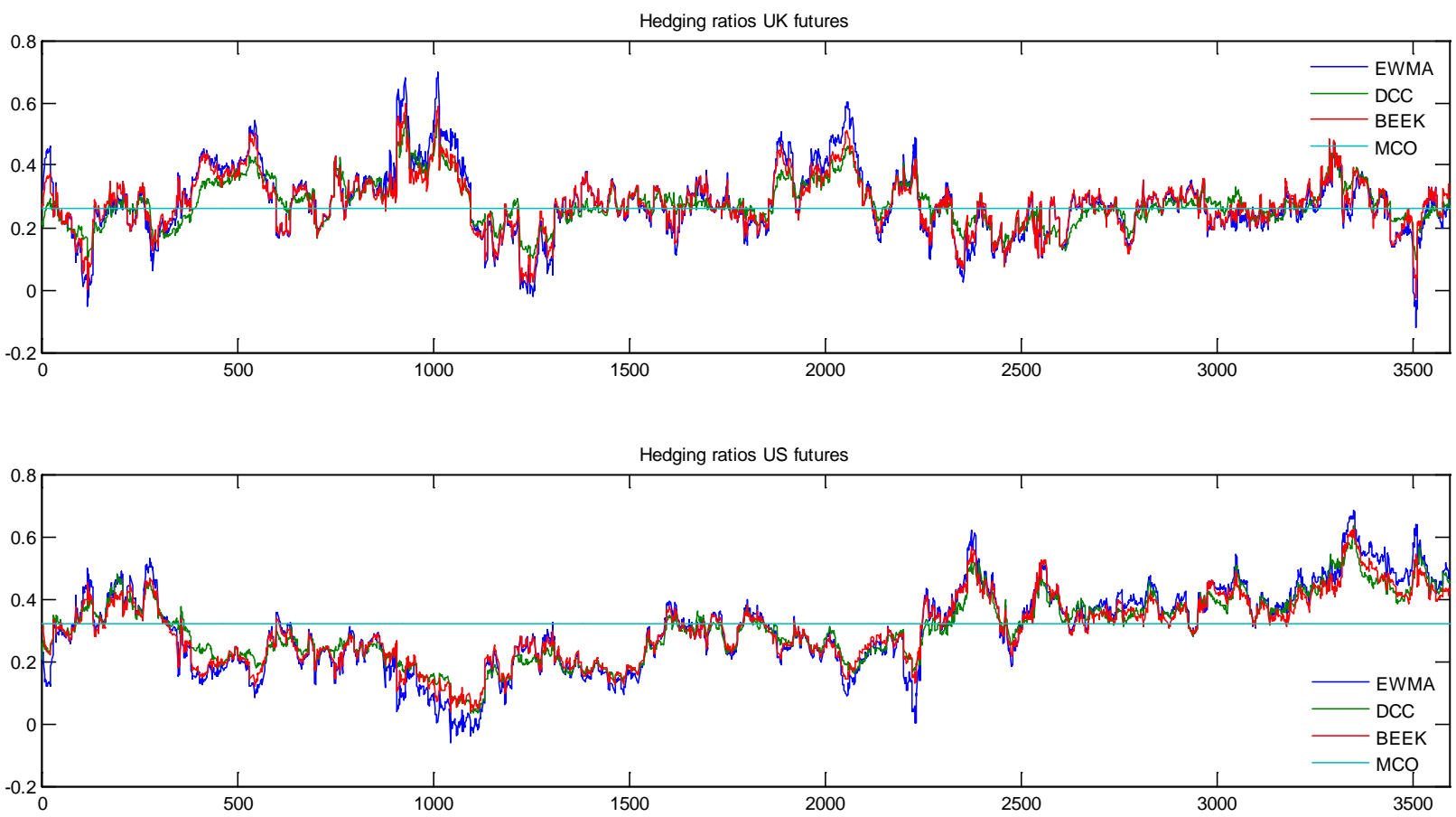

Note: hedging rations for the British Pound (upper panel) and US Dollar (lower panel). 
Figure 3. In-sample Hedging ratios box-plots: Full bond portfolio
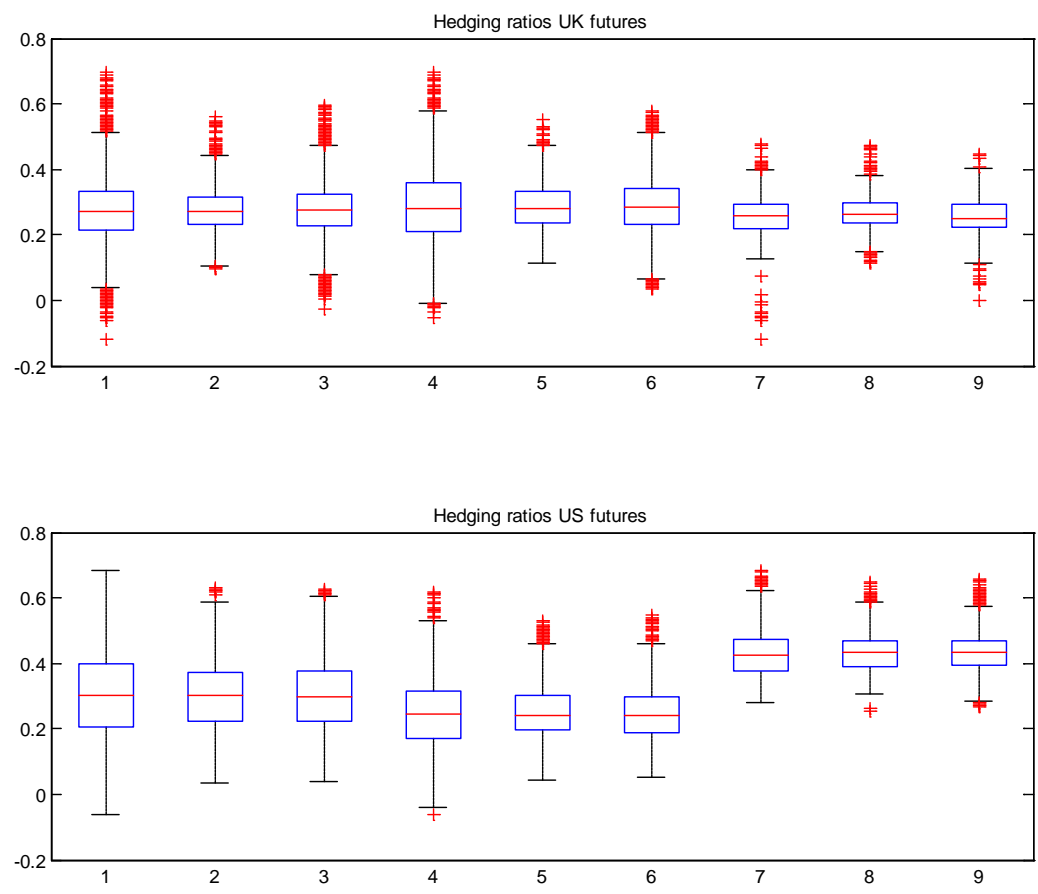

Note: 1-3 full sample; 4-6 Before crisis; 7-9 During Crisis; 1-4-7 EWMA; 2-5-8 DCC; 3-6-9 BEKK.

Figure 4. In-sample Hedging ratios box-plots: Full equity portfolio
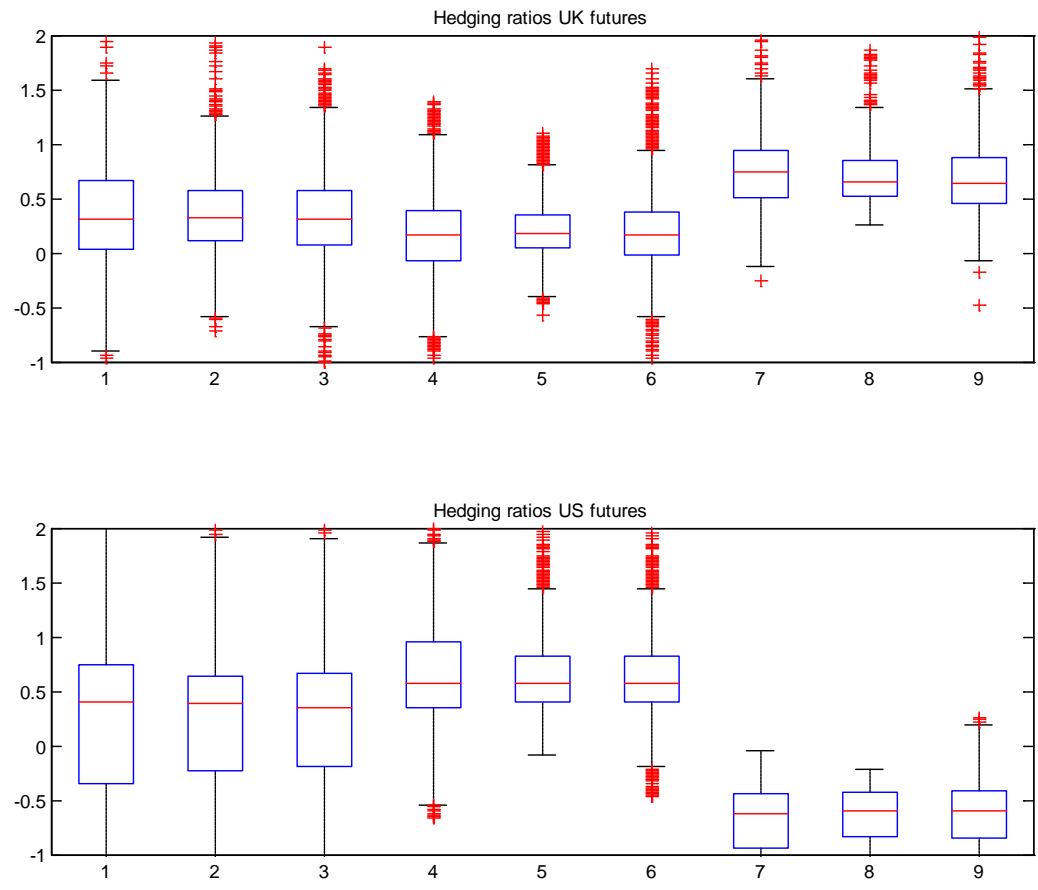

Note: 1-3 full sample; 4-6 Before crisis; 7-9 During Crisis; 1-4-7 EWMA; 2-5-8 DCC; 3-6-9 BEKK. 
Figure 5. In-sample Hedging ratios box-plots: equally weighted equity and bond portfolio
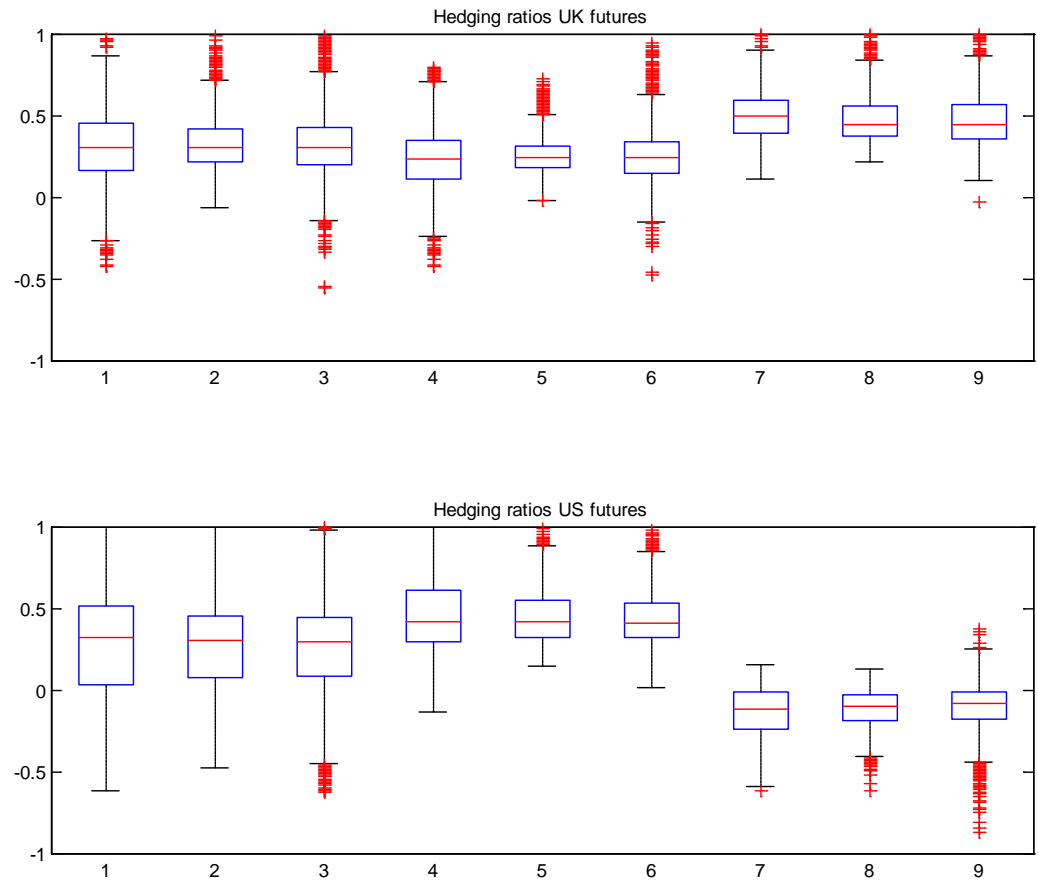

Note: 1-3 full sample; 4-6 Before crisis; 7-9 During Crisis; 1-4-7 EWMA; 2-5-8 DCC; 3-6-9 BEKK.

Figure 6. Out-of-sample Hedging ratio. Full bond portfolio
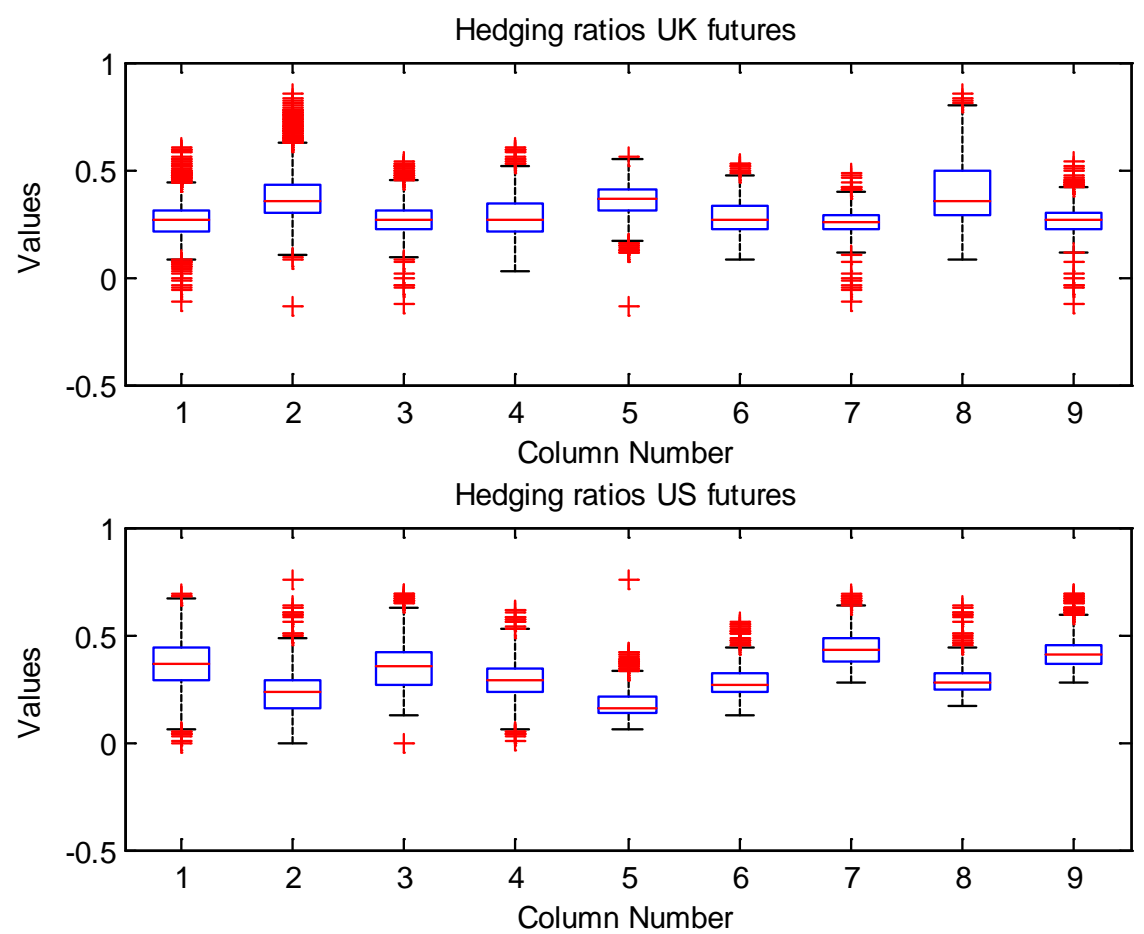

Note: 1-3 full sample; 4-6 Before crisis; 7-9 During Crisis; 1-4-7 EWMA; 2-5-8 DCC; 3-6-9 BEKK. 
Figure 7. Out-of-sample Hedging ratios. Full equity portfolio
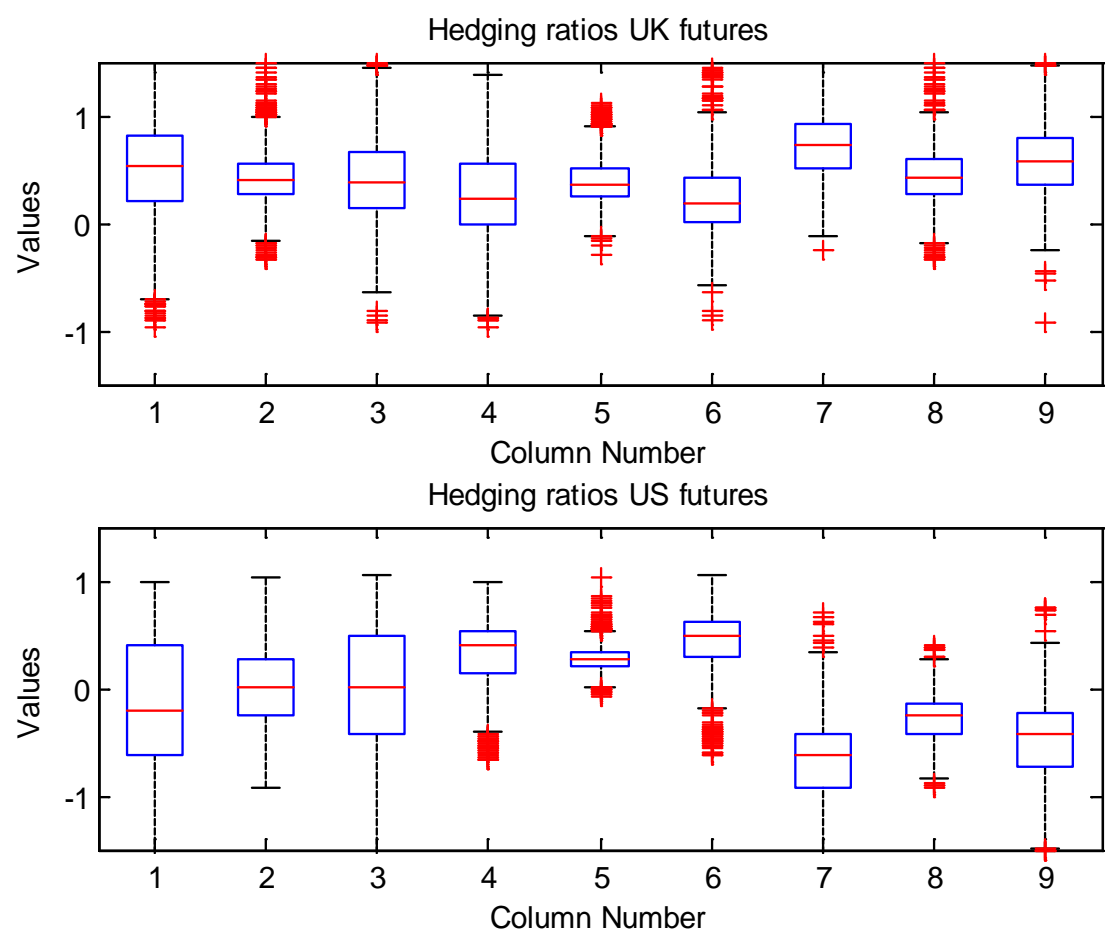

Note: 1-3 full sample; 4-6 Before crisis; 7-9 During Crisis; 1-4-7 EWMA; 2-5-8 DCC; 3-6-9 BEKK.

Figure 8. Out-of-sample Hedging ratios. equally weighted equity and bond portfolio

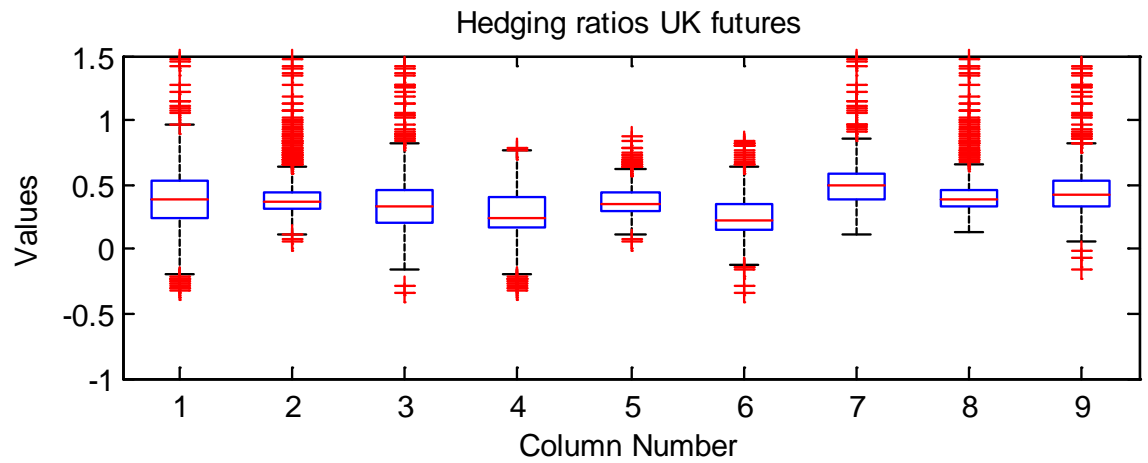

Hedging ratios US futures

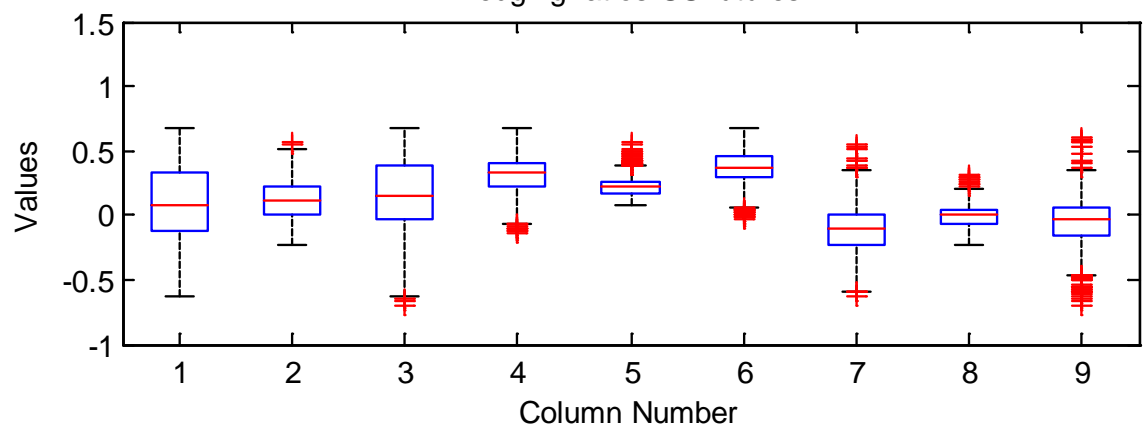

Note: 1-3 full sample; 4-6 Before crisis; 7-9 During Crisis; 1-4-7 EWMA; 2-5-8 DCC; 3-6-9 BEKK. 


\section{Appendix}

Table A.1 OLS MODEL - All maturities - In-sample

\begin{tabular}{|c|c|c|c|c|c|c|c|c|c|c|c|c|c|}
\hline & & $\beta_{1}$ & $\boldsymbol{\beta}_{2}$ & $\sigma_{\mathrm{UH}}$ & $\sigma_{H}$ & HE & $\sigma_{\mathrm{EMU}}$ & $\mathbf{R}_{\mathrm{UH}}$ & $\mathbf{R}_{\mathbf{H}}$ & $\mathbf{R}_{\mathrm{EMU}}$ & $\mathrm{SHR}_{\mathrm{UH}}$ & $\mathrm{SHR}_{\mathrm{H}}$ & SHR $_{\text {EMU }}$ \\
\hline \multirow{3}{*}{ Full Bond } & ALL & 0.2625 & 0.3195 & 6.4343 & 4.3532 & 54.2271 & 3.5602 & -0.1748 & 0.2253 & -0.1998 & -1.1250 & 0.0517 & -0.7113 \\
\hline & $B C$ & 0.2766 & 0.2466 & 5.5678 & 4.0125 & 48.0645 & 3.2519 & -1.5135 & -0.8712 & -0.8216 & -8.4074 & -3.4957 & -2.6718 \\
\hline & DC & 0.2575 & 0.4236 & 8.1317 & 4.8296 & 64.7259 & 4.2042 & 2.9680 & 2.2498 & 1.2325 & 0.3652 & 0.4658 & 0.2932 \\
\hline \multirow{3}{*}{ Full Equity } & ALL & 0.5448 & 0.0580 & 18.8865 & 18.2798 & 6.3218 & 22.4917 & -0.8216 & -0.3743 & -1.8821 & -15.4869 & -6.8421 & -42.3323 \\
\hline & $B C$ & 0.2667 & 0.6405 & 17.3335 & 15.7107 & 17.8482 & 20.1259 & -0.0173 & -0.4241 & -0.6727 & -29.9870 & -6.6629 & -13.5394 \\
\hline & DC & 0.7884 & -0.7475 & 22.1670 & 20.4512 & 14.8817 & 27.3226 & 0.0154 & 3.4324 & -4.2810 & 0.0695 & 0.1678 & -116.9693 \\
\hline \multirow{3}{*}{$\begin{array}{c}\text { Bond + Equity } \\
\text { ( } 0.33 \text { each country) }\end{array}$} & ALL & 0.4036 & 0.1888 & 9.8043 & 8.6617 & 21.9506 & 10.9247 & -0.4988 & -0.0750 & -1.0445 & -4.9022 & -0.6494 & -11.4112 \\
\hline & $B C$ & 0.2716 & 0.4436 & 9.4789 & 7.6746 & 34.4463 & 9.6566 & -1.6365 & -0.6479 & -0.7472 & -15.5454 & -4.9724 & -7.2155 \\
\hline & DC & 0.5230 & -0.1619 & 10.5451 & 9.5013 & 18.8174 & 13.4805 & 2.2498 & 2.8394 & -1.5627 & 0.2134 & 0.2988 & -21.0662 \\
\hline \multirow{3}{*}{$\begin{array}{l}\text { Bond + Equity } \\
\text { (0.60 EMU) }\end{array}$} & ALL & 0.3024 & 0.0486 & 9.7404 & 9.3475 & 7.9051 & 10.9247 & -0.7224 & -0.4490 & -1.0445 & -7.0131 & -4.1969 & -11.4112 \\
\hline & $B C$ & 0.1586 & 0.3341 & 9.1077 & 8.2174 & 18.5955 & 9.6566 & -1.2916 & -0.5982 & -0.7472 & -28.9056 & -4.9157 & -7.2155 \\
\hline & DC & 0.4307 & -0.3446 & 11.1142 & 10.2616 & 14.7541 & 13.4805 & 0.7276 & 1.6128 & -1.5627 & 0.0655 & 0.1572 & -21.0662 \\
\hline
\end{tabular}

Notes: Full bond portfolio (Full Bond), Full equity Portfolio (Full Equity), Bond and equity portfolio (equally 33\% country weight, 50\% bonds, 50\% equities), home biased Bond and equity portfolio, (60\% EMU, 20\% the UK and 20\% the US), for the EMU portfolio the investor is only holding domestic equities and/or bonds based on the kind of international portfolio we are comparing with (full bond, full equity or equities + bonds); whole period (ALL), Before Crisis (BC), During Crisis (DC); Euro units of British Pound future sold $\left(\boldsymbol{\beta}_{1}\right)$, Euro units of US dollar future sold $\left(\boldsymbol{\beta}_{2}\right)$ per Euro invested in an international portfolio; annualized unhedged portfolio standard deviation $\left(\boldsymbol{\sigma}_{\mathrm{UH}}\right)$, annualized hedged portfolio standard deviation $\left(\boldsymbol{\sigma}_{\mathbf{H}}\right)$, Hedging Effectiveness $(\mathbf{H E})$, annualized European portfolio standard deviation $\left(\boldsymbol{\sigma}_{\mathrm{EMU}}\right)$, annualized unhedged portfolio Return ( $\mathbf{R}_{\mathbf{U H}}$ ), annualized hedged portfolio Return ( $\mathbf{R}_{\mathbf{H}}$ ), annualized European portfolio return ( $\mathbf{R}_{\mathbf{E M U}}$ ), modified Sharpe Ratio (SHR) of Israelsen (2005) (when average returns are negative those are multiplied by the standard deviation rather than divided). 
Table A.2 OLS MODEL - 1-3-Year Maturity - In-sample

\begin{tabular}{|c|c|c|c|c|c|c|c|c|c|c|c|c|c|}
\hline & & $\beta_{1}$ & $\beta_{2}$ & $\boldsymbol{\sigma}_{\mathrm{UH}}$ & $\sigma_{H}$ & HE & $\boldsymbol{\sigma}_{\mathrm{EMU}}$ & $\mathbf{R}_{\mathrm{UH}}$ & $\mathbf{R}_{\mathbf{H}}$ & $\mathbf{R}_{\mathrm{EMU}}$ & $\mathrm{SHR}_{\mathrm{UH}}$ & $\mathbf{S H R}_{\mathbf{H}}$ & $\mathrm{SHR}_{\mathrm{EMU}}$ \\
\hline \multirow{3}{*}{ Full Bond } & ALL & 0.2959 & 0.3202 & 5.5272 & 2.4187 & 80.8511 & 1.5492 & -1.3656 & -0.9455 & -1.2423 & -7.5481 & -2.2869 & -1.9245 \\
\hline & BC & 0.2820 & 0.3108 & 5.0349 & 2.3558 & 78.1065 & 1.4230 & -1.9802 & -1.2423 & -1.4889 & -9.9701 & -2.9265 & -2.1187 \\
\hline & DC & 0.3143 & 0.3367 & 6.5555 & 2.5298 & 85.1076 & 1.8028 & 0.0750 & -0.4490 & -0.6231 & 0.0114 & -1.1359 & -1.1232 \\
\hline \multirow{3}{*}{ Full Equity } & ALL & 0.5448 & 0.0580 & 18.8865 & 18.2798 & 6.3218 & 22.4917 & -0.8216 & -0.3743 & -1.8821 & -15.5175 & -6.8421 & -42.3323 \\
\hline & BC & 0.2667 & 0.6405 & 17.3335 & 15.7107 & 17.8482 & 20.1259 & -0.0173 & -0.4241 & -0.6727 & -0.3007 & -6.6629 & -13.5394 \\
\hline & DC & 0.7884 & -0.7475 & 22.1670 & 20.4512 & 14.8817 & 27.3226 & 0.0154 & 3.4324 & -4.2810 & 0.0007 & 0.1678 & -116.9693 \\
\hline \multirow{3}{*}{$\begin{array}{c}\text { Bond }+ \text { Equity } \\
\text { ( } 0.33 \text { each country) }\end{array}$} & ALL & 0.3910 & 0.1877 & 10.2140 & 9.0526 & 21.4474 & 11.1524 & -1.0940 & -0.6231 & -1.5627 & -11.1740 & -5.6403 & -17.4279 \\
\hline & BC & 0.2461 & 0.4744 & 9.8005 & 7.8358 & 36.0750 & 9.8944 & -1.8576 & -0.7720 & -1.0693 & -18.2054 & -6.0494 & -10.5798 \\
\hline & DC & 0.5207 & -0.2072 & 11.1490 & 10.0660 & 18.4835 & 13.6958 & 0.8032 & 1.4859 & -2.4691 & 0.0720 & 0.1476 & -33.8167 \\
\hline \multirow{3}{*}{$\begin{array}{l}\text { Bond +Equity } \\
\text { (0.60 EMU) }\end{array}$} & ALL & 0.2976 & 0.0509 & 10.1193 & 9.7082 & 7.9590 & 11.1524 & -1.2916 & -0.9703 & -1.5627 & -13.0703 & -9.4197 & -17.4279 \\
\hline & BC & 0.1436 & 0.3621 & 9.4101 & 8.4202 & 19.9322 & 9.8944 & -1.5627 & -0.7720 & -1.0693 & -14.7053 & -6.5005 & -10.5798 \\
\hline & DC & 0.4341 & -0.3780 & 11.6458 & 10.7168 & 15.3180 & 13.6958 & -0.5236 & 0.4510 & -2.4691 & -6.0981 & 0.0421 & -33.8167 \\
\hline
\end{tabular}

Notes: Full bond portfolio (Full Bond), Full equity Portfolio (Full Equity), Bond and equity portfolio (equally 33\% country weight, 50\% bonds, 50\% equities), home biased Bond and equity portfolio, (60\% EMU, 20\% the UK and 20\% the US), for the EMU portfolio the investor is only holding domestic equities and/or bonds based on the kind of international portfolio we are comparing with (full bond, full equity or equities + bonds); whole period (ALL), Before Crisis (BC), During Crisis (DC); Euro units of British Pound future sold $\left(\boldsymbol{\beta}_{1}\right)$, Euro units of US dollar future sold $\left(\boldsymbol{\beta}_{2}\right)$ per Euro invested in an international portfolio; annualized unhedged portfolio standard deviation $\left(\boldsymbol{\sigma}_{\mathrm{UH}}\right)$, annualized hedged portfolio standard deviation $\left(\boldsymbol{\sigma}_{\mathbf{H}}\right)$, Hedging Effectiveness (HE), annualized European portfolio standard deviation $\left(\boldsymbol{\sigma}_{\mathrm{EMU}}\right)$, annualized unhedged portfolio Return ( $\mathbf{R}_{\mathbf{U H}}$ ), annualized hedged portfolio Return $\left(\mathbf{R}_{\mathbf{H}}\right)$, annualized European portfolio return ( $\mathbf{R}_{\mathbf{E M U}}$ ), modified Sharpe Ratio (SHR) of Israelsen (2005) (when average returns are negative those are multiplied by the standard deviation rather than divided). 
Table A.3. OLS MODEL - +10-year maturity- In-sample

\begin{tabular}{|c|c|c|c|c|c|c|c|c|c|c|c|c|c|}
\hline & & $\beta_{1}$ & $\beta_{2}$ & $\boldsymbol{\sigma}_{\mathrm{UH}}$ & $\sigma_{\mathrm{H}}$ & HE & $\boldsymbol{\sigma}_{\mathrm{EMU}}$ & $\mathbf{R}_{\mathrm{UH}}$ & $\mathbf{R}_{\mathbf{H}}$ & $\mathbf{R}_{\mathrm{EMU}}$ & SHR $_{\mathrm{UH}}$ & $\mathrm{SHR}_{\mathrm{H}}$ & $\mathrm{SHR}_{\mathrm{EMU}}$ \\
\hline \multirow{3}{*}{ Full Bond } & ALL & 0.2278 & 0.3338 & 8.8671 & 7.5531 & 27.4404 & 7.0018 & 0.6269 & 1.0050 & 0.5012 & 0.0707 & 0.1331 & 0.0716 \\
\hline & BC & 0.2811 & 0.1832 & 7.3739 & 6.5689 & 20.6437 & 6.5479 & -1.2669 & -0.7224 & -0.4988 & -9.3423 & -4.7453 & -3.2658 \\
\hline & DC & 0.1886 & 0.5441 & 11.6705 & 9.0111 & 40.3818 & 7.9703 & 5.0215 & 4.0287 & 2.7110 & 0.4303 & 0.4471 & 0.3401 \\
\hline \multirow{3}{*}{ Full Equity } & ALL & 0.5448 & 0.0580 & 18.8865 & 18.2798 & 6.3218 & 22.4917 & -0.8216 & -0.3743 & -1.8821 & -15.5175 & -6.8421 & -42.3323 \\
\hline & $B C$ & 0.2667 & 0.6405 & 17.3335 & 15.7107 & 17.8482 & 20.1259 & -1.7348 & -0.4241 & -0.6727 & -30.0708 & -6.6629 & -13.5394 \\
\hline & DC & 0.7884 & -0.7475 & 22.1670 & 20.4512 & 14.8817 & 27.3226 & 1.5366 & 3.4324 & -4.2810 & 0.0693 & 0.1678 & -116.9693 \\
\hline \multirow{3}{*}{$\begin{array}{c}\text { Bond }+ \text { Equity } \\
\text { ( } 0.33 \text { each country) }\end{array}$} & ALL & 0.3863 & 0.1959 & 9.6605 & 8.5381 & 21.8859 & 10.9121 & -0.1000 & 0.3255 & -0.6976 & -0.9656 & 0.0381 & -7.6119 \\
\hline & $B C$ & 0.2739 & 0.4119 & 9.4167 & 7.7910 & 31.5478 & 9.6825 & -1.4889 & -0.5734 & -0.5982 & -14.0201 & -4.4670 & -5.7922 \\
\hline & DC & 0.4885 & -0.1017 & 10.2213 & 9.2399 & 18.2819 & 13.4052 & 3.2774 & 3.7172 & -0.8464 & 0.3206 & 0.4023 & -11.3463 \\
\hline \multirow{3}{*}{$\begin{array}{l}\text { Bond +Equity } \\
\text { (0.60 EMU) }\end{array}$} & ALL & 0.2890 & 0.0505 & 9.5825 & 9.2100 & 7.6232 & 10.9121 & -0.3494 & -0.0750 & -0.6976 & -3.3480 & -0.6905 & -7.6119 \\
\hline & $B C$ & 0.1615 & 0.3030 & 9.0554 & 8.2840 & 16.3110 & 9.6825 & -1.1434 & -0.4988 & -0.5982 & -10.3543 & -4.1317 & -5.7922 \\
\hline & $\mathrm{DC}$ & 0.4033 & -0.2977 & 10.7424 & 10.0250 & 12.9116 & 13.4052 & 1.6128 & 2.4289 & -0.8464 & 0.1501 & 0.2423 & -11.3463 \\
\hline
\end{tabular}

Notes: Full bond portfolio (Full Bond), Full equity Portfolio (Full Equity), Bond and equity portfolio (equally 33\% country weight, 50\% bonds, 50\% equities), home biased Bond and equity portfolio, (60\% EMU, 20\% the UK and 20\% the US), for the EMU portfolio the investor is only holding domestic equities and/or bonds based on the kind of international portfolio we are comparing with (full bond, full equity or equities + bonds); whole period (ALL), Before Crisis (BC), During Crisis (DC); Euro units of British Pound future sold $\left(\boldsymbol{\beta}_{1}\right)$, Euro units of US dollar future sold $\left(\boldsymbol{\beta}_{2}\right)$ per Euro invested in an international portfolio; annualized unhedged portfolio standard deviation $\left(\boldsymbol{\sigma}_{\mathrm{UH}}\right)$, annualized hedged portfolio standard deviation $\left(\boldsymbol{\sigma}_{\mathbf{H}}\right)$, Hedging Effectiveness $(\mathbf{H E})$, annualized European portfolio standard deviation $\left(\boldsymbol{\sigma}_{\mathbf{E M U}}\right)$, annualized unhedged portfolio Return ( $\mathbf{R}_{\mathbf{U H}}$ ), annualized hedged portfolio Return $\left(\mathbf{R}_{\mathbf{H}}\right)$, annualized European portfolio return ( $\mathbf{R}_{\mathbf{E M U}}$ ), modified Sharpe Ratio (SHR) of Israelsen (2005) (when average returns are negative those are multiplied by the standard deviation rather than divided). 
Table A.4 EWMA MODEL - All maturities - In-sample

\begin{tabular}{|c|c|c|c|c|c|c|c|c|c|c|c|c|c|}
\hline & & $\beta_{1}$ & $\beta_{2}$ & $\boldsymbol{\sigma}_{\mathrm{UH}}$ & $\sigma_{H}$ & HE & $\boldsymbol{\sigma}_{\mathrm{EMU}}$ & $\mathbf{R}_{\mathrm{UH}}$ & $\mathbf{R}_{\mathbf{H}}$ & $\mathbf{R}_{\mathrm{EMU}}$ & $\mathrm{SHR}_{\mathrm{UH}}$ & $\mathrm{SHR}_{\mathrm{H}}$ & $\mathrm{SHR}_{\mathrm{EMU}}$ \\
\hline \multirow{3}{*}{ Full Bond } & ALL & 0.2782 & 0.3026 & 6.4343 & 4.2691 & 55.9783 & 3.5602 & -0.1748 & -0.3992 & -0.1998 & -1.1250 & -1.7042 & -0.7113 \\
\hline & BC & 0.2885 & 0.2476 & 5.5678 & 3.9906 & 48.6290 & 3.2519 & -1.5100 & -1.4900 & -0.8200 & -8.4074 & -5.9460 & -2.6666 \\
\hline & DC & 0.2543 & 0.4338 & 8.1317 & 4.8425 & 64.5369 & 4.2042 & 2.9700 & 2.2200 & 1.2300 & 0.3652 & 0.4584 & 0.2926 \\
\hline \multirow{3}{*}{ Full Equity } & ALL & 0.3358 & 0.2699 & 18.8865 & 17.1727 & 17.3255 & 22.4917 & -0.8200 & 1.4100 & -1.8800 & -15.4869 & 0.0821 & -42.2844 \\
\hline & BC & 0.1603 & 0.6722 & 17.3335 & 15.5097 & 19.9368 & 20.1259 & -1.7300 & 0.1300 & -0.6700 & -29.9870 & 0.0084 & -13.4844 \\
\hline & DC & 0.7570 & -0.7106 & 22.1670 & 20.4395 & 14.9784 & 27.3226 & 1.5400 & 5.5200 & -4.2800 & 0.0695 & 0.2701 & -116.9407 \\
\hline \multirow{3}{*}{$\begin{array}{c}\text { Bond }+ \text { Equity } \\
\text { ( } 0.33 \text { each country) }\end{array}$} & ALL & 0.3070 & 0.2863 & 9.8043 & 8.2432 & 29.3108 & 10.9247 & -0.5000 & 0.5000 & -1.0400 & -4.9022 & 0.0607 & -11.3617 \\
\hline & $B C$ & 0.2244 & 0.4599 & 9.4789 & 7.6092 & 35.5593 & 9.6566 & -1.6400 & -0.7000 & -0.7500 & -15.5454 & -5.3264 & -7.2425 \\
\hline & DC & 0.5057 & -0.1384 & 10.5451 & 9.5145 & 18.5926 & 13.4805 & 2.2500 & 3.8700 & -1.5600 & 0.2134 & 0.4067 & -21.0296 \\
\hline \multirow{3}{*}{$\begin{array}{l}\text { Bond +Equity } \\
\text { (0.60 EMU) }\end{array}$} & ALL & 0.2033 & 0.1527 & 9.7404 & 8.8374 & 17.6812 & 10.9247 & -0.7200 & 0.2800 & -1.0400 & -7.0131 & 0.0317 & -11.3617 \\
\hline & $B C$ & 0.1118 & 0.3513 & 9.1077 & 8.1409 & 20.1025 & 9.6566 & -3.1738 & -0.5500 & -0.7500 & -28.9056 & -4.4775 & -7.2425 \\
\hline & DC & 0.4234 & -0.3324 & 11.1142 & 10.2335 & 15.2196 & 13.4805 & 0.0072 & 2.8100 & -1.5600 & 0.0655 & 0.2746 & -21.0296 \\
\hline
\end{tabular}

Notes: Full bond portfolio (Full Bond), Full equity Portfolio (Full Equity), Bond and equity portfolio (equally 33\% country weight, 50\% bonds, 50\% equities), home biased Bond and equity portfolio, (60\% EMU, 20\% the UK and 20\% the US), for the EMU portfolio the investor is only holding domestic equities and/or bonds based on the kind of international portfolio we are comparing with (full bond, full equity or equities + bonds); whole period (ALL), Before Crisis (BC), During Crisis (DC); Euro units of British Pound future sold $\left(\boldsymbol{\beta}_{1}\right)$, Euro units of US dollar future sold $\left(\boldsymbol{\beta}_{2}\right)$ per Euro invested in an international portfolio; annualized unhedged portfolio standard deviation $\left(\boldsymbol{\sigma}_{\mathrm{UH}}\right)$, annualized hedged portfolio standard deviation $\left(\boldsymbol{\sigma}_{\mathbf{H}}\right)$, Hedging Effectiveness $(\mathbf{H E})$, annualized European portfolio standard deviation $\left(\boldsymbol{\sigma}_{\mathbf{E}} \mathbf{m}\right)$, annualized unhedged portfolio Return ( $\mathbf{R}_{\mathbf{U H}}$ ), annualized hedged portfolio Return $\left(\mathbf{R}_{\mathbf{H}}\right)$, annualized European portfolio return ( $\mathbf{R}_{\mathbf{E M U}}$ ), modified Sharpe Ratio (SHR) of Israelsen (2005) (when average returns are negative those are multiplied by the standard deviation rather than divided). 
Table A.5. EWMA MODEL- 1-3-year maturity- In-sample

\begin{tabular}{|c|c|c|c|c|c|c|c|c|c|c|c|c|c|}
\hline & & $\beta_{1}$ & $\beta_{2}$ & $\sigma_{\mathrm{UH}}$ & $\sigma_{\mathrm{H}}$ & $\mathrm{HE}$ & $\sigma_{\mathrm{EMU}}$ & $\mathbf{R}_{\mathrm{UH}}$ & $\mathbf{R}_{\mathbf{H}}$ & $\mathbf{R}_{\mathrm{EMU}}$ & $\mathrm{SHR}_{\mathrm{UH}}$ & $\mathrm{SHR}_{\mathrm{H}}$ & $\mathbf{S H R}_{\mathrm{EMU}}$ \\
\hline \multirow{3}{*}{ Full Bond } & ALL & 0.2948 & 0.3199 & 5.5272 & 2.4444 & 80.4419 & 1.5492 & -1.3656 & -1.0198 & -1.2423 & -7.5481 & -2.4927 & -1.9245 \\
\hline & BC & 0.2848 & 0.3138 & 5.0349 & 2.3822 & 77.6134 & 1.4230 & -1.9800 & -1.2400 & -1.4900 & -9.9691 & -2.9539 & -2.1203 \\
\hline & DC & 0.3189 & 0.3346 & 6.5555 & 2.5739 & 84.5841 & 1.8028 & 0.0800 & -0.5200 & -0.6200 & 0.0122 & -1.3384 & -1.1177 \\
\hline \multirow{3}{*}{ Full Equity } & ALL & 0.3358 & 0.2699 & 18.8865 & 17.1727 & 17.3255 & 22.4917 & -0.8200 & 1.4100 & -1.8800 & -15.4869 & 0.0821 & -42.2844 \\
\hline & BC & 0.1603 & 0.6722 & 17.3335 & 15.5097 & 19.9368 & 20.1259 & -1.7300 & 0.1300 & -0.6700 & -29.9870 & 0.0084 & -13.4844 \\
\hline & DC & 0.7570 & -0.7106 & 22.1670 & 20.4395 & 14.9784 & 27.3226 & 1.5400 & 5.5200 & -4.2800 & 0.0695 & 0.2701 & -116.9407 \\
\hline \multirow{3}{*}{$\begin{array}{c}\text { Bond }+ \text { Equity } \\
\text { ( } 0.33 \text { each country) }\end{array}$} & ALL & 0.3153 & 0.2949 & 10.2140 & 8.5308 & 30.2420 & 11.1524 & -1.0900 & 0.1800 & -1.5600 & -11.1333 & 0.0211 & -17.3977 \\
\hline & BC & 0.2226 & 0.4930 & 9.8005 & 7.7669 & 37.1942 & 9.8944 & -1.8600 & -0.5700 & -1.0700 & -18.2289 & -4.4271 & $-10.587 C$ \\
\hline & DC & 0.5380 & -0.1880 & 11.1490 & 10.0474 & 18.7852 & 13.6958 & 0.8000 & 2.4500 & -2.4700 & 0.0718 & 0.2438 & -33.8286 \\
\hline \multirow{3}{*}{$\begin{array}{c}\text { Bond +Equity } \\
\text { (0.60 EMU) }\end{array}$} & ALL & 0.2084 & 0.1632 & 10.1193 & 9.1022 & 19.0918 & 11.1524 & -1.2900 & -0.0500 & -1.5600 & -13.0539 & -0.4551 & -17.3977 \\
\hline & BC & 0.1091 & 0.3813 & 9.4101 & 8.3217 & 21.7956 & 9.8944 & -3.8252 & -0.5200 & -1.0700 & -35.9957 & -4.3273 & -10.5870 \\
\hline & DC & 0.4468 & -0.3678 & 11.6458 & 10.6595 & 16.2212 & 13.6958 & -1.2916 & 1.6100 & -2.4700 & -15.0419 & 0.1510 & -33.8286 \\
\hline
\end{tabular}

Notes: Full bond portfolio (Full Bond), Full equity Portfolio (Full Equity), Bond and equity portfolio (equally 33\% country weight, 50\% bonds, 50\% equities), home biased Bond and equity portfolio, (60\% EMU, 20\% the UK and 20\% the US), for the EMU portfolio the investor is only holding domestic equities and/or bonds based on the kind of international portfolio we are comparing with (full bond, full equity or equities + bonds); whole period (ALL), Before Crisis (BC), During Crisis (DC); Euro units of British Pound future sold $\left(\boldsymbol{\beta}_{1}\right)$, Euro units of US dollar future sold $\left(\boldsymbol{\beta}_{2}\right)$ per Euro invested in an international portfolio; annualized unhedged portfolio standard deviation $\left(\boldsymbol{\sigma}_{\mathrm{UH}}\right)$, annualized hedged portfolio standard deviation $\left(\boldsymbol{\sigma}_{\mathrm{H}}\right)$, Hedging Effectiveness $(\mathbf{H E})$, annualized European portfolio standard deviation $\left(\boldsymbol{\sigma}_{\mathrm{EMU}}\right)$, annualized unhedged portfolio Return ( $\left.\mathbf{R}_{\mathbf{U H}}\right)$, annualized hedged portfolio Return $\left(\mathbf{R}_{\mathbf{H}}\right)$, annualized European portfolio return ( $\mathbf{R}_{\mathrm{EMU}}$ ), modified Sharpe Ratio (SHR) of Israelsen (2005) (when average returns are negative those are multiplied by the standard deviation rather than divided). 
Table A.6. EWMA MODEL- +10-year maturity- In-sample

\begin{tabular}{|c|c|c|c|c|c|c|c|c|c|c|c|c|c|}
\hline & & $\beta_{1}$ & $\beta_{2}$ & $\sigma_{\mathrm{UH}}$ & $\sigma_{\mathrm{H}}$ & HE & $\boldsymbol{\sigma}_{\mathrm{EMU}}$ & $\mathbf{R}_{\mathrm{UH}}$ & $\mathbf{R}_{\mathbf{H}}$ & $\mathbf{R}_{\mathrm{EMU}}$ & $\mathrm{SHR}_{\mathrm{UH}}$ & $\mathrm{SHR}_{\mathrm{H}}$ & $\mathrm{SHR}_{\mathrm{EMU}}$ \\
\hline \multirow{3}{*}{ Full Bond } & ALL & 0.2635 & 0.2974 & 8.8671 & 7.3110 & 32.0191 & 7.0018 & 0.6269 & -0.2497 & 0.5012 & 0.0707 & -1.8255 & 0.0716 \\
\hline & BC & 0.3041 & 0.1785 & 7.3739 & 6.5307 & 21.5632 & 6.5479 & -1.2700 & -1.9300 & -0.5000 & -9.3649 & -12.6043 & -3.2740 \\
\hline & DC & 0.1685 & 0.5800 & 11.6705 & 8.8685 & 42.2540 & 7.9703 & 5.0200 & 3.9000 & 2.7100 & 0.4301 & 0.4398 & 0.3400 \\
\hline \multirow{3}{*}{ Full Equity } & ALL & 0.3358 & 0.2699 & 18.8865 & 17.1727 & 17.3255 & 22.4917 & -0.8200 & 1.4100 & -1.8800 & -15.4869 & 0.0821 & -42.2844 \\
\hline & $B C$ & 0.1603 & 0.6722 & 17.3335 & 15.5097 & 19.9368 & 20.1259 & -1.7300 & 0.1300 & -0.6700 & -29.9870 & 0.0084 & -13.4844 \\
\hline & DC & 0.7570 & -0.7106 & 22.1670 & 20.4395 & 14.9784 & 27.3226 & 1.5400 & 5.5200 & -4.2800 & 0.0695 & 0.2701 & -116.9407 \\
\hline \multirow{3}{*}{$\begin{array}{c}\text { Bond + Equity } \\
\text { ( } 0.33 \text { each country) }\end{array}$} & ALL & 0.2997 & 0.2837 & 9.6605 & 8.2523 & 27.0292 & 10.9121 & -0.1000 & 0.5800 & -0.7000 & -0.9661 & 0.0703 & -7.6385 \\
\hline & BC & 0.2322 & 0.4254 & 9.4167 & 7.7427 & 32.3936 & 9.6825 & -1.4900 & -0.9200 & -0.6000 & -14.0309 & -7.1233 & -5.8095 \\
\hline & DC & 0.4628 & -0.0653 & 10.2213 & 9.2763 & 17.6358 & 13.4052 & 3.2800 & 4.7100 & -0.8500 & 0.3209 & 0.5077 & -11.3944 \\
\hline \multirow{3}{*}{$\begin{array}{l}\text { Bond + Equity } \\
\text { (0.60 EMU) }\end{array}$} & ALL & 0.2000 & 0.1454 & 9.5825 & 8.8318 & 15.0558 & 10.9121 & -0.3500 & 0.3500 & -0.7000 & -3.3539 & 0.0396 & -7.6385 \\
\hline & BC & 0.1206 & 0.3175 & 9.0554 & 8.2356 & 17.2866 & 9.6825 & -2.8099 & -0.7200 & -0.6000 & -25.4450 & -5.9296 & -5.8095 \\
\hline & DC & 0.3918 & -0.2767 & 10.7424 & 10.0374 & 12.6950 & 13.4052 & 4.1068 & 3.5400 & -0.8500 & 0.3823 & 0.3527 & -11.3944 \\
\hline
\end{tabular}

Notes: Full bond portfolio (Full Bond), Full equity Portfolio (Full Equity), Bond and equity portfolio (equally 33\% country weight, 50\% bonds, 50\% equities), home biased Bond and equity portfolio, (60\% EMU, 20\% the UK and 20\% the US), for the EMU portfolio the investor is only holding domestic equities and/or bonds based on the kind of international portfolio we are comparing with (full bond, full equity or equities + bonds); whole period (ALL), Before Crisis (BC), During Crisis (DC); Euro units of British Pound future sold $\left(\boldsymbol{\beta}_{1}\right)$, Euro units of US dollar future sold $\left(\boldsymbol{\beta}_{2}\right)$ per Euro invested in an international portfolio; annualized unhedged portfolio standard deviation $\left(\boldsymbol{\sigma}_{\mathrm{UH}}\right)$, annualized hedged portfolio standard deviation $\left(\boldsymbol{\sigma}_{\mathbf{H}}\right)$, Hedging Effectiveness $(\mathbf{H E})$, annualized European portfolio standard deviation $\left(\boldsymbol{\sigma}_{\mathbf{E}} \mathbf{m}\right)$, annualized unhedged portfolio Return ( $\mathbf{R}_{\mathbf{U H}}$ ), annualized hedged portfolio Return $\left(\mathbf{R}_{\mathbf{H}}\right)$, annualized European portfolio return ( $\mathbf{R}_{\mathbf{E M U}}$ ), modified Sharpe Ratio (SHR) of Israelsen (2005) (when average returns are negative those are multiplied by the standard deviation rather than divided). 
Table A.7. DCC MODEL - All maturities - In-sample

\begin{tabular}{|c|c|c|c|c|c|c|c|c|c|c|c|c|c|}
\hline & & $\beta_{1}$ & $\boldsymbol{\beta}_{2}$ & $\sigma_{\mathrm{UH}}$ & $\sigma_{H}$ & HE & $\boldsymbol{\sigma}_{\mathrm{EMU}}$ & $\mathbf{R}_{\mathrm{UH}}$ & $\mathbf{R}_{\mathbf{H}}$ & $\mathbf{R}_{\mathrm{EMU}}$ & SHR $_{U H}$ & $\mathrm{SHR}_{\mathrm{H}}$ & $\mathrm{SHR}_{\mathrm{EMU}}$ \\
\hline \multirow{3}{*}{ Full Bond } & ALL & 0.2766 & 0.3021 & 6.4343 & 4.2456 & 56.4614 & 3.5602 & -0.1748 & -0.2996 & -0.1998 & -1.1250 & -1.2718 & -0.7113 \\
\hline & $B C$ & 0.2845 & 0.2500 & 5.5678 & 3.9718 & 49.1129 & 3.2519 & -1.5100 & -1.3400 & -0.8200 & -8.4074 & -5.3222 & -2.6666 \\
\hline & DC & 0.2667 & 0.4344 & 8.1317 & 4.8322 & 64.6881 & 4.2042 & 2.9700 & 2.3500 & 1.2300 & 0.3652 & 0.4863 & 0.2926 \\
\hline \multirow{3}{*}{ Full Equity } & ALL & 0.3532 & 0.2700 & 18.8865 & 17.1894 & 17.1643 & 22.4917 & -0.8200 & 0.8000 & -1.8800 & -15.4869 & 0.0465 & -42.2844 \\
\hline & $B C$ & 0.2143 & 0.6481 & 17.3335 & 15.3777 & 21.2931 & 20.1259 & -1.7300 & -0.7000 & -0.6700 & -29.9870 & -10.7644 & -13.4844 \\
\hline & DC & 0.7105 & -0.6468 & 22.1670 & 20.3525 & 15.7008 & 27.3226 & 1.5400 & 5.6500 & -4.2800 & 0.0695 & 0.2776 & -116.9407 \\
\hline \multirow{3}{*}{$\begin{array}{c}\text { Bond }+ \text { Equity } \\
\text { ( } 0.33 \text { each country) }\end{array}$} & ALL & 0.3227 & 0.2782 & 9.8043 & 8.2810 & 28.6606 & 10.9247 & -0.5000 & -0.0200 & -1.0400 & -4.9022 & -0.1656 & -11.3617 \\
\hline & BC & 0.2528 & 0.4486 & 9.4789 & 7.5482 & 36.5888 & 9.6566 & -1.6400 & -1.0700 & -0.7500 & -15.5454 & -8.0766 & -7.2425 \\
\hline & DC & 0.4902 & -0.1135 & 10.5451 & 9.5145 & 18.5926 & 13.4805 & 2.2500 & 3.3300 & -1.5600 & 0.2134 & 0.3500 & -21.0296 \\
\hline \multirow{3}{*}{$\begin{array}{l}\text { Bond +Equity } \\
\text { (0.60 EMU) }\end{array}$} & ALL & 0.2186 & 0.1486 & 9.7404 & 8.8628 & 17.2069 & 10.9247 & -0.7200 & -0.0500 & -1.0400 & -7.0131 & -0.4431 & -11.3617 \\
\hline & BC & 0.1488 & 0.3324 & 9.1077 & 8.0685 & 21.5190 & 9.6566 & -3.1738 & -0.9700 & -0.7500 & -28.9056 & -7.8264 & -7.2425 \\
\hline & $\mathrm{DC}$ & 0.4000 & -0.3004 & 11.1142 & 10.1661 & 16.3327 & 13.4805 & 0.7276 & 2.9700 & -1.5600 & 0.0655 & 0.2921 & -21.0296 \\
\hline
\end{tabular}

Notes: Full bond portfolio (Full Bond), Full equity Portfolio (Full Equity), Bond and equity portfolio (equally 33\% country weight, 50\% bonds, 50\% equities), home biased Bond and equity portfolio, (60\% EMU, 20\% the UK and 20\% the US), for the EMU portfolio the investor is only holding domestic equities and/or bonds based on the kind of international portfolio we are comparing with (full bond, full equity or equities + bonds); whole period (ALL), Before Crisis (BC), During Crisis (DC); Euro units of British Pound future sold $\left(\boldsymbol{\beta}_{1}\right)$, Euro units of US dollar future sold $\left(\boldsymbol{\beta}_{2}\right)$ per Euro invested in an international portfolio; annualized unhedged portfolio standard deviation ( $\left.\boldsymbol{\sigma}_{U H}\right)$, annualized hedged portfolio standard deviation $\left(\boldsymbol{\sigma}_{\mathrm{H}}\right)$, Hedging Effectiveness $(\mathbf{H E})$, annualized European portfolio standard deviation $\left(\boldsymbol{\sigma}_{\mathrm{EMU}}\right)$, annualized unhedged portfolio Return ( $\left.\mathbf{R}_{\mathbf{U H}}\right)$, annualized hedged portfolio Return $\left(\mathbf{R}_{\mathbf{H}}\right)$, annualized European portfolio return ( $\mathbf{R}_{\mathrm{EMU}}$ ), modified Sharpe Ratio (SHR) of Israelsen (2005) (when average returns are negative those are multiplied by the standard deviation rather than divided). 
Table A.8. DCC PARAMETERS- all- year maturity- In-sample

\begin{tabular}{|c|c|c|c|c|c|c|c|c|c|c|c|c|}
\hline & & $\omega_{1}$ & $\boldsymbol{\alpha}_{1}$ & $\boldsymbol{\beta}_{1}$ & $\omega_{2}$ & $\boldsymbol{\alpha}_{2}$ & $\boldsymbol{\beta}_{2}$ & $\omega_{3}$ & $\boldsymbol{\alpha}_{3}$ & $\boldsymbol{\beta}_{3}$ & $\theta_{1}$ & $\theta_{2}$ \\
\hline \multirow{3}{*}{ Full Bond } & ALL & 0.0007 & 0.0405 & 0.9561 & 0.0013 & 0.0418 & 0.9538 & 0.0013 & 0.0273 & 0.9699 & 0.0117 & 0.9861 \\
\hline & BC & 0.0008 & 0.0411 & 0.9538 & 0.0013 & 0.0397 & 0.955 & 0.0007 & 0.022 & 0.9766 & 0.0109 & 0.9857 \\
\hline & DC & 0.0055 & 0.061 & 0.9184 & 0.0022 & 0.056 & 0.9386 & 0.0056 & 0.043 & 0.9462 & 0.0123 & 0.9848 \\
\hline \multirow{3}{*}{ Full Equity } & ALL & 0.0157 & 0.0885 & 0.9001 & 0.0013 & 0.0418 & 0.9538 & 0.0013 & 0.0273 & 0.9699 & 0.0185 & 0.9787 \\
\hline & BC & 0.0133 & 0.0809 & 0.9089 & 0.0013 & 0.0397 & 0.955 & 0.0007 & 0.022 & 0.9766 & 0.0178 & 0.9737 \\
\hline & DC & 0.0215 & 0.0925 & 0.8914 & 0.0022 & 0.056 & 0.9386 & 0.0056 & 0.043 & 0.9462 & 0.0145 & 0.9825 \\
\hline \multirow{3}{*}{$\begin{array}{c}\text { Bond }+ \text { Equity } \\
\text { ( } 0.33 \text { each country) }\end{array}$} & ALL & 0.0054 & 0.0884 & 0.8977 & 0.0013 & 0.0418 & 0.9538 & 0.0013 & 0.0273 & 0.9699 & 0.021 & 0.9736 \\
\hline & BC & 0.0043 & 0.0747 & 0.9147 & 0.0013 & 0.0397 & 0.955 & 0.0007 & 0.022 & 0.9766 & 0.017 & 0.9741 \\
\hline & $D C$ & 0.0098 & 0.1492 & 0.8269 & 0.0022 & 0.056 & 0.9386 & 0.0056 & 0.043 & 0.9462 & 0.0188 & 0.9745 \\
\hline \multirow{3}{*}{$\begin{array}{l}\text { Bond + Equity } \\
\text { (0.60 EMU) }\end{array}$} & ALL & 0.0051 & 0.0958 & 0.8911 & 0.0013 & 0.0418 & 0.9538 & 0.0013 & 0.0273 & 0.9699 & 0.0166 & 0.9806 \\
\hline & BC & 0.0045 & 0.0889 & 0.899 & 0.0013 & 0.0397 & 0.955 & 0.0007 & 0.022 & 0.9766 & 0.0147 & 0.9782 \\
\hline & DC & 0.0082 & 0.123 & 0.8592 & 0.0022 & 0.056 & 0.9386 & 0.0056 & 0.043 & 0.9462 & 0.0131 & 0.9846 \\
\hline
\end{tabular}

Notes: Full bond portfolio (Full Bond), Full equity Portfolio (Full Equity), Bond and equity portfolio (equally 33\% country weight, 50\% bonds, 50\% equities), home biased Bond and equity portfolio, (60\% EMU, 20\% the UK and 20\% the US), whole period (ALL), Before Crisis (BC), During Crisis (DC). Vector of returns $r_{t}=r_{t}^{\text {UH }}, r_{t}^{\text {Fut }}$ GBP,$r_{t}^{\text {Fut_USD }} .1-3$ year maturity bonds. 
Table A.9. DCC MODEL - 1-3-year maturity- In-sample

\begin{tabular}{|c|c|c|c|c|c|c|c|c|c|c|c|c|c|}
\hline & & $\beta_{1}$ & $\boldsymbol{\beta}_{2}$ & $\boldsymbol{\sigma}_{\mathrm{UH}}$ & $\sigma_{H}$ & HE & $\boldsymbol{\sigma}_{\mathrm{EMU}}$ & $\mathbf{R}_{\mathrm{UH}}$ & $\mathbf{R}_{\mathbf{H}}$ & $\mathbf{R}_{\mathrm{EMU}}$ & $\mathrm{SHR}_{\mathrm{UH}}$ & $\mathrm{SHR}_{\mathrm{H}}$ & $\mathrm{SHR}_{\mathrm{EMU}}$ \\
\hline \multirow{3}{*}{ Full Bond } & ALL & 0.2895 & 0.3227 & 5.5272 & 2.4495 & 80.3601 & 1.5492 & -1.3656 & -1.0445 & -1.2423 & -7.5481 & -2.5586 & -1.9245 \\
\hline & $B C$ & 0.2767 & 0.3192 & 5.0349 & 2.3927 & 77.4162 & 1.4230 & -1.9800 & -1.2700 & -1.4900 & -9.9691 & -3.0387 & -2.1203 \\
\hline & DC & 0.3242 & 0.3368 & 6.5555 & 2.6173 & 84.0605 & 1.8028 & 0.0800 & -0.4700 & -0.6200 & 0.0122 & -1.2301 & -1.1177 \\
\hline \multirow{3}{*}{ Full Equity } & ALL & 0.3532 & 0.2700 & 18.8865 & 17.1894 & 17.1643 & 22.4917 & -0.8200 & 0.8000 & -1.8800 & -15.4869 & 0.0465 & -42.2844 \\
\hline & BC & 0.2143 & 0.6481 & 17.3335 & 15.3777 & 21.2931 & 20.1259 & -1.7300 & -0.7000 & -0.6700 & -29.9870 & -10.7644 & -13.4844 \\
\hline & DC & 0.7105 & -0.6468 & 22.1670 & 20.3525 & 15.7008 & 27.3226 & 1.5400 & 5.6500 & -4.2800 & 0.0695 & 0.2776 & -116.9407 \\
\hline \multirow{3}{*}{$\begin{array}{c}\text { Bond }+ \text { Equity } \\
(0.33 \text { each country) }\end{array}$} & ALL & 0.3261 & 0.2901 & 10.2140 & 8.5542 & 29.8586 & 11.1524 & -1.0900 & -0.2500 & -1.5600 & -11.1333 & -2.1386 & -17.3977 \\
\hline & $B C$ & 0.2471 & 0.4849 & 9.8005 & 7.7088 & 38.1312 & 9.8944 & -1.8600 & -0.9500 & -1.0700 & -18.2289 & -7.3234 & -10.5870 \\
\hline & DC & 0.5212 & -0.1640 & 11.1490 & 10.0374 & 18.9461 & 13.6958 & 0.8000 & 2.2000 & -2.4700 & 0.0718 & 0.2192 & -33.8286 \\
\hline \multirow{3}{*}{$\begin{array}{l}\text { Bond +Equity } \\
\text { (0.60 EMU) }\end{array}$} & ALL & 0.2202 & 0.1623 & 10.1193 & 9.1159 & 18.8477 & 11.1524 & -1.2900 & -0.3500 & -1.5600 & -13.0539 & -3.1906 & -17.3977 \\
\hline & $\mathrm{BC}$ & 0.1424 & 0.3658 & 9.4101 & 8.2508 & 23.1225 & 9.8944 & -3.8252 & -0.9500 & -1.0700 & -35.9957 & -7.8383 & -10.5870 \\
\hline & DC & 0.4242 & -0.3357 & 11.6458 & 10.5948 & 17.2350 & 13.6958 & -1.2916 & 1.8900 & -2.4700 & -15.0419 & 0.1784 & -33.8286 \\
\hline
\end{tabular}

Notes: Full bond portfolio (Full Bond), Full equity Portfolio (Full Equity), Bond and equity portfolio (equally 33\% country weight, 50\% bonds, 50\% equities), home biased Bond and equity portfolio, (60\% EMU, 20\% the UK and 20\% the US), for the EMU portfolio the investor is only holding domestic equities and/or bonds based on the kind of international portfolio we are comparing with (full bond, full equity or equities + bonds); whole period (ALL), Before Crisis (BC), During Crisis (DC); Euro units of British Pound future sold $\left(\boldsymbol{\beta}_{1}\right)$, Euro units of US dollar future sold $\left(\boldsymbol{\beta}_{2}\right)$ per Euro invested in an international portfolio; annualized unhedged portfolio standard deviation $\left(\boldsymbol{\sigma}_{\mathrm{UH}}\right)$, annualized hedged portfolio standard deviation $\left(\boldsymbol{\sigma}_{\mathbf{H}}\right)$, Hedging Effectiveness $(\mathbf{H E})$, annualized European portfolio standard deviation $\left(\boldsymbol{\sigma}_{\mathrm{EMU}}\right)$, annualized unhedged portfolio Return ( $\mathbf{R}_{\mathbf{U H}}$ ), annualized hedged portfolio Return $\left(\mathbf{R}_{\mathbf{H}}\right)$, annualized European portfolio return ( $\mathbf{R}_{\mathbf{E M U}}$ ), modified Sharpe Ratio (SHR) of Israelsen (2005) (when average returns are negative those are multiplied by the standard deviation rather than divided). 
Table A.10. DCC PARAMETERS- 1-3 year maturity- In-sample

\begin{tabular}{|c|c|c|c|c|c|c|c|c|c|c|c|c|}
\hline & & $\omega_{1}$ & $\alpha_{1}$ & $\beta_{1}$ & $\omega_{2}$ & $\boldsymbol{\alpha}_{2}$ & $\boldsymbol{\beta}_{2}$ & $\omega_{3}$ & $\boldsymbol{\alpha}_{3}$ & $\boldsymbol{\beta}_{3}$ & $\theta_{1}$ & $\theta_{2}$ \\
\hline \multirow{3}{*}{ Full Bond } & ALL & 0.0005 & 0.0389 & 0.958 & 0.0013 & 0.0418 & 0.9538 & 0.0013 & 0.0273 & 0.9699 & 0.0157 & 0.978 \\
\hline & BC & 0.0006 & 0.0406 & 0.9553 & 0.0013 & 0.0397 & 0.955 & 0.0007 & 0.022 & 0.9766 & 0.0094 & 0.9858 \\
\hline & DC & 0.0027 & 0.0616 & 0.9242 & 0.0022 & 0.056 & 0.9386 & 0.0056 & 0.043 & 0.9462 & 0.0305 & 0.9543 \\
\hline \multirow{3}{*}{ Full Equity } & ALL & 0.0157 & 0.0885 & 0.9001 & 0.0013 & 0.0418 & 0.9538 & 0.0013 & 0.0273 & 0.9699 & 0.0185 & 0.9787 \\
\hline & BC & 0.0133 & 0.0809 & 0.9089 & 0.0013 & 0.0397 & 0.955 & 0.0007 & 0.022 & 0.9766 & 0.0178 & 0.9737 \\
\hline & DC & 0.0215 & 0.0925 & 0.8914 & 0.0022 & 0.056 & 0.9386 & 0.0056 & 0.043 & 0.9462 & 0.0145 & 0.9825 \\
\hline \multirow{3}{*}{$\begin{array}{c}\text { Bond +Equity } \\
\text { ( } 0.33 \text { each country) }\end{array}$} & ALL & 0.0052 & 0.083 & 0.9047 & 0.0013 & 0.0418 & 0.9538 & 0.0013 & 0.0273 & 0.9699 & 0.0224 & 0.973 \\
\hline & BC & 0.0041 & 0.071 & 0.9194 & 0.0013 & 0.0397 & 0.955 & 0.0007 & 0.022 & 0.9766 & 0.019 & 0.9714 \\
\hline & DC & 0.0095 & 0.1349 & 0.8449 & 0.0022 & 0.056 & 0.9386 & 0.0056 & 0.043 & 0.9462 & 0.021 & 0.9718 \\
\hline \multirow{3}{*}{$\begin{array}{l}\text { Bond +Equity } \\
\text { (0.60 EMU) }\end{array}$} & ALL & 0.0049 & 0.0894 & 0.8987 & 0.0013 & 0.0418 & 0.9538 & 0.0013 & 0.0273 & 0.9699 & 0.0177 & 0.9796 \\
\hline & $\mathrm{BC}$ & 0.0044 & 0.0836 & 0.905 & 0.0013 & 0.0397 & 0.955 & 0.0007 & 0.022 & 0.9766 & 0.0162 & 0.9761 \\
\hline & DC & 0.0079 & 0.1134 & 0.8712 & 0.0022 & 0.056 & 0.9386 & 0.0056 & 0.043 & 0.9462 & 0.0142 & 0.9831 \\
\hline
\end{tabular}

Notes: Full bond portfolio (Full Bond), Full equity Portfolio (Full Equity), Bond and equity portfolio (equally 33\% country weight, 50\% bonds, 50\% equities), home biased Bond and equity portfolio, (60\% EMU, 20\% the UK and 20\% the US), whole period (ALL), Before Crisis (BC), During Crisis (DC). Vector of returns $r_{t}=r_{t}^{U H}, r_{t}^{\text {Fut_GBP }}, r_{t}^{\text {Fut_USD }} .1$-3 year maturity bonds. 
Table A.11. DCC MODEL- +10-Year maturity- In-sample

\begin{tabular}{|c|c|c|c|c|c|c|c|c|c|c|c|c|c|}
\hline & & $\beta_{1}$ & $\beta_{2}$ & $\sigma_{\mathrm{UH}}$ & $\sigma_{\mathrm{H}}$ & HE & $\boldsymbol{\sigma}_{\mathrm{EMU}}$ & $\mathbf{R}_{\mathrm{UH}}$ & $\mathbf{R}_{\mathbf{H}}$ & $\mathbf{R}_{\mathrm{EMU}}$ & SHR $_{U H}$ & $\mathrm{SHR}_{\mathrm{H}}$ & $\mathbf{S H R}_{\mathrm{EMU}}$ \\
\hline \multirow{3}{*}{ Full Bond } & ALL & 0.2671 & 0.2925 & 8.8671 & 7.2560 & 33.0366 & 7.0018 & 0.6269 & 0.0000 & 0.5012 & 0.0707 & 0.0000 & 0.0716 \\
\hline & BC & 0.3020 & 0.1796 & 7.3739 & 6.4827 & 22.7126 & 6.5479 & -1.2700 & -1.5400 & -0.5000 & -9.3649 & -9.9834 & -3.2740 \\
\hline & DC & 0.1920 & 0.5711 & 11.6705 & 8.8105 & 43.0066 & 7.9703 & 5.0200 & 4.1300 & 2.7100 & 0.4301 & 0.4688 & 0.3400 \\
\hline \multirow{3}{*}{ Full Equity } & ALL & 0.3532 & 0.2700 & 18.8865 & 17.1894 & 17.1643 & 22.4917 & -0.8200 & 0.8000 & -1.8800 & -15.4869 & 0.0465 & -42.2844 \\
\hline & BC & 0.2143 & 0.6481 & 17.3335 & 15.3777 & 21.2931 & 20.1259 & -1.7300 & -0.7000 & -0.6700 & -29.9870 & -10.7644 & -13.4844 \\
\hline & DC & 0.7105 & -0.6468 & 22.1670 & 20.3525 & 15.7008 & 27.3226 & 1.5400 & 5.6500 & -4.2800 & 0.0695 & 0.2776 & -116.9407 \\
\hline \multirow{3}{*}{$\begin{array}{c}\text { Bond }+ \text { Equity } \\
(0.33 \text { each country })\end{array}$} & ALL & 0.3214 & 0.2733 & 9.6605 & 8.2976 & 26.2256 & 10.9121 & -0.1000 & 0.0500 & -0.7000 & -0.9661 & 0.0060 & -7.6385 \\
\hline & BC & 0.2644 & 0.4120 & 9.4167 & 7.6795 & 33.4931 & 9.6825 & -1.4900 & -1.2900 & -0.6000 & -14.0309 & -9.9066 & -5.8095 \\
\hline & DC & 0.4508 & -0.0373 & 10.2213 & 9.2992 & 17.2290 & 13.4052 & 3.2800 & 3.9000 & -0.8500 & 0.3209 & 0.4194 & -11.3944 \\
\hline \multirow{3}{*}{$\begin{array}{l}\text { Bond +Equity } \\
\text { (0.60 EMU) }\end{array}$} & ALL & 0.2195 & 0.1383 & 9.5825 & 8.8685 & 14.3479 & 10.9121 & -0.3500 & -0.0200 & -0.7000 & -3.3539 & -0.1774 & -7.6385 \\
\hline & $B C$ & 0.1610 & 0.2964 & 9.0554 & 8.1609 & 18.7805 & 9.6825 & -2.8099 & -1.0900 & -0.6000 & -25.4450 & -8.8954 & -5.8095 \\
\hline & $\mathrm{DC}$ & 0.3678 & -0.2439 & 10.7424 & 9.9649 & 13.9515 & 13.4052 & 4.1068 & 3.3500 & -0.8500 & 0.3823 & 0.3362 & -11.3944 \\
\hline
\end{tabular}

Notes: Full bond portfolio (Full Bond), Full equity Portfolio (Full Equity), Bond and equity portfolio (equally 33\% country weight, 50\% bonds, 50\% equities), home biased Bond and equity portfolio, (60\% EMU, 20\% the UK and 20\% the US), for the EMU portfolio the investor is only holding domestic equities and/or bonds based on the kind of international portfolio we are comparing with (full bond, full equity or equities + bonds); whole period (ALL), Before Crisis (BC), During Crisis (DC); Euro units of British Pound future sold $\left(\boldsymbol{\beta}_{1}\right)$, Euro units of US dollar future sold $\left(\boldsymbol{\beta}_{2}\right)$ per Euro invested in an international portfolio; annualized unhedged portfolio standard deviation $\left(\boldsymbol{\sigma}_{\mathrm{UH}}\right)$, annualized hedged portfolio standard deviation $\left(\boldsymbol{\sigma}_{\mathbf{H}}\right)$, Hedging Effectiveness $(\mathbf{H E})$, annualized European portfolio standard deviation $\left(\boldsymbol{\sigma}_{\mathrm{EMU}}\right)$, annualized unhedged portfolio Return ( $\mathbf{R}_{\mathbf{U H}}$ ), annualized hedged portfolio Return ( $\left.\mathbf{R}_{\mathbf{H}}\right)$, annualized European portfolio return ( $\mathbf{R}_{\mathbf{E M U}}$ ), modified Sharpe Ratio (SHR) of Israelsen (2005) (when average returns are negative those are multiplied by the standard deviation rather than divided). 
Table A.12. DCC PARAMETERS- +10 - year maturity- In-sample

\begin{tabular}{|c|c|c|c|c|c|c|c|c|c|c|c|c|}
\hline & & $\omega_{1}$ & $\boldsymbol{\alpha}_{1}$ & $\beta_{1}$ & $\omega_{2}$ & $\boldsymbol{\alpha}_{2}$ & $\boldsymbol{\beta}_{2}$ & $\omega_{3}$ & $\boldsymbol{\alpha}_{3}$ & $\boldsymbol{\beta}_{3}$ & $\theta_{1}$ & $\boldsymbol{\theta}_{2}$ \\
\hline \multirow{3}{*}{ Full Bond } & ALL & 0.0021 & 0.0438 & 0.9499 & 0.0013 & 0.0418 & 0.9538 & 0.0013 & 0.0273 & 0.9699 & 0.0119 & 0.9857 \\
\hline & BC & 0.0029 & 0.0388 & 0.9486 & 0.0013 & 0.0397 & 0.955 & 0.0007 & 0.022 & 0.9766 & 0.0111 & 0.9852 \\
\hline & DC & 0.0123 & 0.0638 & 0.9131 & 0.0022 & 0.056 & 0.9386 & 0.0056 & 0.043 & 0.9462 & 0.0142 & 0.9817 \\
\hline \multirow{3}{*}{ Full Equity } & ALL & 0.0157 & 0.0885 & 0.9001 & 0.0013 & 0.0418 & 0.9538 & 0.0013 & 0.0273 & 0.9699 & 0.0185 & 0.9787 \\
\hline & BC & 0.0133 & 0.0809 & 0.9089 & 0.0013 & 0.0397 & 0.955 & 0.0007 & 0.022 & 0.9766 & 0.0178 & 0.9737 \\
\hline & DC & 0.0215 & 0.0925 & 0.8914 & 0.0022 & 0.056 & 0.9386 & 0.0056 & 0.043 & 0.9462 & 0.0145 & 0.9825 \\
\hline \multirow{3}{*}{$\begin{array}{c}\text { Bond + Equity } \\
(0.33 \text { each country })\end{array}$} & ALL & 0.0055 & 0.0862 & 0.8992 & 0.0013 & 0.0418 & 0.9538 & 0.0013 & 0.0273 & 0.9699 & 0.0184 & 0.9754 \\
\hline & BC & 0.0048 & 0.0798 & 0.9085 & 0.0013 & 0.0397 & 0.955 & 0.0007 & 0.022 & 0.9766 & 0.0144 & 0.978 \\
\hline & DC & 0.0101 & 0.1294 & 0.8413 & 0.0022 & 0.056 & 0.9386 & 0.0056 & 0.043 & 0.9462 & 0.0127 & 0.9836 \\
\hline \multirow{3}{*}{$\begin{array}{l}\text { Bond +Equity } \\
\text { (0.60 EMU) }\end{array}$} & ALL & 0.0058 & 0.1012 & 0.8837 & 0.0013 & 0.0418 & 0.9538 & 0.0013 & 0.0273 & 0.9699 & 0.0144 & 0.9826 \\
\hline & BC & 0.0052 & 0.0942 & 0.8924 & 0.0013 & 0.0397 & 0.955 & 0.0007 & 0.022 & 0.9766 & 0.0121 & 0.9823 \\
\hline & DC & 0.0088 & 0.1301 & 0.8486 & 0.0022 & 0.056 & 0.9386 & 0.0056 & 0.043 & 0.9462 & 0.0111 & 0.987 \\
\hline
\end{tabular}

Notes: Full bond portfolio (Full Bond), Full equity Portfolio (Full Equity), Bond and equity portfolio (equally 33\% country weight, 50\% bonds, 50\% equities), home biased Bond and equity portfolio, (60\% EMU, 20\% the UK and 20\% the US), whole period (ALL), Before Crisis (BC), During Crisis (DC). Vector of returns $r_{t}=r_{t}^{U H}, r_{t}^{\text {Fut } G B P}, r_{t}^{\text {Fut_USD }} .1$-3 year maturity bonds. 
Table A.13. BEKK MODEL - All maturities - In-sample

\begin{tabular}{|c|c|c|c|c|c|c|c|c|c|c|c|c|c|}
\hline & & $\beta_{1}$ & $\beta_{2}$ & $\sigma_{\mathrm{UH}}$ & $\sigma_{\mathrm{H}}$ & HE & $\sigma_{\mathrm{EMU}}$ & $\mathbf{R}_{\mathrm{UH}}$ & $\mathbf{R}_{\mathbf{H}}$ & $\mathbf{R}_{\mathrm{EMU}}$ & SHR $_{U H}$ & $\mathrm{SHR}_{\mathrm{H}}$ & $\mathrm{SHR}_{\mathrm{EMU}}$ \\
\hline \multirow{3}{*}{ Full Bond } & ALL & 0.2781 & 0.3009 & 6.4343 & 4.2544 & 56.2802 & 3.5602 & -0.1748 & -0.3494 & -0.1998 & -1.1250 & -1.4865 & -0.7113 \\
\hline & BC & 0.2871 & 0.2474 & 5.5678 & 3.9686 & 49.1935 & 3.2519 & -1.5135 & -1.2916 & -0.8216 & -8.4267 & -5.1260 & -2.6718 \\
\hline & DC & 0.2546 & 0.4329 & 8.1317 & 4.8451 & 64.4991 & 4.2042 & 2.9680 & 2.0201 & 1.2325 & 0.3650 & 0.4169 & 0.2932 \\
\hline \multirow{3}{*}{ Full Equity } & ALL & 0.5444 & 0.0579 & 18.8865 & 18.2722 & 6.3989 & 22.4917 & -0.8216 & -0.3743 & -1.8821 & -15.5175 & -6.8393 & -42.3323 \\
\hline & BC & 0.1862 & 0.6373 & 17.3335 & 15.4669 & 20.3778 & 20.1259 & -1.7348 & 0.3757 & -0.6727 & -30.0708 & 0.0243 & -13.5394 \\
\hline & DC & 0.7259 & -0.6783 & 22.1670 & 20.6458 & 13.2536 & 27.3226 & 1.5366 & 4.4978 & -4.2810 & 0.0693 & 0.2179 & -116.9693 \\
\hline \multirow{3}{*}{$\begin{array}{c}\text { Bond }+ \text { Equity } \\
\text { ( } 0.33 \text { each country) }\end{array}$} & ALL & 0.3145 & 0.2755 & 9.8043 & 8.2614 & 28.9987 & 10.9247 & -0.4988 & 0.5766 & -1.0445 & -4.8900 & 0.0698 & -11.4112 \\
\hline & BC & 0.2431 & 0.4384 & 9.4789 & 7.5878 & 35.9210 & 9.6566 & -1.6365 & -0.3992 & -0.7472 & -15.5124 & -3.0291 & -7.2155 \\
\hline & DC & 0.4889 & -0.1158 & 10.5451 & 9.6086 & 16.9739 & 13.4805 & 2.2498 & 2.9680 & -1.5627 & 0.2134 & 0.3089 & -21.0662 \\
\hline \multirow{3}{*}{$\begin{array}{l}\text { Bond + Equity } \\
\text { (0.60 EMU) }\end{array}$} & ALL & 0.2089 & 0.1461 & 9.7404 & 8.8600 & 17.2596 & 10.9247 & -0.7224 & 0.3004 & -1.0445 & -7.0363 & 0.0339 & -11.4112 \\
\hline & BC & 0.1341 & 0.3262 & 9.1077 & 8.1179 & 20.5546 & 9.6566 & -1.2916 & -0.3743 & -0.7472 & -11.7637 & -3.0385 & -7.2155 \\
\hline & DC & 0.3992 & -0.3112 & 11.1142 & 10.3102 & 13.9445 & 13.4805 & 0.7276 & 2.2498 & -1.5627 & 0.0655 & 0.2182 & -21.0662 \\
\hline
\end{tabular}

Notes: Full bond portfolio (Full Bond), Full equity Portfolio (Full Equity), Bond and equity portfolio (equally 33\% country weight, 50\% bonds, 50\% equities), home biased Bond and equity portfolio, (60\% EMU, 20\% the UK and 20\% the US), for the EMU portfolio the investor is only holding domestic equities and/or bonds based on the kind of international portfolio we are comparing with (full bond, full equity or equities + bonds); whole period (ALL), Before Crisis (BC), During Crisis (DC); Euro units of British Pound future sold $\left(\boldsymbol{\beta}_{1}\right)$, Euro units of US dollar future sold $\left(\boldsymbol{\beta}_{2}\right)$ per Euro invested in an international portfolio; annualized unhedged portfolio standard deviation $\left(\boldsymbol{\sigma}_{\mathrm{UH}}\right)$, annualized hedged portfolio standard deviation $\left(\boldsymbol{\sigma}_{\mathrm{H}}\right)$, Hedging Effectiveness $(\mathbf{H E})$, annualized European portfolio standard deviation $\left(\boldsymbol{\sigma}_{\mathrm{EMU}}\right)$, annualized unhedged portfolio Return ( $\mathbf{R}_{\mathbf{U H}}$ ), annualized hedged portfolio Return $\left(\mathbf{R}_{\mathbf{H}}\right)$, annualized European portfolio return ( $\mathbf{R}_{\mathrm{EMU}}$ ), modified Sharpe Ratio (SHR) of Israelsen (2005) (when average returns are negative those are multiplied by the standard deviation rather than divided). 
Table A.14. BEKK PARAMETERS - All maturities- In-sample

\begin{tabular}{|c|c|c|c|c|c|c|c|c|c|c|c|c|c|}
\hline & & $\mathrm{C}_{11}$ & $\mathrm{C}_{12}$ & $\mathrm{C}_{13}$ & $\mathrm{C}_{22}$ & $\mathbf{C}_{23}$ & $\mathrm{C}_{33}$ & $\mathbf{A}_{11}$ & $\mathbf{A}_{22}$ & $\mathbf{A}_{33}$ & $\mathbf{B}_{11}$ & $\mathbf{B}_{22}$ & $\mathbf{B}_{33}$ \\
\hline \multirow[b]{2}{*}{ Full Bond } & ALL & 0.0291 & 0.0192 & 0.0248 & 0.0288 & 0.0062 & -0.0271 & 0.1702 & 0.1715 & 0.1445 & 0.9827 & 0.9826 & 0.9877 \\
\hline & BC & 0.0293 & 0.0187 & 0.0222 & 0.0286 & 0.0052 & -0.0216 & 0.1613 & 0.1622 & 0.1253 & 0.9834 & 0.9838 & 0.9906 \\
\hline Full Equity & ALL & 0.1029 & 0.0122 & 0.0167 & 0.0327 & 0.0126 & 0.0298 & 0.2629 & 0.1699 & 0.1674 & 0.9609 & 0.983 & 0.9843 \\
\hline \multirow{3}{*}{$\begin{array}{c}\text { Bond }+ \text { Equity } \\
(0.33 \text { each country) }\end{array}$} & ALL & 0.0617 & 0.0215 & 0.0285 & 0.0318 & 0.005 & -0.0272 & 0.2534 & 0.1757 & 0.1634 & 0.9621 & 0.9814 & 0.9846 \\
\hline & $B C$ & 0.0629 & 0.0188 & 0.0336 & 0.0315 & 0.0017 & -0.0263 & 0.2369 & 0.1586 & 0.1454 & 0.9654 & 0.9839 & 0.9866 \\
\hline & DC & 0.0838 & 0.0341 & 0.0216 & 0.015 & 0.0465 & -0.0234 & 0.312 & 0.1709 & 0.1469 & 0.9395 & 0.9829 & 0.9858 \\
\hline
\end{tabular}

Notes: Full bond portfolio (Full Bond), Full equity Portfolio (Full Equity), Bond and equity portfolio (equally 33\% country weight, 50\% bonds, 50\% equities), home biased Bond and equity portfolio, (60\% EMU, 20\% the UK and 20\% the US), whole period (ALL), Before Crisis (BC), During Crisis (DC). Vector of returns $r_{t}=r_{t}^{U H}, r_{t}^{\text {Fut_GBP }}, r_{t}^{\text {Fut_USD }}$. 1-3 year maturity bonds. 
Table A.15. BEKK MODEL 1-3 year maturity- In-sample

\begin{tabular}{|c|c|c|c|c|c|c|c|c|c|c|c|c|c|}
\hline & & $\beta_{1}$ & $\boldsymbol{\beta}_{2}$ & $\boldsymbol{\sigma}_{\mathrm{UH}}$ & $\sigma_{\mathrm{H}}$ & HE & $\boldsymbol{\sigma}_{\mathrm{EMU}}$ & $\mathbf{R}_{\mathrm{UH}}$ & $\mathbf{R}_{\mathbf{H}}$ & $\mathbf{R}_{\mathrm{EMU}}$ & $\mathrm{SHR}_{\mathrm{UH}}$ & $\mathrm{SHR}_{\mathrm{H}}$ & $\mathrm{SHR}_{\mathrm{EMU}}$ \\
\hline \multirow{3}{*}{ Full Bond } & ALL & 0.2924 & 0.3228 & 5.5272 & 2.4393 & 80.5237 & 1.5492 & -1.3656 & -1.0198 & -1.2423 & -7.5481 & -2.4875 & -1.9245 \\
\hline & $\mathrm{BC}$ & 0.2820 & 0.3169 & 5.0349 & 2.3717 & 77.8107 & 1.4230 & -1.9800 & -1.1200 & -1.4900 & -9.9691 & -2.6563 & -2.1203 \\
\hline & DC & 0.3207 & 0.3335 & 6.5555 & 2.5788 & 84.5259 & 1.8028 & 0.0800 & -0.5200 & -0.6200 & 0.0122 & -1.3410 & -1.1177 \\
\hline \multirow{3}{*}{ Full Equity } & ALL & 0.5444 & 0.0579 & 18.8865 & 18.2722 & 6.3989 & 22.4917 & -0.8216 & -0.3743 & -1.8821 & -15.5175 & -6.8393 & -42.3323 \\
\hline & BC & 0.1862 & 0.6373 & 17.3335 & 15.4669 & 20.3778 & 20.1259 & -1.7348 & 0.3757 & -0.6727 & -30.0708 & 0.0243 & -13.5394 \\
\hline & DC & 0.7259 & -0.6783 & 22.1670 & 20.6458 & 13.2536 & 27.3226 & 1.5366 & 4.4978 & -4.2810 & 0.0693 & 0.2179 & -116.9693 \\
\hline \multirow{3}{*}{$\begin{array}{c}\text { Bond }+ \text { Equity } \\
(0.33 \text { each country) }\end{array}$} & ALL & 0.4201 & 0.1891 & 10.2140 & 9.0540 & 21.4234 & 11.1524 & -1.0940 & -0.6479 & -1.5627 & -11.1740 & -5.8661 & -17.4279 \\
\hline & $\mathrm{BC}$ & 0.2741 & 0.4757 & 9.8005 & 7.8438 & 35.9448 & 9.8944 & -1.8576 & -0.8216 & -1.0693 & -18.2054 & -6.4446 & -10.5798 \\
\hline & DC & 0.5513 & -0.2054 & 11.1490 & 10.0499 & 18.7450 & 13.6958 & 0.8032 & 1.4605 & -2.4691 & 0.0720 & 0.1453 & -33.8167 \\
\hline \multirow{3}{*}{$\begin{array}{l}\text { Bond +Equity } \\
\text { (0.60 EMU) }\end{array}$} & ALL & 0.3151 & 0.0517 & 10.1193 & 9.7005 & 8.1055 & 11.1524 & -1.2916 & -1.0198 & -1.5627 & -13.0703 & -9.8924 & -17.4279 \\
\hline & $\mathrm{BC}$ & 0.1604 & 0.3628 & 9.4101 & 8.4143 & 20.0452 & 9.8944 & -1.5627 & -0.8216 & -1.0693 & -14.7053 & -6.9133 & -10.5798 \\
\hline & DC & 0.4526 & -0.3769 & 11.6458 & 10.6958 & 15.6498 & 13.6958 & -0.5236 & 0.4259 & -2.4691 & -6.0981 & 0.0398 & -33.8167 \\
\hline
\end{tabular}

Notes: Full bond portfolio (Full Bond), Full equity Portfolio (Full Equity), Bond and equity portfolio (equally 33\% country weight, 50\% bonds, 50\% equities), home biased Bond and equity portfolio, (60\% EMU, 20\% the UK and 20\% the US), for the EMU portfolio the investor is only holding domestic equities and/or bonds based on the kind of international portfolio we are comparing with (full bond, full equity or equities + bonds); whole period (ALL), Before Crisis (BC), During Crisis (DC); Euro units of British Pound future sold $\left(\boldsymbol{\beta}_{1}\right)$, Euro units of US dollar future sold $\left(\boldsymbol{\beta}_{2}\right)$ per Euro invested in an international portfolio; annualized unhedged portfolio standard deviation $\left(\boldsymbol{\sigma}_{\mathrm{UH}}\right)$, annualized hedged portfolio standard deviation $\left(\boldsymbol{\sigma}_{\mathbf{H}}\right)$, Hedging Effectiveness $(\mathbf{H E})$, annualized European portfolio standard deviation $\left(\boldsymbol{\sigma}_{\mathrm{EMU}}\right)$, annualized unhedged portfolio Return ( $\mathbf{R}_{\mathbf{U H}}$ ), annualized hedged portfolio Return $\left(\mathbf{R}_{\mathbf{H}}\right)$, annualized European portfolio return ( $\mathbf{R}_{\mathbf{E M U}}$ ), modified Sharpe Ratio (SHR) of Israelsen (2005) (when average returns are negative those are multiplied by the standard deviation rather than divided). 
Table A.16. BEKK PARAMETERS 1-3-year maturity- In-sample

\begin{tabular}{|c|c|c|c|c|c|c|c|c|c|c|c|c|c|}
\hline & & $\mathrm{C}_{11}$ & $\mathrm{C}_{12}$ & $\mathrm{C}_{13}$ & $\mathrm{C}_{22}$ & $\mathrm{C}_{23}$ & $\mathbf{C}_{33}$ & $\mathbf{A}_{11}$ & $\mathbf{A}_{22}$ & $\mathbf{A}_{33}$ & $\mathbf{B}_{11}$ & $\mathbf{B}_{22}$ & $\mathbf{B}_{33}$ \\
\hline \multirow{3}{*}{ Full Bond } & ALL & 0.0391 & 0.0319 & 0.0514 & -0.0308 & 0.0095 & -0.0259 & 0.1947 & 0.1832 & 0.1539 & 0.9741 & 0.9786 & 0.9835 \\
\hline & BC & 0.0478 & 0.0353 & 0.0583 & 0.032 & -0.0176 & 0 & 0.2007 & 0.1756 & 0.1364 & 0.9674 & 0.9784 & 0.9849 \\
\hline & DC & 0.0425 & 0.0368 & 0.0674 & -0.0253 & 0.0083 & 0.0404 & 0.181 & 0.1682 & 0.1799 & 0.9778 & 0.9819 & 0.9775 \\
\hline \multirow{3}{*}{ Full Equity } & ALL & 0.1029 & 0.0122 & 0.0167 & 0.0327 & 0.0126 & 0.0298 & 0.2629 & 0.1699 & 0.1674 & 0.9609 & 0.983 & 0.9843 \\
\hline & BC & 0.1115 & 0.0121 & 0.027 & 0.0316 & 0.007 & 0.0267 & 0.2588 & 0.1538 & 0.1446 & 0.9605 & 0.9852 & 0.9873 \\
\hline & DC & 0.1693 & 0.0075 & -0.0246 & 0.0286 & 0.0489 & 0.0199 & 0.303 & 0.1608 & 0.1546 & 0.9421 & 0.9853 & 0.9845 \\
\hline \multirow{3}{*}{$\begin{array}{c}\text { Bond }+ \text { Equity } \\
\text { (0.33 each country) }\end{array}$} & ALL & 0.0603 & 0.0206 & 0.028 & 0.0329 & 0.006 & -0.0272 & 0.2496 & 0.1779 & 0.1685 & 0.9638 & 0.981 & 0.9838 \\
\hline & $B C$ & 0.0629 & 0.0185 & 0.0347 & 0.0331 & 0.0028 & -0.0274 & 0.2357 & 0.1629 & 0.1502 & 0.9661 & 0.983 & 0.9857 \\
\hline & DC & 0.0854 & 0.0302 & 0.0135 & 0.0221 & 0.044 & -0.0303 & 0.3062 & 0.171 & 0.153 & 0.9422 & 0.9828 & 0.9851 \\
\hline \multirow{3}{*}{$\begin{array}{l}\text { Bond +Equity } \\
\text { (0.60 EMU) }\end{array}$} & ALL & 0.0573 & 0.014 & 0.0189 & 0.0322 & 0.0111 & 0.0292 & 0.2599 & 0.1689 & 0.1657 & 0.9615 & 0.9831 & 0.9846 \\
\hline & BC & 0.0625 & 0.014 & 0.0288 & 0.0311 & 0.0053 & 0.0265 & 0.2548 & 0.1523 & 0.1434 & 0.961 & 0.9854 & 0.9873 \\
\hline & DC & 0.0908 & 0.0097 & -0.0179 & 0.0291 & 0.0471 & -0.024 & 0.2943 & 0.1605 & 0.1533 & 0.9454 & 0.9852 & 0.9849 \\
\hline
\end{tabular}

Notes: Full bond portfolio (Full Bond), Full equity Portfolio (Full Equity), Bond and equity portfolio (equally 33\% country weight, 50\% bonds, 50\% equities), home biased Bond and equity portfolio, (60\% EMU, 20\% the UK and 20\% the US), whole period (ALL), Before Crisis (BC), During Crisis (DC). Vector of returns $r_{t}=r_{t}^{U H}, r_{t}^{\text {Fut_GBP }}, r_{t}^{\text {Fut_USD }} .1$-3 year maturity bonds. 
Table A.17. BEKK MODEL - +10-year maturity- In-sample

\begin{tabular}{|c|c|c|c|c|c|c|c|c|c|c|c|c|c|}
\hline & & $\beta_{1}$ & $\beta_{2}$ & $\boldsymbol{\sigma}_{\mathrm{UH}}$ & $\boldsymbol{\sigma}_{\mathrm{H}}$ & HE & $\boldsymbol{\sigma}_{\mathrm{EMU}}$ & $\mathbf{R}_{\mathrm{UH}}$ & $\mathbf{R}_{\mathbf{H}}$ & $\mathbf{R}_{\mathrm{EMU}}$ & SHR $_{U H}$ & $\mathrm{SHR}_{\mathrm{H}}$ & $\mathrm{SHR}_{\mathrm{EMU}}$ \\
\hline \multirow{3}{*}{ Full Bond } & ALL & 0.2672 & 0.2887 & 8.8671 & 7.2938 & 32.3370 & 7.0018 & 0.6269 & -0.1000 & 0.5012 & 0.0707 & -0.7290 & 0.0716 \\
\hline & BC & 0.3002 & 0.1791 & 7.3739 & 6.4904 & 22.5287 & 6.5479 & -1.2669 & -1.5627 & -0.4988 & -9.3423 & -10.1426 & -3.2658 \\
\hline & DC & 0.1763 & 0.5761 & 11.6705 & 8.8586 & 42.3825 & 7.9703 & 5.0215 & 3.6912 & 2.7110 & 0.4303 & 0.4167 & 0.3401 \\
\hline \multirow{3}{*}{ Full Equity } & ALL & 0.5444 & 0.0579 & 18.8865 & 18.2722 & 6.3989 & 22.4917 & -0.8216 & -0.3743 & -1.8821 & -15.5175 & -6.8393 & -42.3323 \\
\hline & $B C$ & 0.1862 & 0.6373 & 17.3335 & 15.4669 & 20.3778 & 20.1259 & -1.7348 & 0.3757 & -0.6727 & -30.0708 & 0.0243 & -13.5394 \\
\hline & DC & 0.7259 & -0.6783 & 22.1670 & 20.6458 & 13.2536 & 27.3226 & 1.5366 & 4.4978 & -4.2810 & 0.0693 & 0.2179 & -116.9693 \\
\hline \multirow{3}{*}{$\begin{array}{c}\text { Bond + Equity } \\
\text { (0.33 each country) }\end{array}$} & ALL & 0.3137 & 0.2675 & 9.6605 & 8.2614 & 26.8685 & 10.9121 & -0.1000 & 0.7276 & -0.6976 & -0.9656 & 0.0881 & -7.6119 \\
\hline & $B C$ & 0.2545 & 0.4008 & 9.4167 & 7.7217 & 32.7601 & 9.6825 & -1.4889 & -0.5236 & -0.5982 & -14.0201 & -4.0433 & -5.7922 \\
\hline & DC & 0.4519 & -0.0407 & 10.2213 & 9.3368 & 16.5590 & 13.4052 & 3.2774 & 3.7950 & -0.8464 & 0.3206 & 0.4065 & -11.3463 \\
\hline \multirow{3}{*}{$\begin{array}{l}\text { Bond +Equity } \\
\text { (0.60 EMU) }\end{array}$} & ALL & 0.2888 & 0.0505 & 9.5825 & 9.2060 & 7.7049 & 10.9121 & -0.3494 & -0.0750 & -0.6976 & -3.3480 & -0.6902 & -7.6119 \\
\hline & BC & 0.1611 & 0.3029 & 9.0554 & 8.2795 & 16.4024 & 9.6825 & -1.1434 & -0.4988 & -0.5982 & -10.3543 & -4.1295 & -5.7922 \\
\hline & DC & 0.4032 & -0.2976 & 10.7424 & 10.0112 & 13.1499 & 13.4052 & 1.6128 & 2.4289 & -0.8464 & 0.1501 & 0.2426 & -11.3463 \\
\hline
\end{tabular}

Notes: Full bond portfolio (Full Bond), Full equity Portfolio (Full Equity), Bond and equity portfolio (equally 33\% country weight, 50\% bonds, 50\% equities), home biased Bond and equity portfolio, (60\% EMU, 20\% the UK and 20\% the US), for the EMU portfolio the investor is only holding domestic equities and/or bonds based on the kind of international portfolio we are comparing with (full bond, full equity or equities + bonds); whole period (ALL), Before Crisis (BC), During Crisis (DC); Euro units of British Pound future sold $\left(\boldsymbol{\beta}_{1}\right)$, Euro units of US dollar future sold $\left(\boldsymbol{\beta}_{2}\right)$ per Euro invested in an international portfolio; annualized unhedged portfolio standard deviation $\left(\boldsymbol{\sigma}_{\mathrm{UH}}\right)$, annualized hedged portfolio standard deviation $\left(\boldsymbol{\sigma}_{\mathbf{H}}\right)$, Hedging Effectiveness $(\mathbf{H E})$, annualized European portfolio standard deviation $\left(\boldsymbol{\sigma}_{\mathrm{EMU}}\right)$, annualized unhedged portfolio Return ( $\mathbf{R}_{\mathbf{U H}}$ ), annualized hedged portfolio Return $\left(\mathbf{R}_{\mathbf{H}}\right)$, annualized European portfolio return ( $\mathbf{R}_{\mathbf{E M U}}$ ), modified Sharpe Ratio (SHR) of Israelsen (2005) (when average returns are negative those are multiplied by the standard deviation rather than divided). 
Table A.18. BEKK PARAMETERS - +10year maturities- In-sample

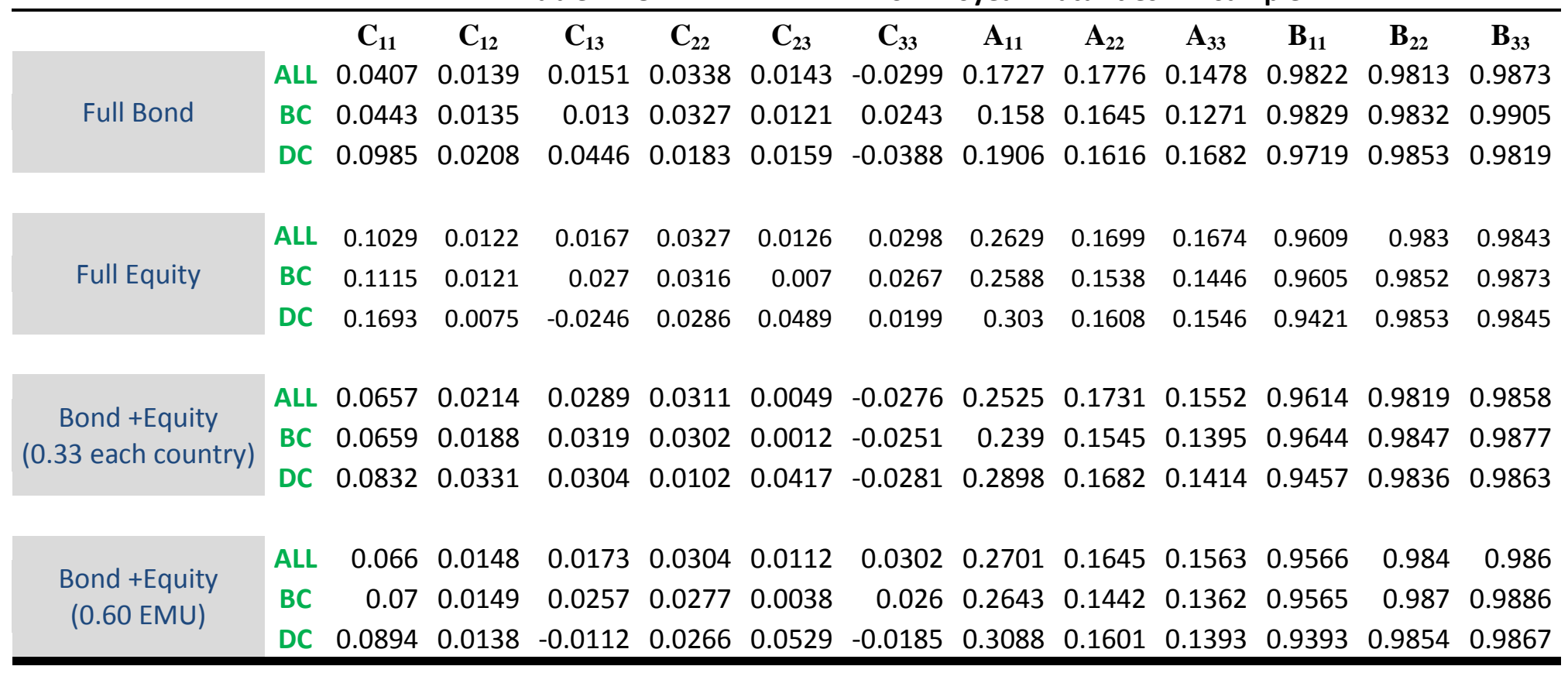

Notes: Full bond portfolio (Full Bond), Full equity Portfolio (Full Equity), Bond and equity portfolio (equally 33\% country weight, 50\% bonds, 50\% equities), home biased Bond and equity portfolio, (60\% EMU, 20\% the UK and 20\% the US), whole period (ALL), Before Crisis (BC), During Crisis (DC). Vector of returns $r_{t}=r_{t}^{U H}, r_{t}^{\text {Fut_GBP }}, r_{t}^{\text {Fut_USD }} .1-3$ year maturity bonds. 
Table A.19. OLS MODEL-All maturities - Out-of-sample

\begin{tabular}{|c|c|c|c|c|c|c|c|c|c|c|c|c|c|}
\hline & & $\beta_{1}$ & $\boldsymbol{\beta}_{2}$ & $\boldsymbol{\sigma}_{\mathrm{UH}}$ & $\sigma_{H}$ & HE & $\boldsymbol{\sigma}_{\mathrm{EMU}}$ & $\mathbf{R}_{\mathrm{UH}}$ & $\mathbf{R}_{\mathbf{H}}$ & $\mathbf{R}_{\mathrm{EMU}}$ & SHR $_{\mathrm{UH}}$ & $\mathrm{SHR}_{\mathrm{H}}$ & $\mathrm{SHR}_{\mathrm{EMU}}$ \\
\hline \multirow{3}{*}{ Full Bond } & ALL & $\begin{array}{l}0.2644 \\
\mathbf{0 . 0 2 2 0}\end{array}$ & $\begin{array}{l}0.2814 \\
\mathbf{0 . 0 7 5 7}\end{array}$ & 6.7623 & 4.4108 & 57.4547 & 3.7992 & 0.2100 & 0.6800 & 0.1300 & 0.0300 & 0.1500 & 0.0300 \\
\hline & BC & $\begin{array}{c}0.2794 \\
0.0208\end{array}$ & $\begin{array}{l}0.2115 \\
0.0095\end{array}$ & 5.0128 & 3.8305 & 41.6089 & 3.3424 & -2.4900 & -0.9200 & -1.0500 & -12.4600 & -3.5200 & -3.5000 \\
\hline & DC & $\begin{array}{r}0.2495 \\
\mathbf{0 . 0 0 9 8}\end{array}$ & $\begin{array}{l}0.3509 \\
0.0406\end{array}$ & 8.1349 & 4.9198 & 63.4246 & 4.2047 & 2.9600 & -2.1000 & 1.2200 & 0.3600 & -10.3200 & 0.2900 \\
\hline \multirow{3}{*}{ Full Equity } & ALL & $\begin{array}{l}0.4495 \\
\mathbf{0 . 2 3 3 6}\end{array}$ & $\begin{array}{l}0.2230 \\
\mathbf{0 . 5 1 3 4}\end{array}$ & 18.3956 & 18.0013 & 4.2412 & 22.2192 & 1.0600 & 2.9500 & -0.1400 & 0.0600 & 0.1600 & -3.0600 \\
\hline & BC & $\begin{array}{l}0.2228 \\
\mathbf{0 . 0 5 8 4}\end{array}$ & $\begin{array}{l}0.7077 \\
\mathbf{0 . 0 7 1 4}\end{array}$ & 13.5760 & 13.2030 & 5.4192 & 15.4552 & 0.4500 & 4.2900 & 4.5400 & 0.0300 & 0.3300 & 0.2900 \\
\hline & DC & $\begin{array}{r}0.6748 \\
0.0593\end{array}$ & $\begin{array}{c}-0.2585 \\
\mathbf{0 . 2 3 4 4}\end{array}$ & 22.1763 & 21.7503 & 3.8049 & 27.3345 & 1.6600 & 0.3300 & -4.1600 & 0.0700 & 0.0200 & -113.6700 \\
\hline \multirow{3}{*}{$\begin{array}{c}\text { Bond +Equity } \\
\text { ( } 0.33 \text { each country) }\end{array}$} & ALL & $\begin{array}{l}0.3570 \\
\mathbf{0 . 1 0 9 0}\end{array}$ & $\begin{array}{l}0.2522 \\
0.2191\end{array}$ & 9.0076 & 8.3393 & 14.2884 & 10.8509 & 0.6300 & 1.8100 & -0.0100 & 0.0700 & 0.2200 & -0.0700 \\
\hline & BC & $\begin{array}{l}0.2511 \\
0.0201\end{array}$ & $\begin{array}{l}0.4596 \\
\mathbf{0 . 0 3 2 0}\end{array}$ & 7.1292 & 6.1718 & 25.0534 & 7.2977 & -1.0300 & 1.6500 & 1.7100 & -7.3300 & 0.2700 & 0.2300 \\
\hline & DC & $\begin{array}{r}0.4621 \\
0.0328\end{array}$ & $\begin{array}{l}0.0462 \\
0.0973\end{array}$ & 10.5500 & 10.0425 & 9.3884 & 13.4868 & 2.3100 & -0.8900 & -1.5000 & 0.2200 & -8.9500 & -20.2900 \\
\hline \multirow{3}{*}{$\begin{array}{l}\text { Bond + Equity } \\
\text { (0.60 EMU) }\end{array}$} & ALL & $\begin{array}{l}0.2580 \\
\mathbf{0 . 1 1 6 6}\end{array}$ & $\begin{array}{l}0.1273 \\
\mathbf{0 . 2 4 5 6}\end{array}$ & 9.2475 & 8.9772 & 5.7603 & 10.8509 & 0.3800 & 1.3500 & -0.0100 & 0.0400 & 0.1500 & -0.0700 \\
\hline & BC & $\begin{array}{l}0.1454 \\
\mathbf{0 . 0 3 2 6}\end{array}$ & $\begin{array}{l}0.3592 \\
\mathbf{0 . 0 3 6 1}\end{array}$ & 6.8722 & 6.5533 & 9.0645 & 7.2977 & -0.0200 & 2.0000 & 1.7100 & -0.1400 & 0.3100 & 0.2300 \\
\hline & DC & $\begin{array}{r}0.3699 \\
0.0306\end{array}$ & $\begin{array}{c}-0.1031 \\
\mathbf{0 . 1 1 1 2}\end{array}$ & 11.1190 & 10.8655 & 4.5082 & 13.4868 & 0.7800 & -0.8000 & -1.5000 & 0.0700 & -8.7000 & -20.2900 \\
\hline
\end{tabular}

Notes: Full bond portfolio (Full Bond), Full equity Portfolio (Full Equity), Bond and equity portfolio (equally 33\% country weight, 50\% bonds, 50\% equities), home biased Bond and equity portfolio, (60\% EMU, 20\% the UK and 20\% the US), for the EMU portfolio the investor is only holding domestic equities and/or bonds based on the kind of international portfolio we are comparing with (full bond, full equity or equities + bonds), whole period (ALL), Before Crisis (BC), During Crisis (DC), Euro units of British pound future sold ( $\left.\boldsymbol{\beta}_{1}\right)$, Euro units of US dollar future sold ( $\boldsymbol{\beta}_{2}$ ) per Euro invested in an international portfolio, annualized unhedged whole period (ALL), Before Crisis (BC), During Crisis (DC), Euro units of British pound future sold $\left(\boldsymbol{\beta}_{1}\right)$, Euro units of US dollar future sold $\left(\boldsymbol{\beta}_{2}\right)$ per Euro invested in an international portfolio, annualized unhedged portfolio standard deviation $\left(\boldsymbol{\sigma}_{\mathrm{UH}}\right)$, , annualized hedged portfolio standard deviation $\left(\boldsymbol{\sigma}_{\mathrm{H}}\right)$, Hedging Effectiveness $(\mathbf{H E})$, , annualized European portfolio standard deviation $\left(\boldsymbol{\sigma}_{\mathrm{EMU}}\right)$, annualized unhedged portfolio Return
$\left(\mathbf{R}_{\mathrm{UH}}\right)$, annualized hedged portfolio Return $\left(\mathbf{R}_{\mathbf{H}}\right)$, annualized European portfolio return $\left(\mathbf{R}_{\mathrm{EMU}}\right)$, Sharpe Ratio (SHR). When returns are negative, following Israelsen (2005), we use the improved Sharpe ratio index that $\left(\mathbf{R}_{\mathrm{UH}}\right)$, annualized hedged portfolio Return $\left(\mathbf{R}_{\mathrm{H}}\right)$, , annualized European portfolio return $\left(\mathbf{R}_{\mathrm{EMU}}\right)$,
is the result of multiplying the average returns by the standard deviation. All maturities bonds. 
Table A.20. OLS MODEL-1-3-Year Maturity - Out-of-sample

\begin{tabular}{|c|c|c|c|c|c|c|c|c|c|c|c|c|c|}
\hline & & $\beta_{1}$ & $\beta_{2}$ & $\boldsymbol{\sigma}_{\mathrm{UH}}$ & $\sigma_{\mathrm{H}}$ & HE & $\boldsymbol{\sigma}_{\mathrm{EMU}}$ & $\mathbf{R}_{\mathrm{UH}}$ & $\mathbf{R}_{\mathbf{H}}$ & $\mathbf{R}_{\mathrm{EMU}}$ & SHR $_{U H}$ & $\mathrm{SHR}_{\mathrm{H}}$ & $\mathrm{SHR}_{\mathrm{EMU}}$ \\
\hline \multirow{4}{*}{ Full Bond } & ALL & $\begin{array}{l}0.2853 \\
0.0166\end{array}$ & $\begin{array}{l}0.3188 \\
0.0156\end{array}$ & 5.4712 & 2.3287 & 81.8835 & 1.5968 & -1.4400 & -0.7900 & -0.9400 & -7.8800 & -1.8400 & -1.5000 \\
\hline & \multirow[t]{2}{*}{ BC } & 0.2758 & 0.3041 & \multirow[t]{2}{*}{4.0970} & \multirow[t]{2}{*}{2.0795} & \multirow[t]{2}{*}{74.2378} & \multirow[t]{2}{*}{1.3543} & \multirow[t]{2}{*}{-2.9300} & \multirow[t]{2}{*}{-0.9900} & \multirow[t]{2}{*}{-1.2900} & \multirow[t]{2}{*}{-12.0100} & \multirow[t]{2}{*}{-2.0500} & \multirow{2}{*}{-1.7400} \\
\hline & & $\begin{array}{l}\mathbf{0 . 0 1 2 7} \\
0.2948\end{array}$ & $\begin{array}{l}0.0055 \\
0.3334\end{array}$ & & & & & & & & & & \\
\hline & Uc & $\begin{array}{l}0.2948 \\
0.0144\end{array}$ & $\begin{array}{l}0.3334 \\
0.0056\end{array}$ & 6.5578 & 2.5533 & 84.8409 & 1.8062 & 0.0600 & -1.0300 & -0.6100 & 0.0100 & -2.6400 & -1.1100 \\
\hline \multirow{3}{*}{ Full Equity } & ALL & $\begin{array}{l}0.4495 \\
\mathbf{0 . 2 3 3 6}\end{array}$ & $\begin{array}{l}0.2230 \\
0.5134\end{array}$ & 18.3956 & 18.0013 & 4.2412 & 22.2192 & 1.0600 & 2.9500 & -0.1400 & 0.0600 & 0.1600 & -3.0600 \\
\hline & BC & $\begin{array}{l}0.2228 \\
0.0584\end{array}$ & $\begin{array}{l}0.7077 \\
\mathbf{0 . 0 7 1 4}\end{array}$ & 13.5760 & 13.2030 & 5.4192 & 15.4552 & 0.4500 & 4.2900 & 4.5400 & 0.0300 & 0.3300 & 0.2900 \\
\hline & DC & $\begin{array}{r}0.6748 \\
0.0593\end{array}$ & $\begin{array}{c}-0.2585 \\
\mathbf{0 . 2 3 4 4}\end{array}$ & 22.1763 & 21.7503 & 3.8049 & 27.3345 & 1.6600 & 0.3300 & -4.1600 & 0.0700 & 0.0200 & -113.6700 \\
\hline \multirow{3}{*}{$\begin{array}{c}\text { Bond }+ \text { Equity } \\
\text { ( } 0.33 \text { each country) }\end{array}$} & ALL & $\begin{array}{l}0.3674 \\
\mathbf{0 . 1 2 1 6}\end{array}$ & $\begin{array}{l}0.2709 \\
0.2491\end{array}$ & 9.4721 & 8.8457 & 12.7899 & 11.0567 & -0.2000 & 1.0600 & -0.5400 & -1.9000 & 0.1200 & -5.9700 \\
\hline & BC & $\begin{array}{c}0.2493 \\
\mathbf{0 . 0 2 3 5}\end{array}$ & $\begin{array}{l}0.5059 \\
\mathbf{0 . 0 3 3 4}\end{array}$ & 7.4085 & 6.4595 & 23.9776 & 7.5115 & -1.2500 & 1.6200 & 1.5900 & -9.2900 & 0.2500 & 0.2100 \\
\hline & DC & $\begin{array}{c}0.4848 \\
\mathbf{0 . 0 3 5 8}\end{array}$ & $\begin{array}{l}0.0375 \\
\mathbf{0 . 1 1 4 7}\end{array}$ & 11.1536 & 10.7050 & 7.8822 & 13.7015 & 0.8600 & -0.3500 & -2.4000 & 0.0800 & -3.7900 & -32.9200 \\
\hline \multirow{3}{*}{$\begin{array}{l}\text { Bond + Equity } \\
\text { (0.60 EMU) }\end{array}$} & ALL & $\begin{array}{l}0.2662 \\
\mathbf{0 . 1 2 6 5}\end{array}$ & $\begin{array}{l}0.1448 \\
0.2714\end{array}$ & 9.6668 & 9.4020 & 5.4035 & 11.0567 & -0.3400 & 0.7200 & -0.5400 & -3.2600 & 0.0800 & -5.9700 \\
\hline & BC & $\begin{array}{c}0.1440 \\
0.0356\end{array}$ & $\begin{array}{l}0.4007 \\
\mathbf{0 . 0 3 7 2}\end{array}$ & 7.1385 & 6.8309 & 8.4338 & 7.5115 & -0.2200 & 1.9800 & 1.5900 & -1.5700 & 0.2900 & 0.2100 \\
\hline & DC & $\begin{array}{l}0.3876 \\
0.0326\end{array}$ & $\begin{array}{l}-0.1095 \\
\mathbf{0 . 1 2 5 4}\end{array}$ & 11.6509 & 11.3987 & 4.2823 & 13.7015 & -0.4500 & -0.1500 & -2.4000 & -5.2900 & -1.7300 & -32.9200 \\
\hline
\end{tabular}

Notes: Full bond portfolio (Full Bond), Full equity Portfolio (Full Equity), Bond and equity portfolio (equally 33\% country weight, 50\% bonds, 50\% equities), home biased Bond and equity portfolio, (60\% EMU, 20\% the UK and 20\% the US), for the EMU portfolio the investor is only holding domestic equities and/or bonds based on the kind of international portfolio we are comparing with (full bond, full equity or equities + bonds), (B) whole period (ALL), Before Crisis (BC), During Crisis (DC), Euro units of British pound future sold $\left(\boldsymbol{\beta}_{1}\right)$, Euro units of US dollar future sold $\left(\boldsymbol{\beta}_{2}\right)$ per Euro invested in an international portfolio, annualized unhedged portfolio standard deviation $\left(\boldsymbol{\sigma}_{\mathrm{UH}}\right)$, , annualized hedged portfolio standard deviation $\left(\boldsymbol{\sigma}_{\mathrm{H}}\right)$, Hedging Effectiveness $(\mathbf{H E})$ ), , annualized European portfolio standard deviation ( $\left.\boldsymbol{\sigma}_{\mathrm{EMU}}\right)$, annualized unhedged portfolio Return $\left(\mathbf{R}_{\mathrm{UH}}\right)$, annualized hedged portfolio Return $\left(\mathbf{R}_{\mathbf{H}}\right)$, , annualized European portfolio return ( $\left.\mathbf{R}_{\mathrm{EMU}}\right)$, Sharpe Ratio (SHR). When returns are negative, following Israelsen (2005), we use the improved Sharpe ratio index tha is the result of multiplying the average returns by the standard deviation. All maturities bonds. 
Table A.21. OLS MODEL- +10-year maturity- Out-of-sample

\begin{tabular}{|c|c|c|c|c|c|c|c|c|c|c|c|c|c|}
\hline & & $\beta_{1}$ & $\boldsymbol{\beta}_{2}$ & $\boldsymbol{\sigma}_{\mathrm{UH}}$ & $\sigma_{\mathrm{H}}$ & HE & $\boldsymbol{\sigma}_{\mathrm{EMU}}$ & $\mathbf{R}_{\mathrm{UH}}$ & $\mathbf{R}_{\mathbf{H}}$ & $\mathbf{R}_{\mathrm{EMU}}$ & SHR $_{U H}$ & $\mathrm{SHR}_{\mathrm{H}}$ & $\mathrm{SHR}_{\mathrm{EMU}}$ \\
\hline \multirow{4}{*}{ Full Bond } & ALL & $\begin{array}{l}0.2461 \\
0.0483\end{array}$ & $\begin{array}{l}0.2485 \\
0.1394\end{array}$ & 9.6471 & 7.9222 & 32.5624 & 7.2925 & 1.4000 & 1.7000 & 0.9700 & 0.1400 & 0.2100 & 0.1300 \\
\hline & BC & $\begin{array}{l}0.2901 \\
0.0273\end{array}$ & $\begin{array}{l}0.1225 \\
0.0143\end{array}$ & 7.0368 & 6.4034 & 17.1935 & 6.5385 & -2.0900 & -0.8600 & -0.9300 & -14.7000 & -5.5000 & -6.0900 \\
\hline & DC & 0.2025 & 0.3736 & 116756 & 01861 & 200070 & 70730 & 10800 & 35100 & 26600 & 01300 & (2) & 02300 \\
\hline & & 0.0096 & 0.0842 & $11.6 / 56$ & 9.1801 & $38.09 / 9$ & 1.9730 & 4.9800 & -3.5100 & 2.0600 & 0.4300 & -32.2800 & 0.3300 \\
\hline \multirow{3}{*}{ Full Equity } & ALL & $\begin{array}{l}0.4495 \\
\mathbf{0 . 2 3 3 6}\end{array}$ & $\begin{array}{l}0.2230 \\
\mathbf{0 . 5 1 3 4}\end{array}$ & 18.3956 & 18.0013 & 4.2412 & 22.2192 & 1.0600 & 2.9500 & -0.1400 & 0.0600 & 0.1600 & -3.0600 \\
\hline & BC & $\begin{array}{l}0.2228 \\
\mathbf{0 . 0 5 8 4}\end{array}$ & $\begin{array}{l}0.7077 \\
\mathbf{0 . 0 7 1 4}\end{array}$ & 13.5760 & 13.2030 & 5.4192 & 15.4552 & 0.4500 & 4.2900 & 4.5400 & 0.0300 & 0.3300 & 0.2900 \\
\hline & DC & $\begin{array}{l}0.6748 \\
0.0593\end{array}$ & $\begin{array}{c}-0.2585 \\
\mathbf{0 . 2 3 4 4}\end{array}$ & 22.1763 & 21.7503 & 3.8049 & 27.3345 & 1.6600 & 0.3300 & -4.1600 & 0.0700 & 0.0200 & -113.6700 \\
\hline \multirow{3}{*}{$\begin{array}{c}\text { Bond +Equity } \\
\text { ( } 0.33 \text { each country) }\end{array}$} & ALL & $\begin{array}{l}0.3478 \\
\mathbf{0 . 0 9 4 2}\end{array}$ & $\begin{array}{l}0.2358 \\
\mathbf{0 . 1 8 8 3}\end{array}$ & 8.8453 & 8.1451 & 15.2056 & 10.8702 & 1.2300 & 2.3200 & 0.4200 & 0.1400 & 0.2900 & 0.0400 \\
\hline & BC & $\begin{array}{l}0.2564 \\
0.0186\end{array}$ & $\begin{array}{l}0.4151 \\
\mathbf{0 . 0 3 2 1}\end{array}$ & 7.1956 & 6.2768 & 23.9077 & 7.4940 & -0.8300 & 1.6900 & 1.7700 & -5.9400 & 0.2700 & 0.2400 \\
\hline & DC & $\begin{array}{l}0.4386 \\
\mathbf{0 . 0 2 8 2}\end{array}$ & $\begin{array}{l}0.0576 \\
0.0767\end{array}$ & 10.2259 & 9.6524 & 10.9013 & 13.4109 & 3.3100 & -1.6100 & -0.8100 & 0.3200 & -15.5500 & -10.8000 \\
\hline \multirow{3}{*}{$\begin{array}{l}\text { Bond + Equity } \\
\text { (0.60 EMU) }\end{array}$} & ALL & $\begin{array}{l}0.2511 \\
\mathbf{0 . 1 0 4 2}\end{array}$ & $\begin{array}{l}0.1098 \\
\mathbf{0 . 2 1 7 3}\end{array}$ & 9.0638 & 8.8062 & 5.6036 & 10.8702 & 0.9100 & 1.8000 & 0.4200 & 0.1000 & 0.2000 & 0.0400 \\
\hline & BC & $\begin{array}{l}0.1507 \\
\mathbf{0 . 0 3 0 1}\end{array}$ & $\begin{array}{l}0.3158 \\
\mathbf{0 . 0 3 6 4}\end{array}$ & 6.9744 & 6.6610 & 8.7866 & 7.4940 & 0.1600 & 2.0100 & 1.7700 & 0.0200 & 0.3000 & 0.2400 \\
\hline & DC & $\begin{array}{c}0.3509 \\
\mathbf{0 . 0 2 7 6}\end{array}$ & $\begin{array}{c}-0.0950 \\
\mathbf{0 . 0 9 3 3}\end{array}$ & 10.7478 & 10.5159 & 4.2687 & 13.4109 & 1.6600 & -1.7100 & -0.8100 & 0.1500 & -18.0100 & -10.8000 \\
\hline
\end{tabular}

Notes: Full bond portfolio (Full Bond), Full equity Portfolio (Full Equity), Bond and equity portfolio (equally 33\% country weight, 50\% bonds, 50\% equities), home biased Bond and equity portfolio, (60\% EMU, 20\% the UK and 20\% the US), for the EMU portfolio the investor is only holding domestic equities and/or bonds based on the kind of international portfolio we are comparing with (full bond, full equity or equities + bonds), whole period (ALL), Before Crisis (BC), During Crisis (DC), Euro units of British pound future sold ( $\left.\boldsymbol{\beta}_{1}\right)$, Euro units of US dollar future sold ( $\boldsymbol{\beta}_{2}$ ) per Euro invested in an international portfolio, annualized unhedged whole period (ALL), Before Crisis (BC), During Crisis (DC), Euro units of British pound future sold $\left(\boldsymbol{\beta}_{1}\right)$, Euro units of US dollar future sold $\left(\boldsymbol{\beta}_{2}\right)$ per Euro invested in an international portfolio, annualized unhedged portfolio standard deviation $\left(\boldsymbol{\sigma}_{\mathrm{UH}}\right)$, , annualized hedged portfolio standard deviation $\left(\boldsymbol{\sigma}_{\mathbf{H}}\right)$, Hedging Effectiveness $(\mathbf{H E})$, , annualized European portfolio standard deviation $\left(\boldsymbol{\sigma}_{\mathrm{EMU}}\right)$, annualized unhedged portfolio Return $\left(\mathbf{R}_{\mathrm{UH}}\right)$, annualized hedged portfolio Return $\left(\mathbf{R}_{\mathbf{H}}\right)$, , annualized European portfolio return ( $\left.\mathbf{R}_{\mathrm{EMU}}\right)$, Sharpe Ratio (SHR). When returns are negative, following Israelsen (2005), we use the improved Sharpe ratio index tha is the result of multiplying the average returns by the standard deviation. All maturities bonds. 
Table A.22. EWMA MODEL-All maturities- Out-of-sample

\begin{tabular}{|c|c|c|c|c|c|c|c|c|c|c|c|c|c|}
\hline & & $\beta_{1}$ & $\boldsymbol{\beta}_{2}$ & $\sigma_{U H}$ & $\sigma_{\mathrm{H}}$ & HE & $\boldsymbol{\sigma}_{\mathrm{EMU}}$ & $\mathbf{R}_{\mathrm{UH}}$ & $\mathbf{R}_{\mathbf{H}}$ & $\mathbf{R}_{\mathrm{EMU}}$ & SHR $_{\mathrm{UH}}$ & $\mathrm{SHR}_{\mathrm{H}}$ & $\mathrm{SHR}_{\mathrm{EMU}}$ \\
\hline \multirow{3}{*}{ Full Bond } & ALL & $\begin{array}{l}0.2678 \\
0.0904\end{array}$ & $\begin{array}{l}0.3611 \\
0.1148\end{array}$ & 6.7623 & 4.3594 & 58.4404 & 3.7992 & 0.2100 & 0.3400 & 0.1300 & 0.0300 & 0.0800 & 0.0300 \\
\hline & BC & $\begin{array}{l}0.2820 \\
0.1077\end{array}$ & $\begin{array}{l}0.2879 \\
0.0984\end{array}$ & 5.0128 & 3.7854 & 42.9759 & 3.3424 & -2.4900 & -1.4100 & -1.0500 & -12.4600 & -5.3200 & -3.5000 \\
\hline & DC & $\begin{array}{l}0.2536 \\
\mathbf{0 . 0 6 6 0}\end{array}$ & $\begin{array}{l}0.4339 \\
0.0778\end{array}$ & 8.1349 & 4.8623 & 64.2737 & 4.2047 & 2.9600 & 2.1000 & 1.2000 & 0.3600 & 0.4300 & 0.2800 \\
\hline \multirow{3}{*}{ Full Equity } & ALL & $\begin{array}{l}0.5132 \\
0.4704\end{array}$ & $\begin{array}{c}-0.1862 \\
\mathbf{0 . 6 2 6 2}\end{array}$ & 18.3956 & 17.2406 & 12.1629 & 22.2192 & 1.0600 & 2.7300 & -0.1400 & 0.0600 & 0.1600 & -3.0600 \\
\hline & BC & $\begin{array}{l}0.2709 \\
0.4393\end{array}$ & $\begin{array}{l}0.3203 \\
\mathbf{0 . 3 2 0 4}\end{array}$ & 13.5760 & 12.9849 & 8.5194 & 15.4552 & 0.4500 & 0.6200 & 4.5400 & 0.0300 & 0.0500 & 0.2900 \\
\hline & DC & $\begin{array}{l}0.7540 \\
\mathbf{0 . 3 6 4 8}\end{array}$ & $\begin{array}{c}-0.6894 \\
\mathbf{0 . 4 1 4 3}\end{array}$ & 22.1763 & 20.6220 & 13.5258 & 27.3345 & 1.6600 & 4.8700 & -4.1800 & 0.0700 & 0.2400 & -114.2100 \\
\hline \multirow{3}{*}{$\begin{array}{c}\text { Bond }+ \text { Equity } \\
\text { ( } 0.33 \text { each country) }\end{array}$} & ALL & $\begin{array}{l}0.3905 \\
\mathbf{0 . 2 1 6 3}\end{array}$ & $\begin{array}{l}0.0875 \\
0.2728\end{array}$ & 9.0076 & 8.0530 & 20.0723 & 10.8509 & 0.6300 & 1.5300 & -0.0100 & 0.0700 & 0.1900 & -0.0700 \\
\hline & BC & $\begin{array}{l}0.2765 \\
\mathbf{0 . 1 9 6 9}\end{array}$ & $\begin{array}{l}0.3041 \\
0.1474\end{array}$ & 7.1292 & 6.1183 & 26.3492 & 7.2977 & -1.0300 & -0.4000 & 1.7100 & -7.3300 & -2.4300 & 0.2300 \\
\hline & DC & $\begin{array}{l}0.5038 \\
0.1704\end{array}$ & $\begin{array}{l}-0.1278 \\
\mathbf{0 . 1 8 4 0}\end{array}$ & 10.5500 & 9.5978 & 17.2353 & 13.4868 & 2.3100 & 3.4800 & -1.5300 & 0.2200 & 0.3600 & -20.6000 \\
\hline \multirow{3}{*}{$\begin{array}{l}\text { Bond + Equity } \\
\text { (0.60 EMU) }\end{array}$} & ALL & $\begin{array}{l}0.3034 \\
0.2359\end{array}$ & $\begin{array}{c}-0.0742 \\
\mathbf{0 . 3 1 7 3}\end{array}$ & 9.2475 & 8.6198 & 13.1157 & 10.8509 & 0.3800 & 1.2200 & -0.0100 & 0.0400 & 0.1400 & -0.0700 \\
\hline & BC & $\begin{array}{l}0.1846 \\
0.2137\end{array}$ & $\begin{array}{l}0.1744 \\
0.1625\end{array}$ & 6.8722 & 6.4764 & 11.1853 & 7.2977 & -0.0200 & -0.0100 & 1.7100 & -0.1400 & -0.0600 & 0.2300 \\
\hline & DC & $\begin{array}{l}0.4214 \\
0.1940\end{array}$ & $\begin{array}{l}-0.3210 \\
\mathbf{0 . 2 2 8 4}\end{array}$ & 11.1190 & 10.3199 & 13.8568 & 13.4868 & 0.7800 & 2.4500 & -1.5300 & 0.0700 & 0.2400 & -20.6000 \\
\hline
\end{tabular}

Notes: Full bond portfolio (Full Bond), Full equity Portfolio (Full Equity), Bond and equity portfolio (equally 33\% country weight, 50\% bonds, 50\% equities), home biased Bond and equity portfolio, (60\% EMU, 20\% the UK and 20\% the US), for the EMU portfolio the investor is only holding domestic equities and/or bonds based on the kind of international portfolio we are comparing with (full bond, full equity or equities + bonds), ( whole period (ALL), Before Crisis (BC), During Crisis (DC), Euro units of British pound future sold $\left(\boldsymbol{\beta}_{1}\right)$, Euro units of US dollar future sold $\left(\boldsymbol{\beta}_{2}\right)$ per Euro invested in an international portfolio, annualized unhedged portfolio standard deviation $\left(\boldsymbol{\sigma}_{\mathrm{UH}}\right)$, , annualized hedged portfolio standard deviation $\left(\boldsymbol{\sigma}_{\mathbf{H}}\right)$, Hedging Effectiveness $(\mathbf{H E})$, , annualized European portfolio standard deviation $\left(\boldsymbol{\sigma}_{\mathrm{EMU}}\right)$, annualized unhedged portfolio Return $\left(\mathbf{R}_{\mathrm{UH}}\right)$, annualized hedged portfolio Return $\left(\mathbf{R}_{\mathbf{H}}\right)$, , annualized European portfolio return ( $\left.\mathbf{R}_{\mathrm{EMU}}\right)$, Sharpe Ratio (SHR). When returns are negative, following Israelsen (2005), we use the improved Sharpe ratio index that is the result of multiplying the average returns by the standard deviation. All maturities bonds. 
Table A.23. EWMA MODEL-1-3-Year Maturity- Out-of-sample

\begin{tabular}{|c|c|c|c|c|c|c|c|c|c|c|c|c|c|}
\hline & & $\beta_{1}$ & $\boldsymbol{\beta}_{2}$ & $\boldsymbol{\sigma}_{\mathrm{UH}}$ & $\sigma_{H}$ & HE & $\boldsymbol{\sigma}_{\mathrm{EMU}}$ & $\mathbf{R}_{\mathrm{UH}}$ & $\mathbf{R}_{\mathbf{H}}$ & $\mathbf{R}_{\mathrm{EMU}}$ & $\mathbf{S H R}_{\mathrm{UH}}$ & $\mathrm{SHR}_{\mathrm{H}}$ & SHR $_{\mathrm{EMU}}$ \\
\hline \multirow{3}{*}{ Full Bond } & ALL & $\begin{array}{l}0.2983 \\
0.0487\end{array}$ & $\begin{array}{l}0.3332 \\
0.0332\end{array}$ & 5.4712 & 2.3578 & 81.4282 & 1.5968 & -1.4400 & -0.9000 & -0.9400 & -7.8800 & -2.1200 & -1.5000 \\
\hline & BC & $\begin{array}{l}0.2778 \\
0.0524\end{array}$ & $\begin{array}{l}0.3321 \\
0.0353\end{array}$ & 4.0970 & 2.1056 & 73.5865 & 1.3543 & -2.9300 & -1.2200 & -1.2900 & -12.0100 & -2.5800 & -1.7400 \\
\hline & DC & $\begin{array}{l}0.3186 \\
0.0344\end{array}$ & $\begin{array}{l}0.3344 \\
0.0309\end{array}$ & 6.5578 & 2.5849 & 84.4628 & 1.8062 & 0.0600 & -0.5700 & -0.6400 & 0.0100 & -1.4800 & -1.1500 \\
\hline \multirow{3}{*}{ Full Equity } & ALL & $\begin{array}{l}0.5132 \\
\mathbf{0 . 4 7 0 4}\end{array}$ & $\begin{array}{c}-0.1862 \\
\mathbf{0 . 6 2 6 2}\end{array}$ & 18.3956 & 17.2406 & 12.1629 & 22.2192 & 1.0600 & 2.7300 & -0.1400 & 0.0600 & 0.1600 & -3.0600 \\
\hline & BC & $\begin{array}{l}0.2709 \\
\mathbf{0 . 4 3 9 3}\end{array}$ & $\begin{array}{l}0.3203 \\
\mathbf{0 . 3 2 0 4}\end{array}$ & 13.5760 & 12.9849 & 8.5194 & 15.4552 & 0.4500 & 0.6200 & 4.5400 & 0.0300 & 0.0500 & 0.2900 \\
\hline & DC & $\begin{array}{c}0.7540 \\
\mathbf{0 . 3 6 4 8}\end{array}$ & $\begin{array}{c}-0.6894 \\
\mathbf{0 . 4 1 4 3}\end{array}$ & 22.1763 & 20.6220 & 13.5258 & 27.3345 & 1.6600 & 4.8700 & -4.1800 & 0.0700 & 0.2400 & -114.2100 \\
\hline \multirow{3}{*}{$\begin{array}{c}\text { Bond }+ \text { Equity } \\
\text { ( } 0.33 \text { each country) }\end{array}$} & ALL & $\begin{array}{l}0.4058 \\
0.2365\end{array}$ & $\begin{array}{l}0.0735 \\
0.3137\end{array}$ & 9.4721 & 8.4692 & 20.0563 & 11.0567 & -0.2000 & 0.9000 & -0.5400 & -1.9000 & 0.1100 & -5.9700 \\
\hline & BC & $\begin{array}{c}0.2744 \\
0.2119\end{array}$ & $\begin{array}{l}0.3262 \\
\mathbf{0 . 1 5 4 7}\end{array}$ & 7.4085 & 6.3759 & 25.9331 & 7.5115 & -1.2500 & -0.3000 & 1.5900 & -9.2900 & -1.9400 & 0.2100 \\
\hline & DC & $\begin{array}{l}0.5363 \\
\mathbf{0 . 1 8 0 8}\end{array}$ & $\begin{array}{c}-0.1775 \\
\mathbf{0 . 2 1 4 3}\end{array}$ & 11.1536 & 10.1317 & 17.4840 & 13.7015 & 0.8600 & 2.1100 & -2.4200 & 0.0800 & 0.2100 & -33.2200 \\
\hline \multirow{3}{*}{$\begin{array}{c}\text { Bond +Equity } \\
\text { (0.60 EMU) }\end{array}$} & ALL & $\begin{array}{l}0.3129 \\
0.2513\end{array}$ & $\begin{array}{c}-0.0819 \\
\mathbf{0 . 3 4 8 6}\end{array}$ & 9.6668 & 8.9667 & 13.9602 & 11.0567 & -0.3400 & 0.6800 & -0.5400 & -3.2600 & 0.0800 & -5.9700 \\
\hline & BC & $\begin{array}{l}0.1797 \\
0.2265\end{array}$ & $\begin{array}{l}0.1946 \\
\mathbf{0 . 1 7 1 0}\end{array}$ & 7.1385 & 6.7201 & 11.3805 & 7.5115 & -0.2200 & 0.0800 & 1.5900 & -1.5700 & 0.0100 & 0.2100 \\
\hline & DC & $\begin{array}{l}0.4452 \\
\mathbf{0 . 1 9 9 6}\end{array}$ & $\begin{array}{c}-0.3566 \\
\mathbf{0 . 2 4 8 6}\end{array}$ & 11.6509 & 10.7464 & 14.9242 & 13.7015 & -0.4500 & 1.2800 & -2.4200 & -5.2900 & 0.1200 & -33.2200 \\
\hline
\end{tabular}

Notes: Full bond portfolio (Full Bond), Full equity Portfolio (Full Equity), Bond and equity portfolio (equally 33\% country weight, 50\% bonds, 50\% equities), home biased Bond and equity portfolio, (60\% EMU, 20\% the UK and 20\% the US), for the EMU portfolio the investor is only holding domestic equities and/or bonds based on the kind of international portfolio we are comparing with (full bond, full equity or equities + bonds), whe whole period (ALL), Before Crisis (BC), During Crisis (DC), Euro units of British pound future sold $\left(\boldsymbol{\beta}_{1}\right)$, Euro units of US dollar future sold $\left(\boldsymbol{\beta}_{2}\right)$ per Euro invested in an international portfolio, annualized unhedged portfolio standard deviation $\left(\boldsymbol{\sigma}_{\mathrm{UH}}\right)$, , annualized hedged portfolio standard deviation $\left(\boldsymbol{\sigma}_{\mathrm{H}}\right)$, Hedging Effectiveness $(\mathbf{H E})$, , annualized European portfolio standard deviation $\left(\boldsymbol{\sigma}_{\mathrm{EMU}}\right)$, annualized unhedged portfolio Return $\left(\mathbf{R}_{\mathbf{U H}}\right)$, annualized hedged portfolio Return $\left(\mathbf{R}_{\mathbf{H}}\right)$, , annualized European portfolio return ( $\mathbf{R}_{\mathbf{E M U}}$ ), Sharpe Ratio (SHR). When returns are negative, following Israelsen (2005), we use the improved Sharpe ratio index that is the result of multiplying the average returns by the standard deviation. 1-3 year maturity bonds. 
Table A.24. EWMA MODEL- +10-year maturity- Out-of-sample

\begin{tabular}{|c|c|c|c|c|c|c|c|c|c|c|c|c|c|}
\hline & & $\beta_{1}$ & $\boldsymbol{\beta}_{2}$ & $\boldsymbol{\sigma}_{\mathrm{UH}}$ & $\boldsymbol{\sigma}_{\mathrm{H}}$ & HE & $\boldsymbol{\sigma}_{\mathrm{EMU}}$ & $\mathbf{R}_{\mathrm{UH}}$ & $\mathbf{R}_{\mathbf{H}}$ & $\mathbf{R}_{\mathrm{EMU}}$ & SHR $_{U H}$ & $\mathrm{SHR}_{\mathrm{H}}$ & SHR $_{\text {EMU }}$ \\
\hline \multirow{4}{*}{ Full Bond } & ALL & $\begin{array}{l}0.2362 \\
\mathbf{0 . 1 7 6 3}\end{array}$ & $\begin{array}{l}0.4079 \\
\mathbf{0 . 2 6 0 3}\end{array}$ & 9.6471 & 7.7246 & 35.8849 & 7.2925 & 1.4000 & 0.9400 & 0.9700 & 0.1400 & 0.1200 & 0.1300 \\
\hline & BC & 0.3059 & 0.2339 & & & & & & & & & & \\
\hline & & 0.1765 & 0.1749 & 1.0368 & 6.3310 & 19.0536 & 6.5385 & -2.0900 & $-1 . / 300$ & -0.9300 & $-14 . / 000$ & -10.9500 & -6.0900 \\
\hline & DC & $\begin{array}{c}0.1669 \\
0.1463\end{array}$ & $\begin{array}{l}0.5808 \\
0.2113\end{array}$ & 11.6756 & 8.8953 & 41.9544 & 7.9730 & 4.9800 & 3.6600 & 2.6400 & 0.4300 & 0.4100 & 0.3300 \\
\hline \multirow{3}{*}{ Full Equity } & ALL & $\begin{array}{l}0.5132 \\
0.4704\end{array}$ & $\begin{array}{c}-0.1862 \\
\mathbf{0 . 6 2 6 2}\end{array}$ & 18.3956 & 17.2406 & 12.1629 & 22.2192 & 1.0600 & 2.7300 & -0.1400 & 0.0600 & 0.1600 & -3.0600 \\
\hline & BC & $\begin{array}{l}0.2709 \\
0.4393\end{array}$ & $\begin{array}{l}0.3203 \\
\mathbf{0 . 3 2 0 4}\end{array}$ & 13.5760 & 12.9849 & 8.5194 & 15.4552 & 0.4500 & 0.6200 & 4.5400 & 0.0300 & 0.0500 & 0.2900 \\
\hline & DC & $\begin{array}{l}0.7540 \\
\mathbf{0 . 3 6 4 8}\end{array}$ & $\begin{array}{c}-0.6894 \\
\mathbf{0 . 4 1 4 3}\end{array}$ & 22.1763 & 20.6220 & 13.5258 & 27.3345 & 1.6600 & 4.8700 & -4.1800 & 0.0700 & 0.2400 & -114.2100 \\
\hline \multirow{3}{*}{$\begin{array}{c}\text { Bond + Equity } \\
(0.33 \text { each country) }\end{array}$} & ALL & $\begin{array}{l}0.3747 \\
\mathbf{0 . 1 9 6 4}\end{array}$ & $\begin{array}{l}0.1108 \\
0.2255\end{array}$ & 8.8453 & 7.9624 & 18.9664 & 10.8702 & 1.2300 & 1.8300 & 0.4200 & 0.1400 & 0.2300 & 0.0400 \\
\hline & BC & $\begin{array}{c}0.2884 \\
0.1916\end{array}$ & $\begin{array}{l}0.2771 \\
\mathbf{0 . 1 5 5 7}\end{array}$ & 7.1956 & 6.2475 & 24.6147 & 7.4940 & -0.8300 & -0.5600 & 1.7700 & -5.9400 & -3.5000 & 0.2400 \\
\hline & DC & $\begin{array}{l}0.4605 \\
\mathbf{0 . 1 6 0 4}\end{array}$ & $\begin{array}{c}-0.0543 \\
\mathbf{0 . 1 5 0 1}\end{array}$ & 10.2259 & 9.3607 & 16.2052 & 13.4109 & 3.3100 & 4.2600 & -0.8300 & 0.3200 & 0.4600 & -11.1200 \\
\hline \multirow{3}{*}{$\begin{array}{l}\text { Bond + Equity } \\
\text { (0.60 EMU) }\end{array}$} & ALL & $\begin{array}{l}0.2943 \\
\mathbf{0 . 2 2 1 1}\end{array}$ & $\begin{array}{c}-0.0591 \\
\mathbf{0 . 2 7 6 3}\end{array}$ & 9.0638 & 8.5585 & 10.8386 & 10.8702 & 0.9100 & 1.4500 & 0.4200 & 0.1000 & 0.1700 & 0.0400 \\
\hline & BC & $\begin{array}{l}0.1988 \\
0.2105\end{array}$ & $\begin{array}{l}0.1482 \\
\mathbf{0 . 1 6 7 2}\end{array}$ & 6.9744 & 6.6206 & 9.8903 & 7.4940 & 0.1600 & -0.1700 & 1.7700 & 0.0200 & -1.1500 & 0.2400 \\
\hline & DC & $\begin{array}{l}0.3891 \\
\mathbf{0 . 1 8 8 2}\end{array}$ & $\begin{array}{c}-0.2651 \\
\mathbf{0 . 1 9 8 1}\end{array}$ & 10.7478 & 10.1252 & 11.2498 & 13.4109 & 1.6600 & 3.0900 & -0.8300 & 0.1500 & 0.3100 & -11.1200 \\
\hline
\end{tabular}

Notes: Full bond portfolio (Full Bond), Full equity Portfolio (Full Equity), Bond and equity portfolio (equally 33\% country weight, 50\% bonds, 50\% equities), home biased Bond and equity portfolio, (60\% EMU, 20\% the UK and 20\% the US), for the EMU portfolio the investor is only holding domestic equities and/or bonds based on the kind of international portfolio we are comparing with (full bond, full equity or equities + bonds), whole period (ALL), Before Crisis (BC), During Crisis (DC), Euro units of British pound future sold ( $\left.\boldsymbol{\beta}_{1}\right)$, Euro units of US dollar future sold ( $\boldsymbol{\beta}_{2}$ ) per Euro invested in an international portfolio, annualized unhedged whole period (ALL), Before Crisis (BC), During Crisis (DC), Euro units of British pound future sold $\left(\boldsymbol{\beta}_{1}\right)$, Euro units of US dollar future sold $\left(\boldsymbol{\beta}_{2}\right)$ per Euro invested in an international portfolio, annualized unhedged portfolio standard deviation $\left(\boldsymbol{\sigma}_{\mathrm{UH}}\right)$, , annualized hedged portfolio standard deviation $\left(\boldsymbol{\sigma}_{\mathrm{H}}\right)$, Hedging Effectiveness $(\mathbf{H E})$ ), , annualized European portfolio standard deviation $\left(\boldsymbol{\sigma}_{\mathrm{EMU}}\right)$, annualized unhedged portfolio Return $\left(\mathbf{R}_{\mathbf{U H}}\right)$, annualized hedged portfolio Return $\left(\mathbf{R}_{\mathbf{H}}\right)$, , annualized European portfolio return ( $\left.\mathbf{R}_{\mathbf{E M U}}\right)$, Sharpe Ratio (SHR). When returns are negative, following Israelsen (2005), we use the improved Sharpe ratio index that is the result of multiplying the average returns by the standard deviation. +10-year maturity bonds. 
Table A.25. DCC MODEL - All maturities- Out-of-sample

\begin{tabular}{|c|c|c|c|c|c|c|c|c|c|c|c|c|c|}
\hline & & $\beta_{1}$ & $\beta_{2}$ & $\boldsymbol{\sigma}_{\mathrm{UH}}$ & $\boldsymbol{\sigma}_{\mathrm{H}}$ & HE & $\boldsymbol{\sigma}_{\mathrm{EMU}}$ & $\mathbf{R}_{\mathrm{UH}}$ & $\mathbf{R}_{\mathbf{H}}$ & $\mathbf{R}_{\mathrm{EMU}}$ & SHR $_{\mathrm{UH}}$ & $\mathrm{SHR}_{\mathrm{H}}$ & $\mathrm{SHR}_{\mathrm{EMU}}$ \\
\hline \multirow{4}{*}{ Full Bond } & ALL & $\begin{array}{l}0.3782 \\
0.1217\end{array}$ & $\begin{array}{l}0.2321 \\
0.0853\end{array}$ & 6.7623 & 4.5520 & 54.6875 & 3.7992 & 0.2100 & 0.7100 & 0.1300 & 0.0300 & 0.1600 & 0.0300 \\
\hline & BC & 0.3594 & 0.1785 & 5.0128 & 3.9049 & 39.3177 & 3.3424 & -2.4900 & -1.3000 & -1.0500 & -12.4600 & -5.0700 & -3.5000 \\
\hline & & 0.0763 & 0.0701 & $0.01<0$ & & & & & & & & & \\
\hline & DC & $\begin{array}{l}0.3969 \\
0.1519\end{array}$ & $\begin{array}{l}0.2853 \\
0.0628\end{array}$ & 8.1349 & 5.1131 & 60.4934 & 4.2047 & 2.9600 & 2.7400 & 1.2200 & 0.3600 & 0.5400 & 0.2900 \\
\hline \multirow{3}{*}{ Full Equity } & ALL & $\begin{array}{l}0.4311 \\
0.2811\end{array}$ & $\begin{array}{c}-0.0015 \\
\mathbf{0 . 3 3 4 4}\end{array}$ & 18.3956 & 17.4398 & 10.1212 & 22.2192 & 1.0600 & 3.0000 & -0.1400 & 0.0600 & 0.1700 & -3.0600 \\
\hline & BC & $\begin{array}{l}0.4053 \\
0.2176\end{array}$ & $\begin{array}{l}0.2868 \\
0.1299\end{array}$ & 13.5760 & 12.9374 & 9.1866 & 15.4552 & 0.4500 & 1.7500 & 4.5400 & 0.0300 & 0.1400 & 0.2900 \\
\hline & DC & $\begin{array}{l}0.4568 \\
\mathbf{0 . 3 3 0 4}\end{array}$ & $\begin{array}{l}-0.2878 \\
\mathbf{0 . 2 0 4 0}\end{array}$ & 22.1763 & 20.9831 & 10.4710 & 27.3345 & 1.6600 & 4.2600 & -4.1600 & 0.0700 & 0.2000 & -113.6700 \\
\hline \multirow{3}{*}{$\begin{array}{c}\text { Bond +Equity } \\
\text { ( } 0.33 \text { each country) }\end{array}$} & ALL & $\begin{array}{l}0.3936 \\
\mathbf{0 . 1 3 7 8}\end{array}$ & $\begin{array}{l}0.1082 \\
\mathbf{0 . 1 4 1 4}\end{array}$ & 9.0076 & 8.1101 & 18.9343 & 10.8509 & 0.6300 & 1.4700 & -0.0100 & 0.0700 & 0.1800 & -0.0700 \\
\hline & BC & $\begin{array}{l}0.3737 \\
\mathbf{0 . 1 0 8 2}\end{array}$ & $\begin{array}{l}0.2250 \\
\mathbf{0 . 0 7 2 5}\end{array}$ & 7.1292 & 6.1452 & 25.6997 & 7.2977 & -1.0300 & 0.0700 & 1.7100 & -7.3300 & 0.0100 & 0.2300 \\
\hline & DC & $\begin{array}{c}0.4134 \\
0.1595\end{array}$ & $\begin{array}{l}-0.0079 \\
\mathbf{0 . 0 8 7 1}\end{array}$ & 10.5500 & 9.6771 & 15.8632 & 13.4868 & 2.3100 & 2.8900 & -1.5000 & 0.2200 & 0.3000 & -20.2900 \\
\hline \multirow{3}{*}{$\begin{array}{l}\text { Bond +Equity } \\
\text { (0.60 EMU) }\end{array}$} & ALL & $\begin{array}{c}0.2609 \\
0.1328\end{array}$ & $\begin{array}{l}0.0138 \\
0.1579\end{array}$ & 9.2475 & 8.7297 & 10.8842 & 10.8509 & 0.3800 & 1.3000 & -0.0100 & 0.0400 & 0.1500 & -0.0700 \\
\hline & BC & $\begin{array}{l}0.2511 \\
\mathbf{0 . 1 0 1 2}\end{array}$ & $\begin{array}{l}0.1469 \\
\mathbf{0 . 0 6 1 2}\end{array}$ & 6.8722 & 6.4548 & 11.7767 & 7.2977 & -0.0200 & 0.5400 & 1.7100 & -0.1400 & 0.0800 & 0.2300 \\
\hline & DC & $\begin{array}{l}0.2707 \\
\mathbf{0 . 1 5 7 4}\end{array}$ & $\begin{array}{c}-0.1185 \\
\mathbf{0 . 1 0 4 1}\end{array}$ & 11.1190 & 10.5162 & 10.5483 & 13.4868 & 0.7800 & 2.0600 & -1.5000 & 0.0700 & 0.2000 & -20.2900 \\
\hline
\end{tabular}

Notes: Full bond portfolio (Full Bond), Full equity Portfolio (Full Equity), Bond and equity portfolio (equally 33\% country weight, 50\% bonds, 50\% equities), home biased Bond and equity portfolio, (60\% EMU, 20\% the UK and 20\% the US), for the EMU portfolio the investor is only holding domestic equities and/or bonds based on the kind of international portfolio we are comparing with (full bond, full equity or equities + bonds), the UK whole period (ALL), Before Crisis (BC), During Crisis (DC), Euro units of British pound future sold $\left(\boldsymbol{\beta}_{1}\right)$, Euro units of US dollar future sold $\left(\boldsymbol{\beta}_{2}\right)$ per Euro invested in an international portfolio, annualized unhedged portfolio standard deviation $\left(\boldsymbol{\sigma}_{\mathrm{UH}}\right)$, , annualized hedged portfolio standard deviation $\left(\boldsymbol{\sigma}_{\mathrm{H}}\right)$, Hedging Effectiveness $(\mathrm{HE})$, , annualized European portfolio standard deviation ( $\left.\boldsymbol{\sigma}_{\mathrm{EMU}}\right)$, annualized unhedged portfolio Return $\left(\mathbf{R}_{\mathbf{U H}}\right)$, annualized hedged portfolio Return $\left(\mathbf{R}_{\mathbf{H}}\right)$, , annualized European portfolio return ( $\mathbf{R}_{\mathbf{E M U}}$ ), Sharpe Ratio (SHR). When returns are negative, following Israelsen (2005), we use the improved Sharpe ratio index that is the result of multiplying the average returns by the standard deviation. All maturities bonds. 
Table A.26. DCC MODEL - 1-3-Year Maturity- Out-of-sample

\begin{tabular}{|c|c|c|c|c|c|c|c|c|c|c|c|c|c|}
\hline & & $\beta_{1}$ & $\beta_{2}$ & $\sigma_{U H}$ & $\boldsymbol{\sigma}_{\mathrm{H}}$ & HE & $\boldsymbol{\sigma}_{\mathrm{EMU}}$ & $\mathbf{R}_{\mathrm{UH}}$ & $\mathbf{R}_{\mathbf{H}}$ & $\mathbf{R}_{\mathrm{EMU}}$ & $\mathrm{SHR}_{\mathrm{UH}}$ & $\mathrm{SHR}_{\mathrm{H}}$ & SHR $_{\text {EMU }}$ \\
\hline \multirow{4}{*}{ Full Bond } & ALL & $\begin{array}{l}0.4004 \\
0.0984\end{array}$ & $\begin{array}{l}0.2296 \\
0.0809\end{array}$ & 5.4712 & 2.6650 & 76.2735 & 1.5968 & -1.4400 & -0.5600 & -0.9400 & -7.8800 & -1.4800 & -1.5000 \\
\hline & BC & 0.4021 & 0.2092 & & & & & & & & & & \\
\hline & & 0.0847 & 0.0802 & $4.09 / 0$ & 2.3891 & 65.9946 & 1.3543 & -2.9300 & -1.2100 & -1.2900 & -12.0100 & -2.9000 & $-1 . / 400$ \\
\hline & DC & $\begin{array}{c}0.3988 \\
01104\end{array}$ & 0.2498 & 6.5578 & 2.9138 & 80.2570 & 1.8062 & 0.0600 & 0.1000 & -0.6100 & 0.0100 & 0.0400 & -1.1100 \\
\hline \multirow{3}{*}{ Full Equity } & ALL & $\begin{array}{c}0.4311 \\
\mathbf{0 . 2 8 1 1}\end{array}$ & $\begin{array}{c}-0.0015 \\
\mathbf{0 . 3 3 4 4}\end{array}$ & 18.3956 & 17.4398 & 10.1212 & 22.2192 & 1.0600 & 3.0000 & -0.1400 & 0.0600 & 0.1700 & -3.0600 \\
\hline & $B C$ & $\begin{array}{c}0.4053 \\
0.2176\end{array}$ & $\begin{array}{l}0.2868 \\
\mathbf{0 . 1 2 9 9}\end{array}$ & 13.5760 & 12.9374 & 9.1866 & 15.4552 & 0.4500 & 1.7500 & 4.5400 & 0.0300 & 0.1400 & 0.2900 \\
\hline & DC & $\begin{array}{l}0.4568 \\
\mathbf{0 . 3 3 0 4}\end{array}$ & $\begin{array}{c}-0.2878 \\
\mathbf{0 . 2 0 4 0}\end{array}$ & 22.1763 & 20.9831 & 10.4710 & 27.3345 & 1.6600 & 4.2600 & -4.1600 & 0.0700 & 0.2000 & -113.6700 \\
\hline \multirow{3}{*}{$\begin{array}{c}\text { Bond }+ \text { Equity } \\
(0.33 \text { each country) }\end{array}$} & ALL & $\begin{array}{c}0.4018 \\
0.1502\end{array}$ & $\begin{array}{l}0.1033 \\
0.1692\end{array}$ & 9.4721 & 8.5307 & 18.8895 & 11.0567 & -0.2000 & 0.9000 & -0.5400 & -1.9000 & 0.1000 & -5.9700 \\
\hline & $B C$ & $\begin{array}{l}0.3767 \\
\mathbf{0 . 1 2 0 4}\end{array}$ & $\begin{array}{l}0.2444 \\
0.0822\end{array}$ & 7.4085 & 6.4088 & 25.1679 & 7.5115 & -1.2500 & 0.0700 & 1.5900 & -9.2900 & 0.0100 & 0.2100 \\
\hline & DC & $\begin{array}{c}0.4267 \\
\mathbf{0 . 1 7 1 3}\end{array}$ & $\begin{array}{c}-0.0369 \\
\mathbf{0 . 1 0 4 5}\end{array}$ & 11.1536 & 10.2141 & 16.1363 & 13.7015 & 0.8600 & 1.7200 & -2.4000 & 0.0800 & 0.1700 & -32.9200 \\
\hline \multirow{3}{*}{$\begin{array}{l}\text { Bond + Equity } \\
\text { (0.60 EMU) }\end{array}$} & ALL & $\begin{array}{l}0.2671 \\
\mathbf{0 . 1 4 4 2}\end{array}$ & $\begin{array}{l}0.0112 \\
\mathbf{0 . 1 8 0 8}\end{array}$ & 9.6668 & 9.0838 & 11.6987 & 11.0567 & -0.3400 & 0.7700 & -0.5400 & -3.2600 & 0.0800 & -5.9700 \\
\hline & BC & $\begin{array}{l}0.2534 \\
\mathbf{0 . 1 1 1 7}\end{array}$ & $\begin{array}{l}0.1650 \\
0.0703\end{array}$ & 7.1385 & 6.7068 & 11.7312 & 7.5115 & -0.2200 & 0.5300 & 1.5900 & -1.5700 & 0.0800 & 0.2100 \\
\hline & DC & $\begin{array}{l}0.2808 \\
\mathbf{0 . 1 6 9 4}\end{array}$ & $\begin{array}{c}-0.1416 \\
\mathbf{0 . 1 1 5 8}\end{array}$ & 11.6509 & 10.9489 & 11.6868 & 13.7015 & -0.4500 & 1.0100 & -2.4000 & -5.2900 & 0.0900 & -32.9200 \\
\hline
\end{tabular}

Notes: Full bond portfolio (Full Bond), Full equity Portfolio (Full Equity), Bond and equity portfolio (equally 33\% country weight, 50\% bonds, 50\% equities), home biased Bond and equity portfolio, (60\% EMU, 20\% the UK and 20\% the US), for the EMU portfolio the investor is only holding domestic equities and/or bonds based on the kind of international portfolio we are comparing with (full bond, full equity or equities + bonds), ( whole period (ALL), Before Crisis (BC), During Crisis (DC), Euro units of British pound future sold $\left(\boldsymbol{\beta}_{1}\right)$, Euro units of US dollar future sold $\left(\boldsymbol{\beta}_{2}\right)$ per Euro invested in an international portfolio, annualized unhedged portfolio standard deviation $\left(\boldsymbol{\sigma}_{\mathrm{UH}}\right)$, , annualized hedged portfolio standard deviation $\left(\boldsymbol{\sigma}_{\mathbf{H}}\right)$, Hedging Effectiveness $(\mathbf{H E})$, , annualized European portfolio standard deviation $\left(\boldsymbol{\sigma}_{\mathrm{EMU}}\right)$, annualized unhedged portfolio Return $\left(\mathbf{R}_{\mathrm{UH}}\right)$, annualized hedged portfolio Return $\left(\mathbf{R}_{\mathbf{H}}\right)$, , annualized European portfolio return ( $\left.\mathbf{R}_{\mathrm{EMU}}\right)$, Sharpe Ratio (SHR). When returns are negative, following Israelsen (2005), we use the improved Sharpe ratio index tha is the result of multiplying the average returns by the standard deviation. All maturities bonds. 
Table A.27. DCC MODEL - 10+-Year Maturity- Out-of-sample

\begin{tabular}{|c|c|c|c|c|c|c|c|c|c|c|c|c|c|}
\hline & & $\boldsymbol{\beta}_{1}$ & $\boldsymbol{\beta}_{2}$ & $\sigma_{U H}$ & $\sigma_{\mathrm{H}}$ & HE & $\boldsymbol{\sigma}_{\mathrm{EMU}}$ & $\mathbf{R}_{\mathrm{UH}}$ & $\mathbf{R}_{\mathbf{H}}$ & $\mathbf{R}_{\mathrm{EMU}}$ & SHR $_{\mathrm{UH}}$ & $\mathrm{SHR}_{\mathrm{H}}$ & $\mathrm{SHR}_{\mathrm{EMU}}$ \\
\hline \multirow{3}{*}{ Full Bond } & ALL & $\begin{array}{l}0.3738 \\
\mathbf{0 . 1 7 1 9}\end{array}$ & $\begin{array}{l}0.2315 \\
0.1344\end{array}$ & 9.6471 & 7.8829 & 33.2300 & 7.2925 & 1.4000 & 1.5900 & 0.9700 & 0.1400 & 0.2000 & 0.1300 \\
\hline & BC & $\begin{array}{c}0.3574 \\
0.0921\end{array}$ & $\begin{array}{l}0.1280 \\
0.0798\end{array}$ & 7.0368 & 6.3649 & 18.1847 & 6.5385 & -2.0900 & -1.1600 & -0.9300 & -14.7000 & -7.3800 & -6.0900 \\
\hline & DC & $\begin{array}{l}0.3901 \\
\mathbf{0 . 2 2 3 5}\end{array}$ & $\begin{array}{l}0.3343 \\
0.0919\end{array}$ & 11.6756 & 9.1446 & 38.6553 & 7.9730 & 4.9800 & 4.4000 & 2.6600 & 0.4300 & 0.4800 & 0.3300 \\
\hline \multirow{3}{*}{ Full Equity } & ALL & $\begin{array}{l}0.4311 \\
0.2811\end{array}$ & $\begin{array}{c}-0.0015 \\
\mathbf{0 . 3 3 4 4}\end{array}$ & 18.3956 & 17.4398 & 10.1212 & 22.2192 & 1.0600 & 3.0000 & -0.1400 & 0.0600 & 0.1700 & -3.0600 \\
\hline & $B C$ & $\begin{array}{l}0.4053 \\
0.2176\end{array}$ & $\begin{array}{l}0.2868 \\
\mathbf{0 . 1 2 9 9}\end{array}$ & 13.5760 & 12.9374 & 9.1866 & 15.4552 & 0.4500 & 1.7500 & 4.5400 & 0.0300 & 0.1400 & 0.2900 \\
\hline & DC & $\begin{array}{l}0.4568 \\
\mathbf{0 . 3 3 0 4}\end{array}$ & $\begin{array}{l}-0.2878 \\
\mathbf{0 . 2 0 4 0}\end{array}$ & 22.1763 & 20.9831 & 10.4710 & 27.3345 & 1.6600 & 4.2600 & -4.1600 & 0.0700 & 0.2000 & -113.6700 \\
\hline \multirow{3}{*}{$\begin{array}{c}\text { Bond + Equity } \\
\text { ( } 0.33 \text { each country) }\end{array}$} & ALL & $\begin{array}{l}0.3908 \\
\mathbf{0 . 1 2 8 2}\end{array}$ & $\begin{array}{l}0.1191 \\
0.1104\end{array}$ & 8.8453 & 8.0110 & 17.9744 & 10.8702 & 1.2300 & 1.7700 & 0.4200 & 0.1400 & 0.2200 & 0.0400 \\
\hline & BC & $\begin{array}{l}0.3809 \\
0.0997\end{array}$ & $\begin{array}{l}0.2064 \\
0.0695\end{array}$ & 7.1956 & 6.2683 & 24.1127 & 7.4940 & -0.8300 & 0.0900 & 1.7700 & -5.9400 & 0.0100 & 0.2400 \\
\hline & DC & $\begin{array}{l}0.4006 \\
\mathbf{0 . 1 5 0 7}\end{array}$ & $\begin{array}{l}0.0324 \\
0.0663\end{array}$ & 10.2259 & 9.4305 & 14.9502 & 13.4109 & 3.3100 & 3.4800 & -0.8100 & 0.3200 & 0.3700 & -10.8000 \\
\hline \multirow{3}{*}{$\begin{array}{l}\text { Bond + Equity } \\
\text { (0.60 EMU) }\end{array}$} & ALL & $\begin{array}{l}0.2601 \\
0.1202\end{array}$ & $\begin{array}{l}0.0213 \\
0.1289\end{array}$ & 9.0638 & 8.6535 & 8.8497 & 10.8702 & 0.9100 & 1.5900 & 0.4200 & 0.1000 & 0.1800 & 0.0400 \\
\hline & BC & $\begin{array}{l}0.2577 \\
0.0925\end{array}$ & $\begin{array}{l}0.1276 \\
0.0577\end{array}$ & 6.9744 & 6.5928 & 10.6451 & 7.4940 & 0.1600 & 0.6200 & 1.7700 & 0.0200 & 0.0900 & 0.2400 \\
\hline & DC & $\begin{array}{l}0.2626 \\
\mathbf{0 . 1 4 2 5}\end{array}$ & $\begin{array}{c}-0.0843 \\
\mathbf{0 . 0 8 6 0}\end{array}$ & 10.7478 & 10.3032 & 8.1015 & 13.4109 & 1.6600 & 2.5600 & -0.8100 & 0.1500 & 0.2500 & -10.8000 \\
\hline
\end{tabular}

Notes: Full bond portfolio (Full Bond), Full equity Portfolio (Full Equity), Bond and equity portfolio (equally 33\% country weight, 50\% bonds, 50\% equities), home biased Bond and equity portfolio, (60\% EMU, 20\% the UK and 20\% the US), for the EMU portfolio the investor is only holding domestic equities and/or bonds based on the kind of international portfolio we are comparing with (full bond, full equity or equities + bonds), (B) whole period (ALL), Before Crisis (BC), During Crisis (DC), Euro units of British pound future sold $\left(\boldsymbol{\beta}_{1}\right)$, Euro units of US dollar future sold $\left(\boldsymbol{\beta}_{2}\right)$ per Euro invested in an international portfolio, annualized unhedged portfolio standard deviation $\left(\boldsymbol{\sigma}_{\mathrm{UH}}\right)$, , annualized hedged portfolio standard deviation $\left(\boldsymbol{\sigma}_{\mathrm{H}}\right)$, Hedging Effectiveness $(\mathbf{H E})$ ), , annualized European portfolio standard deviation ( $\left.\boldsymbol{\sigma}_{\mathrm{EMU}}\right)$, annualized unhedged portfolio Return $\left(\mathbf{R}_{\mathrm{UH}}\right)$, annualized hedged portfolio Return $\left(\mathbf{R}_{\mathbf{H}}\right)$, , annualized European portfolio return ( $\left.\mathbf{R}_{\mathrm{EMU}}\right)$, Sharpe Ratio (SHR). When returns are negative, following Israelsen (2005), we use the improved Sharpe ratio index tha is the result of multiplying the average returns by the standard deviation. 10+ year maturity bonds. 
Table A.28. BEKK MODEL - All maturities- Out-of-sample

\begin{tabular}{|c|c|c|c|c|c|c|c|c|c|c|c|c|c|}
\hline & & $\beta_{1}$ & $\beta_{2}$ & $\boldsymbol{\sigma}_{\mathrm{UH}}$ & $\boldsymbol{\sigma}_{\mathrm{H}}$ & HE & $\boldsymbol{\sigma}_{\mathrm{EMU}}$ & $\mathbf{R}_{\mathrm{UH}}$ & $\mathbf{R}_{\mathbf{H}}$ & $\mathbf{R}_{\mathrm{EMU}}$ & SHR $_{\mathrm{UH}}$ & $\mathrm{SHR}_{\mathrm{H}}$ & $\mathrm{SHR}_{\mathrm{EMU}}$ \\
\hline \multirow{4}{*}{ Full Bond } & ALL & $\begin{array}{l}0.2701 \\
0.0788\end{array}$ & $\begin{array}{l}0.3490 \\
\mathbf{0 . 1 0 1 4}\end{array}$ & 6.7623 & 4.3544 & 58.5361 & 3.7992 & 0.2100 & 0.5500 & 0.1300 & 0.0300 & 0.1300 & 0.0300 \\
\hline & BC & $\begin{array}{l}0.2761 \\
0.0849\end{array}$ & 0.2806 & 5.0128 & 3.7742 & 43.3117 & 3.3424 & -2.4900 & -1.0000 & -1.0500 & -12.4600 & -3.7900 & -3.5000 \\
\hline & DC & $\begin{array}{l}0.2649 \\
0.2642\end{array}$ & $\begin{array}{l}0.0751 \\
0.4170\end{array}$ & 81210 & 18625 & חمר2 61 & & & & & & & \\
\hline & & 0.0719 & 0.0750 & 8.1349 & 4.8023 & 64.2109 & 4.2047 & 2.9600 & 2.1100 & 1.1400 & 0.3600 & 0.4300 & 0.2100 \\
\hline \multirow{3}{*}{ Full Equity } & ALL & $\begin{array}{l}0.4394 \\
0.4524\end{array}$ & $\begin{array}{c}-0.0277 \\
\mathbf{0 . 6 0 4 5}\end{array}$ & 18.3956 & 17.3494 & 11.0508 & 22.2192 & 1.0600 & 2.5500 & -0.1400 & 0.0600 & 0.1500 & -3.0600 \\
\hline & BC & $\begin{array}{l}0.2401 \\
\mathbf{0 . 3 4 3 5}\end{array}$ & $\begin{array}{l}0.4526 \\
\mathbf{0 . 2 8 6 7}\end{array}$ & 13.5760 & 12.9554 & 8.9343 & 15.4552 & 0.4500 & 0.9800 & 4.5400 & 0.0300 & 0.0800 & 0.2900 \\
\hline & DC & $\begin{array}{l}0.6375 \\
\mathbf{0 . 4 6 0 7}\end{array}$ & $\begin{array}{c}-0.5048 \\
\mathbf{0 . 4 3 5 7}\end{array}$ & 22.1763 & 20.8218 & 11.8421 & 27.3345 & 1.6600 & 4.1400 & -4.2300 & 0.0700 & 0.2000 & -115.7500 \\
\hline \multirow{3}{*}{$\begin{array}{c}\text { Bond }+ \text { Equity } \\
\text { ( } 0.33 \text { each country) }\end{array}$} & ALL & $\begin{array}{c}0.3532 \\
\mathbf{0 . 2 0 7 8}\end{array}$ & $\begin{array}{l}0.1517 \\
\mathbf{0 . 2 6 4 7}\end{array}$ & 9.0076 & 8.0874 & 19.3880 & 10.8509 & 0.6310 & 1.4693 & -0.0061 & 0.0701 & 0.1817 & -0.0658 \\
\hline & BC & $\begin{array}{l}0.2579 \\
0.1611\end{array}$ & $\begin{array}{l}0.3655 \\
\mathbf{0 . 1 2 4 6}\end{array}$ & 7.1292 & 6.1075 & 26.6090 & 7.2977 & -1.0275 & -0.0524 & 1.7081 & -7.3256 & -0.3199 & 0.2341 \\
\hline & DC & $\begin{array}{c}0.4480 \\
0.2058\end{array}$ & $\begin{array}{c}-0.0607 \\
\mathbf{0 . 1 8 3 4}\end{array}$ & 10.5500 & 9.6627 & 16.1128 & 13.4868 & 2.3061 & 3.0038 & -1.5851 & 0.2186 & 0.3109 & -21.3782 \\
\hline \multirow{3}{*}{$\begin{array}{l}\text { Bond +Equity } \\
\text { (0.60 EMU) }\end{array}$} & ALL & $\begin{array}{l}0.2636 \\
\mathbf{0 . 2 2 9 2}\end{array}$ & $\begin{array}{l}0.0082 \\
0.3027\end{array}$ & 9.2475 & 8.6643 & 12.2160 & 10.8509 & 0.3796 & 1.1363 & -0.0061 & 0.0410 & 0.1312 & -0.0658 \\
\hline & BC & $\begin{array}{l}0.1665 \\
\mathbf{0 . 1 6 8 6}\end{array}$ & $\begin{array}{l}0.2444 \\
0.1388\end{array}$ & 6.8722 & 6.4626 & 11.5658 & 7.2977 & -0.0204 & 0.2701 & 1.7081 & -0.1403 & 0.0418 & 0.2341 \\
\hline & DC & $\begin{array}{l}0.3601 \\
0.2405\end{array}$ & $\begin{array}{c}-0.2265 \\
\mathbf{0 . 2 3 0 3}\end{array}$ & 11.1190 & 10.4029 & 12.4666 & 13.4868 & 0.7785 & 2.0042 & -1.5851 & 0.0700 & 0.1927 & -21.3782 \\
\hline
\end{tabular}

Notes: Full bond portfolio (Full Bond), Full equity Portfolio (Full Equity), Bond and equity portfolio (equally 33\% country weight, 50\% bonds, 50\% equities), home biased Bond and equity portfolio, (60\% EMU, 20\% the UK and 20\% the US), for the EMU portfolio the investor is only holding domestic equities and/or bonds based on the kind of international portfolio we are comparing with (full bond, full equity or equities + bonds), (B) whole period (ALL), Before Crisis (BC), During Crisis (DC), Euro units of British pound future sold $\left(\boldsymbol{\beta}_{1}\right)$, Euro units of US dollar future sold $\left(\boldsymbol{\beta}_{2}\right)$ per Euro invested in an international portfolio, annualized unhedged portfolio standard deviation $\left(\boldsymbol{\sigma}_{\mathrm{UH}}\right)$, , annualized hedged portfolio standard deviation $\left(\boldsymbol{\sigma}_{\mathrm{H}}\right)$, Hedging Effectiveness $(\mathbf{H E})$ ), , annualized European portfolio standard deviation ( $\left.\boldsymbol{\sigma}_{\mathrm{EMU}}\right)$, annualized unhedged portfolio Return $\left(\mathbf{R}_{\mathrm{UH}}\right)$, annualized hedged portfolio Return $\left(\mathbf{R}_{\mathbf{H}}\right)$, , annualized European portfolio return ( $\left.\mathbf{R}_{\mathrm{EMU}}\right)$, Sharpe Ratio (SHR). When returns are negative, following Israelsen (2005), we use the improved Sharpe ratio index tha is the result of multiplying the average returns by the standard deviation. All maturities bonds. 
Table A.29. BEKK MODEL - 1-3-Year Maturity- Out-of-sample

\begin{tabular}{|c|c|c|c|c|c|c|c|c|c|c|c|c|c|}
\hline & & $\beta_{1}$ & $\boldsymbol{\beta}_{2}$ & $\sigma_{U H}$ & $\sigma_{H}$ & HE & $\boldsymbol{\sigma}_{\mathrm{EMU}}$ & $\mathbf{R}_{\mathrm{UH}}$ & $\mathbf{R}_{\mathbf{H}}$ & $\mathbf{R}_{\mathrm{EMU}}$ & $\mathbf{S H R}_{\mathrm{UH}}$ & $\mathrm{SHR}_{\mathrm{H}}$ & SHR $_{\mathrm{EMU}}$ \\
\hline \multirow{4}{*}{ Full Bond } & ALL & $\begin{array}{l}0.2936 \\
0.0455\end{array}$ & $\begin{array}{l}0.3324 \\
0.0305\end{array}$ & 5.4712 & 2.3644 & 81.3244 & 1.5968 & -1.4400 & -0.9000 & -0.9400 & -7.8800 & -2.1300 & -1.5000 \\
\hline & \multirow{2}{*}{$\mathrm{BC}$} & 0.2734 & 0.3346 & \multirow{2}{*}{4.0970} & \multirow{2}{*}{2.0958} & \multirow{2}{*}{73.8331} & \multirow{2}{*}{1.3543} & \multirow{2}{*}{-2.9300} & \multirow{2}{*}{-1.1000} & \multirow{2}{*}{-1.2900} & \multirow{2}{*}{-12.0100} & \multirow{2}{*}{-2.3100} & \multirow{2}{*}{-1.7400} \\
\hline & & 0.0444 & 0.0280 & & & & & & & & & & \\
\hline & DC & $\begin{array}{l}0.3137 \\
\mathbf{0 . 0 3 6 9}\end{array}$ & $\begin{array}{l}0.3302 \\
0.0327\end{array}$ & 6.5578 & 2.6049 & 84.2219 & 1.8062 & 0.0600 & -0.7000 & -0.7000 & 0.0100 & -1.8300 & -1.2600 \\
\hline \multirow{3}{*}{ Full Equity } & ALL & $\begin{array}{l}0.4394 \\
0.4524\end{array}$ & $\begin{array}{l}-0.0277 \\
\mathbf{0 . 6 0 4 5}\end{array}$ & 18.3956 & 17.3494 & 11.0508 & 22.2192 & 1.0600 & 2.5500 & -0.1400 & 0.0600 & 0.1500 & -3.0600 \\
\hline & BC & $\begin{array}{l}0.2401 \\
0.3435\end{array}$ & $\begin{array}{l}0.4526 \\
\mathbf{0 . 2 8 6 7}\end{array}$ & 13.5760 & 12.9554 & 8.9343 & 15.4552 & 0.4500 & 0.9800 & 4.5400 & 0.0300 & 0.0800 & 0.2900 \\
\hline & DC & $\begin{array}{l}0.6375 \\
\mathbf{0 . 4 6 0 7}\end{array}$ & $\begin{array}{c}-0.5048 \\
\mathbf{0 . 4 3 5 7}\end{array}$ & 22.1763 & 20.8218 & 11.8421 & 27.3345 & 1.6600 & 4.1400 & -4.2300 & 0.0700 & 0.2000 & -115.7500 \\
\hline & ALL & $\begin{array}{l}0.3635 \\
0.2274\end{array}$ & $\begin{array}{l}0.1452 \\
0.3021\end{array}$ & 9.4721 & 8.5131 & 19.2247 & 11.0567 & -0.2003 & 0.7630 & -0.5403 & -1.8971 & 0.0896 & -5.9742 \\
\hline $\begin{array}{c}\text { Bond }+ \text { Equity } \\
\text { ( } 0.33 \text { each country) }\end{array}$ & BC & $\begin{array}{l}0.2523 \\
0.1722\end{array}$ & $\begin{array}{l}0.3896 \\
0.1371\end{array}$ & 7.4085 & 6.3645 & 26.1987 & 7.5115 & -1.2537 & -0.0989 & 1.5853 & -9.2879 & -0.6293 & 0.2111 \\
\hline & DC & $\begin{array}{l}0.4740 \\
0.2218\end{array}$ & $\begin{array}{c}-0.0976 \\
\mathbf{0 . 2 1 1 8}\end{array}$ & 11.1536 & 10.2123 & 16.1670 & 13.7015 & 0.8572 & 1.6265 & -2.4816 & 0.0769 & 0.1593 & -34.0011 \\
\hline & ALL & $\begin{array}{l}0.2695 \\
0.2434\end{array}$ & $\begin{array}{l}0.0045 \\
\mathbf{0 . 3 3 3 5}\end{array}$ & 9.6668 & 9.0217 & 12.9016 & 11.0567 & -0.3376 & 0.5612 & -0.5403 & -3.2636 & 0.0622 & -5.9742 \\
\hline $\begin{array}{l}\text { Bond +Equity } \\
\text { (0.60 EMU) }\end{array}$ & BC & $\begin{array}{c}0.1583 \\
0.1778\end{array}$ & $\begin{array}{l}0.2662 \\
0.1515\end{array}$ & 7.1385 & 6.7062 & 11.7446 & 7.5115 & -0.2200 & 0.2462 & 1.5853 & -1.5703 & 0.0367 & 0.2111 \\
\hline & DC & $\begin{array}{l}0.3800 \\
0.2496\end{array}$ & $\begin{array}{c}-0.2556 \\
\mathbf{0 . 2 5 1 4}\end{array}$ & 11.6509 & 10.8464 & 13.3336 & 13.7015 & -0.4543 & 0.8751 & -2.4816 & -5.2934 & 0.0807 & -34.0011 \\
\hline
\end{tabular}

Notes: Full bond portfolio (Full Bond), Full equity Portfolio (Full Equity), Bond and equity portfolio (equally 33\% country weight, 50\% bonds, 50\% equities), home biased Bond and equity portfolio, (60\% EMU, 20\% the UK and 20\% the US), for the EMU portfolio the investor is only holding domestic equities and/or bonds based on the kind of international portfolio we are comparing with (full bond, full equity or equities + bonds), whole period (ALL), Before Crisis (BC), During Crisis (DC), Euro units of British pound future sold $\left(\boldsymbol{\beta}_{1}\right)$, Euro units of US dollar future sold $\left(\boldsymbol{\beta}_{2}\right)$ per Euro invested in an international portfolio, annualized unhedged portfolio standard deviation $\left(\boldsymbol{\sigma}_{\mathrm{UH}}\right)$, , annualized hedged portfolio standard deviation $\left(\boldsymbol{\sigma}_{\mathrm{H}}\right)$, Hedging Effectiveness $(\mathbf{H E})$, , annualized European portfolio standard deviation $\left(\boldsymbol{\sigma}_{\mathrm{EMU}}\right)$, annualized unhedged portfolio Return $\left(\mathbf{R}_{\mathrm{UH}}\right)$, annualized hedged portfolio Return $\left(\mathbf{R}_{\mathbf{H}}\right)$, , annualized European portfolio return ( $\mathbf{R}_{\mathrm{EMU}}$ ), Sharpe Ratio (SHR). When returns are negative, following Israelsen (2005), we use the improved Sharpe ratio index that is the result of multiplying the average returns by the standard deviation. All maturities bonds. 
Table A.30. BEKK MODEL - 10+-Year Maturity- Out-of-sample

\begin{tabular}{|c|c|c|c|c|c|c|c|c|c|c|c|c|c|}
\hline & & $\beta_{1}$ & $\beta_{2}$ & $\sigma_{U H}$ & $\sigma_{\mathrm{H}}$ & HE & $\boldsymbol{\sigma}_{\mathrm{EMU}}$ & $\mathbf{R}_{\mathrm{UH}}$ & $\mathbf{R}_{\mathbf{H}}$ & $\mathbf{R}_{\mathrm{EMU}}$ & SHR $_{U H}$ & $\mathrm{SHR}_{\mathrm{H}}$ & $\mathrm{SHR}_{\mathrm{EMU}}$ \\
\hline \multirow{3}{*}{ Full Bond } & ALL & $\begin{array}{l}0.2473 \\
0.1539\end{array}$ & $\begin{array}{l}0.3703 \\
0.2330\end{array}$ & 9.6471 & 7.7125 & 36.0864 & 7.2925 & 1.4000 & 1.1900 & 0.9700 & 0.1400 & 0.1500 & 0.1300 \\
\hline & BC & $\begin{array}{l}0.2978 \\
0.1329\end{array}$ & $\begin{array}{l}0.2061 \\
\mathbf{0 . 1 2 7 2}\end{array}$ & 7.0368 & 6.3115 & 19.5515 & 6.5385 & -2.0900 & -1.1800 & -0.9300 & -14.7000 & -7.4400 & -6.0900 \\
\hline & DC & $\begin{array}{l}0.1972 \\
\mathbf{0 . 1 5 6 9}\end{array}$ & $\begin{array}{l}0.5335 \\
\mathbf{0 . 1 9 6 7}\end{array}$ & 11.6756 & 8.8888 & 42.0400 & 7.9730 & 4.9800 & 3.6000 & 2.5800 & 0.4300 & 0.4000 & 0.3200 \\
\hline \multirow{3}{*}{ Full Equity } & ALL & $\begin{array}{c}0.4394 \\
\mathbf{0 . 4 5 2 4}\end{array}$ & $\begin{array}{c}-0.0277 \\
\mathbf{0 . 6 0 4 5}\end{array}$ & 18.3956 & 17.3494 & 11.0508 & 22.2192 & 1.0600 & 2.5500 & -0.1400 & 0.0600 & 0.1500 & -3.0600 \\
\hline & $B C$ & $\begin{array}{c}0.2401 \\
0.3435\end{array}$ & $\begin{array}{l}0.4526 \\
\mathbf{0 . 2 8 6 7}\end{array}$ & 13.5760 & 12.9554 & 8.9343 & 15.4552 & 0.4500 & 0.9800 & 4.5400 & 0.0300 & 0.0800 & 0.2900 \\
\hline & DC & $\begin{array}{l}0.6375 \\
\mathbf{0 . 4 6 0 7}\end{array}$ & $\begin{array}{c}-0.5048 \\
\mathbf{0 . 4 3 5 7}\end{array}$ & 22.1763 & 20.8218 & 11.8421 & 27.3345 & 1.6600 & 4.1400 & -4.2300 & 0.0700 & 0.2000 & -115.7500 \\
\hline \multirow{3}{*}{$\begin{array}{c}\text { Bond }+ \text { Equity } \\
(0.33 \text { each country) }\end{array}$} & ALL & $\begin{array}{l}0.3461 \\
\mathbf{0 . 1 9 0 7}\end{array}$ & $\begin{array}{l}0.1658 \\
0.2249\end{array}$ & 8.8453 & 7.9874 & 18.4569 & 10.8702 & 1.2264 & 1.8538 & 0.4169 & 0.1387 & 0.2321 & 0.0384 \\
\hline & BC & $\begin{array}{l}0.2753 \\
\mathbf{0 . 1 6 0 4}\end{array}$ & $\begin{array}{l}0.3418 \\
\mathbf{0 . 1 2 1 3}\end{array}$ & 7.1956 & 6.2395 & 24.8071 & 7.4940 & -0.8261 & -0.0259 & 1.7670 & -5.9441 & -0.1613 & 0.2358 \\
\hline & DC & $\begin{array}{c}0.4164 \\
\mathbf{0 . 1 9 2 4}\end{array}$ & $\begin{array}{c}-0.0091 \\
\mathbf{0 . 1 5 7 7}\end{array}$ & 10.2259 & 9.4092 & 15.3339 & 13.4109 & 3.3073 & 3.7558 & -0.8875 & 0.3234 & 0.3992 & -11.9016 \\
\hline \multirow{3}{*}{$\begin{array}{l}\text { Bond + Equity } \\
\text { (0.60 EMU) }\end{array}$} & ALL & $\begin{array}{l}0.2587 \\
\mathbf{0 . 2 1 1 8}\end{array}$ & $\begin{array}{l}0.0193 \\
\mathbf{0 . 2 6 2 6}\end{array}$ & 9.0638 & 8.5862 & 10.2607 & 10.8702 & 0.9093 & 1.4471 & 0.4169 & 0.1003 & 0.1685 & 0.0384 \\
\hline & BC & $\begin{array}{l}0.1857 \\
\mathbf{0 . 1 6 8 9}\end{array}$ & $\begin{array}{l}0.2205 \\
\mathbf{0 . 1 3 3 8}\end{array}$ & 6.9744 & 6.6041 & 10.3382 & 7.4940 & 0.1570 & 0.2628 & 1.7670 & 0.0225 & 0.0398 & 0.2358 \\
\hline & DC & $\begin{array}{l}0.3313 \\
\mathbf{0 . 2 2 4 8}\end{array}$ & $\begin{array}{c}-0.1805 \\
\mathbf{0 . 1 9 8 8}\end{array}$ & 10.7478 & 10.1830 & 10.2343 & 13.4109 & 1.6623 & 2.6374 & -0.8875 & 0.1547 & 0.2590 & -11.9016 \\
\hline
\end{tabular}

Notes: Full bond portfolio (Full Bond), Full equity Portfolio (Full Equity), Bond and equity portfolio (equally 33\% country weight, 50\% bonds, 50\% equities), home biased Bond and equity portfolio, (60\% EMU, 20\% the UK and 20\% the US), for the EMU portfolio the investor is only holding domestic equities and/or bonds based on the kind of international portfolio we are comparing with (full bond, full equity or equities + bonds), whole period (ALL), Before Crisis (BC), During Crisis (DC), Euro units of British pound future sold ( $\boldsymbol{\beta}_{1}$ ), Euro units of US dollar future sold $\left(\boldsymbol{\beta}_{2}\right)$ per Euro invested in an international portfolio, annualized unhedged portfolio standard deviation $\left(\boldsymbol{\sigma}_{\mathbf{U H}}\right)$, , annualized hedged portfolio standard deviation $\left(\boldsymbol{\sigma}_{\mathrm{H}}\right)$, Hedging

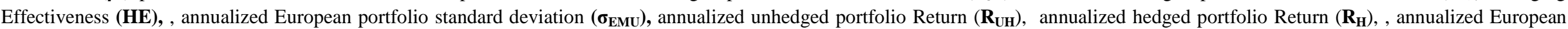
portfolio return $\left(\mathbf{R}_{\mathbf{E M U}}\right)$, Sharpe Ratio (SHR). When returns are negative, following Israelsen (2005), we use the improved Sharpe ratio index that is the result of multiplying the average returns by the standard deviation. $10+$ year maturity bonds. 
Figure A.1. Hedging ratio. Full bond / 1-3-year maturity
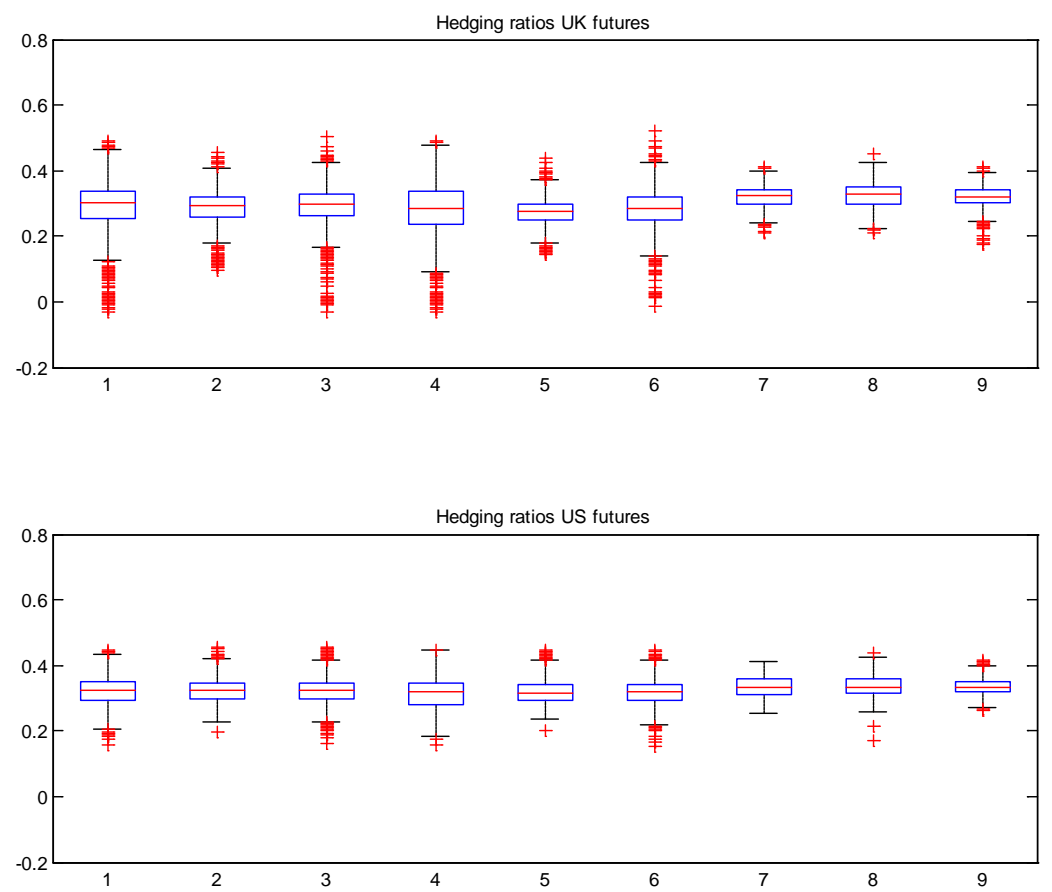

Figure A.2. Hedging ratios. Full bond / 10+-year maturity
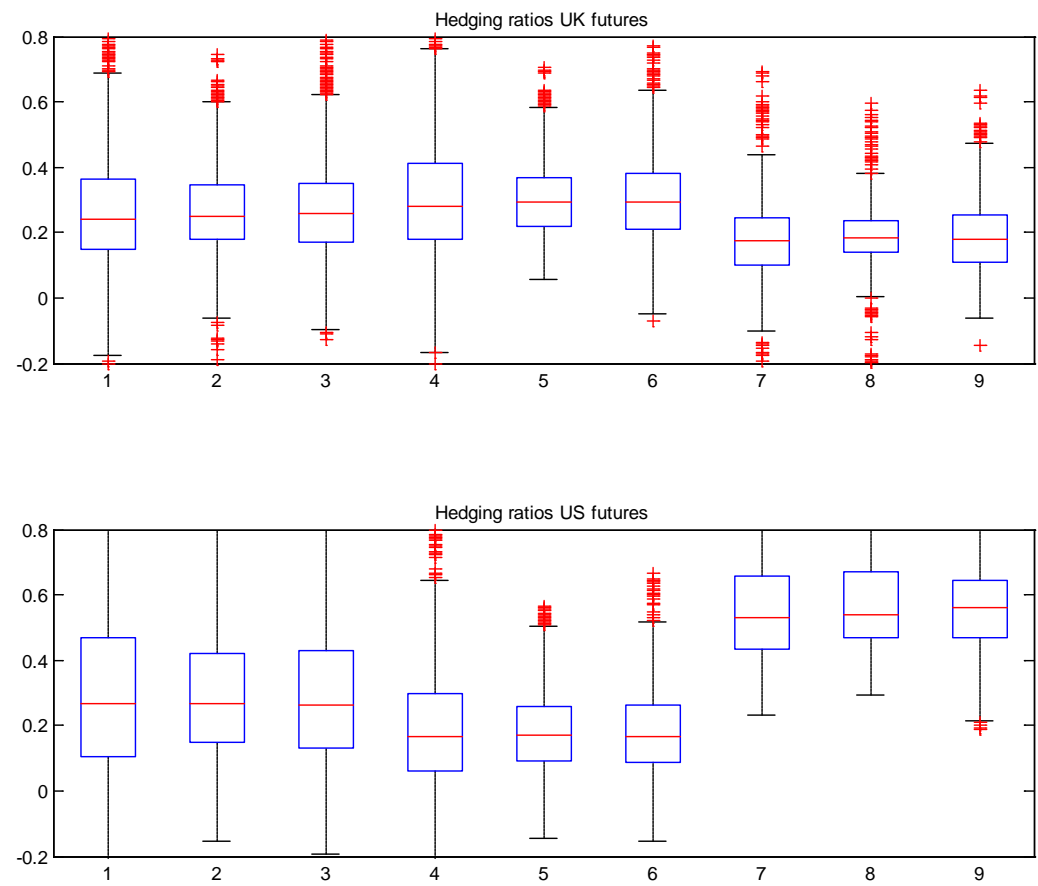
Figure A.3. Hedging ratios. Equity + Bond (0.33) / 1-3-year maturity
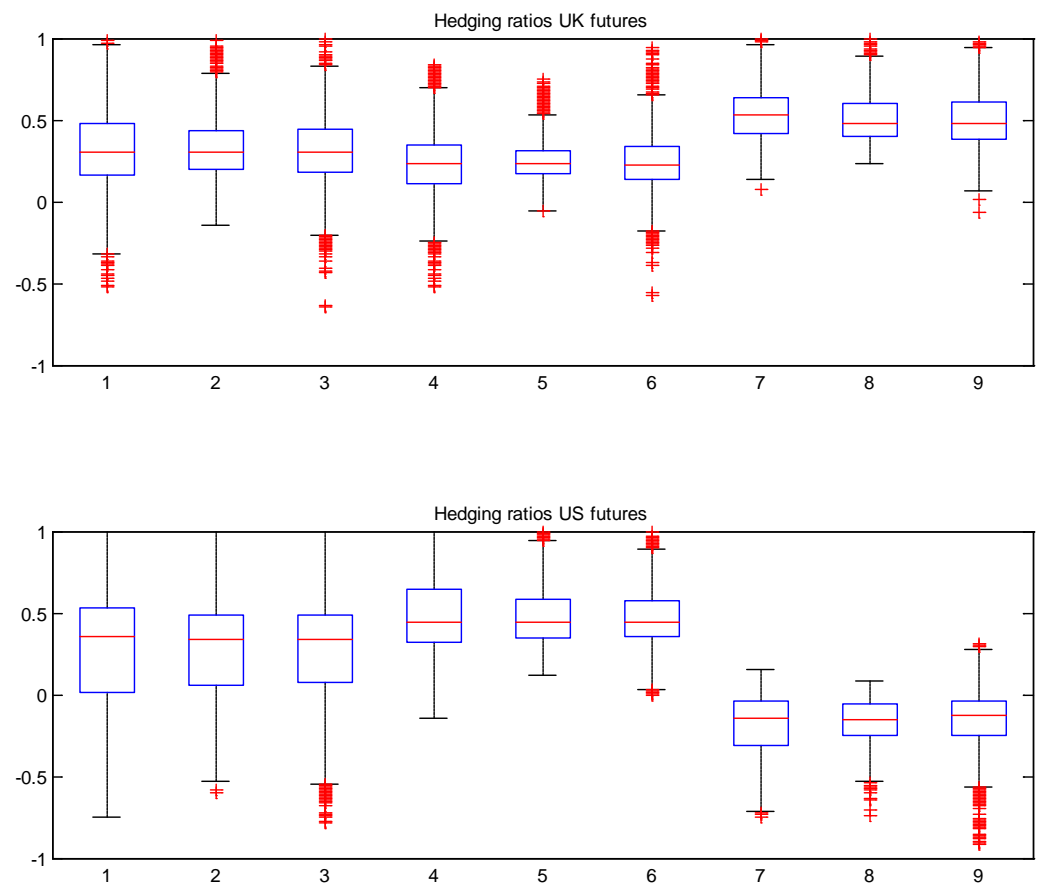

Figure A.4. Hedging ratios. Equity + Bond (0.33) / 10+-year maturity
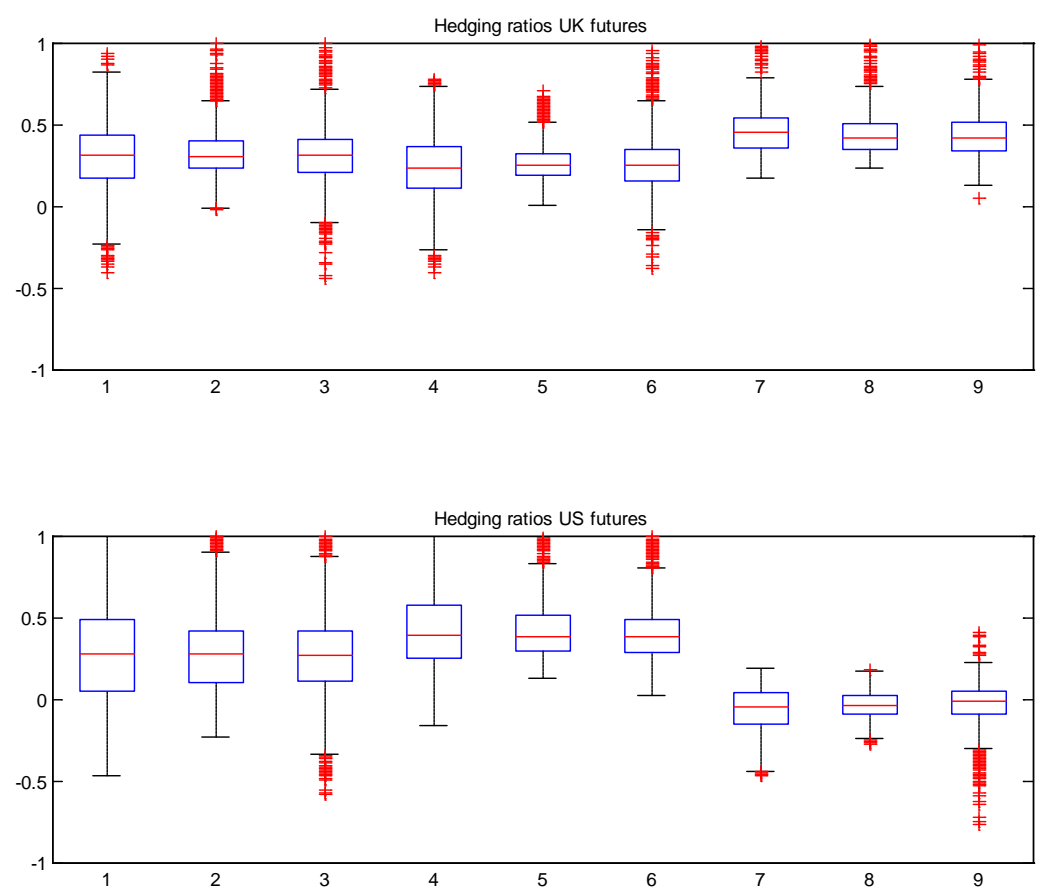
Figure A.5. Hedging ratios. Equity + Bond (0.6/0.20/0.20) / 1-3-year maturity
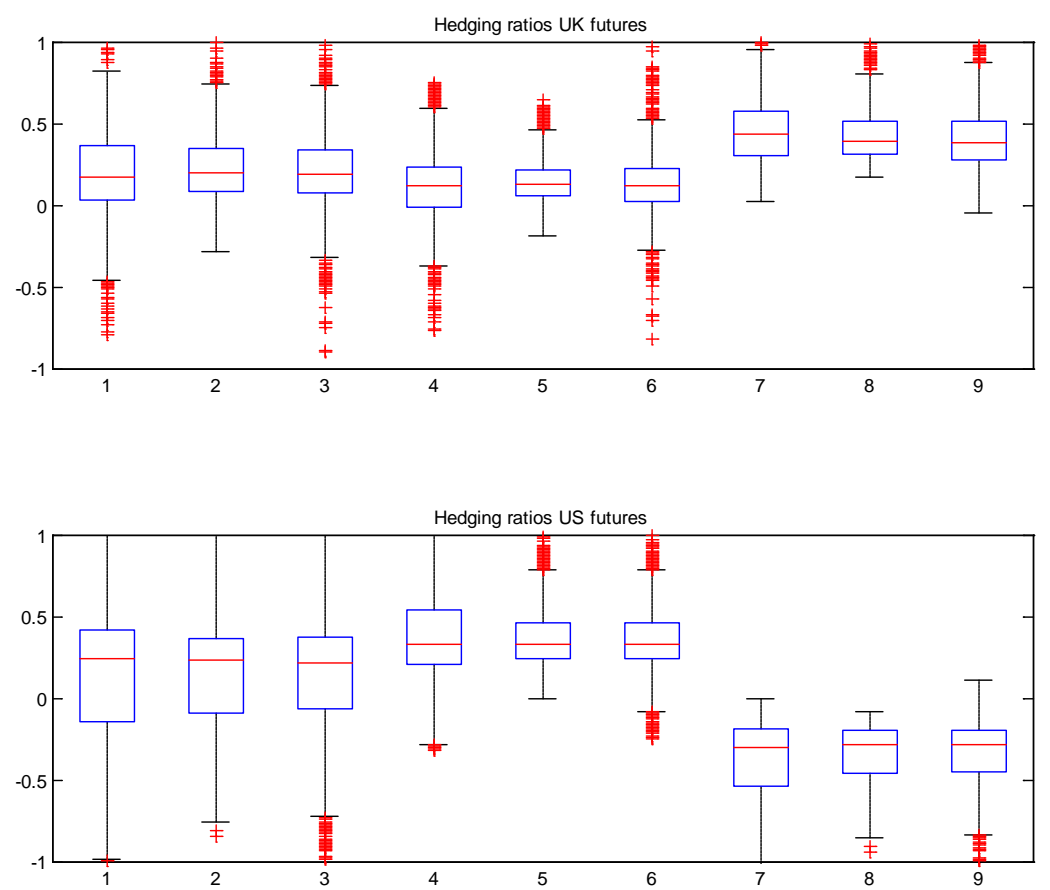

Figure A.6. Hedging ratios. Equity + Bond $(0.6 / 0.20 / 0.20) / 10+$ year maturity
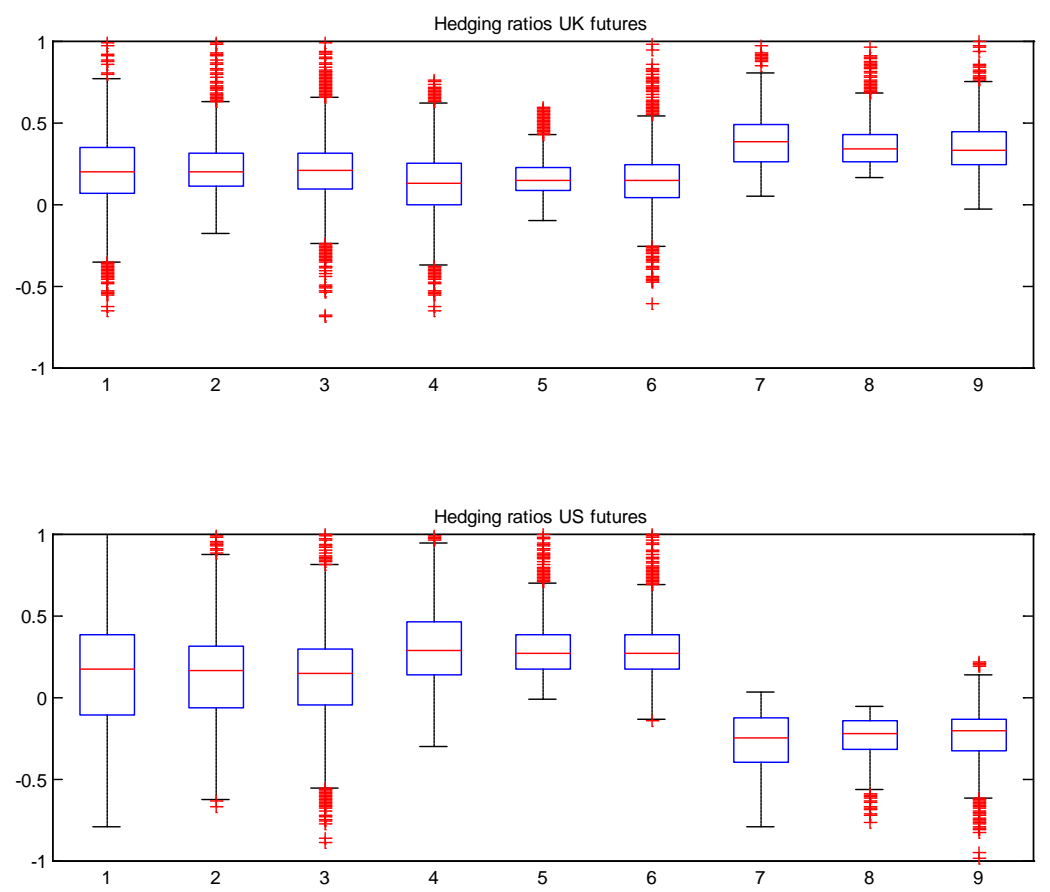
Figure A.7. Hedging ratio. Full bond / 1-3-year maturity- Out-of-Sample

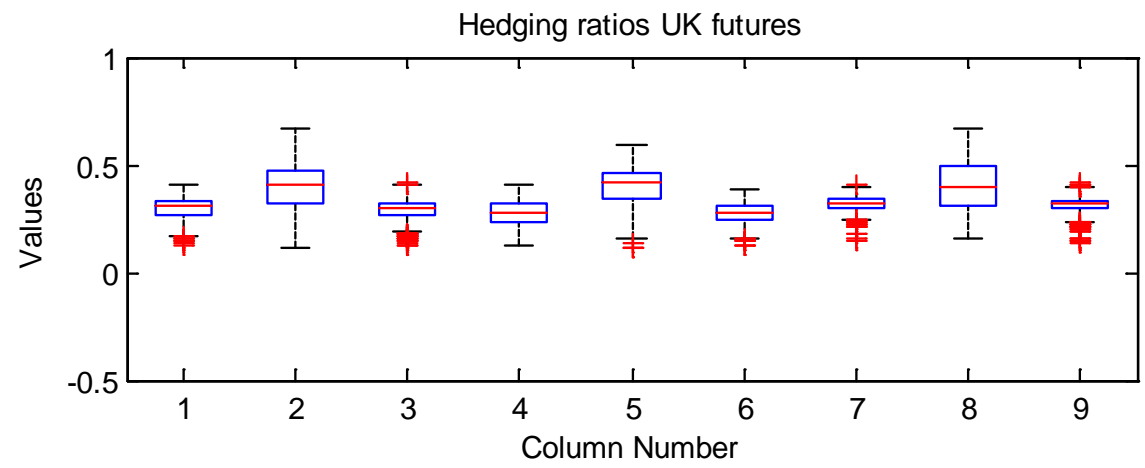

Hedging ratios US futures

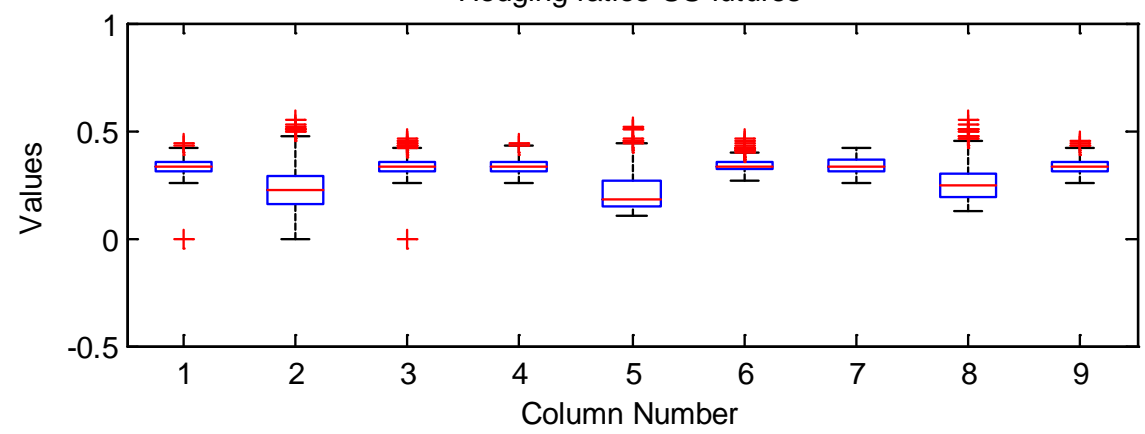

Figure A.8. Hedging ratios. Full bond / 10+-year maturity- Out-of-Sample
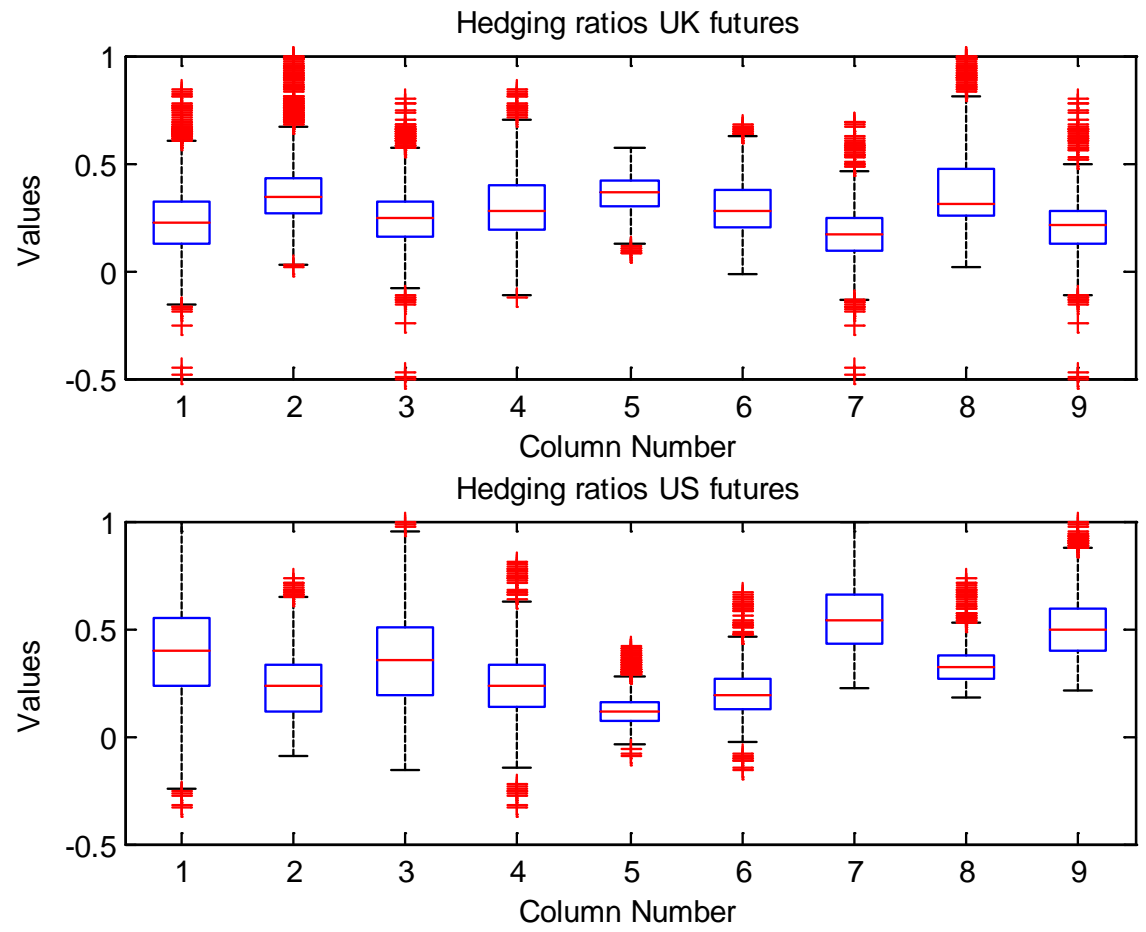
Figure A.9. Hedging ratios. Equity + Bond (0.33) / 1-3-year maturity- Out-of-Sample

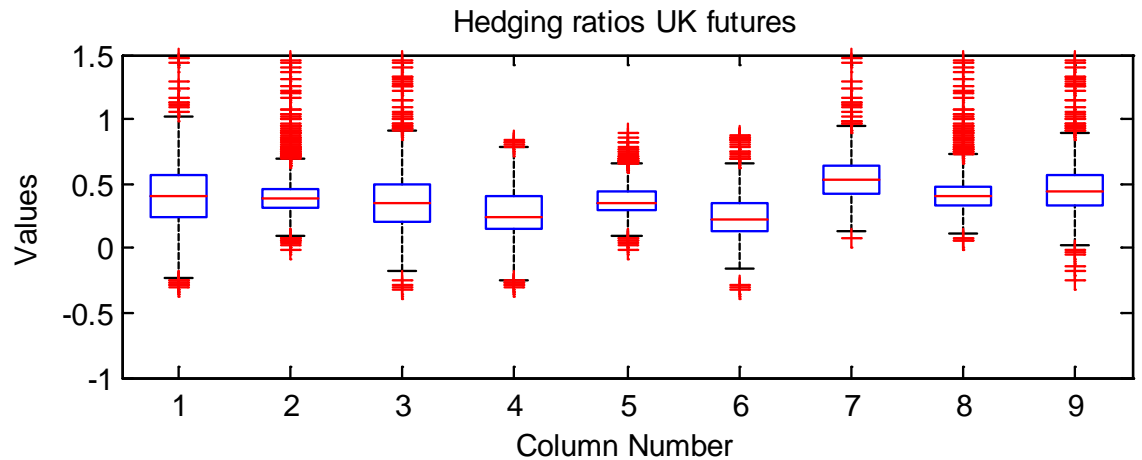

Hedging ratios US futures

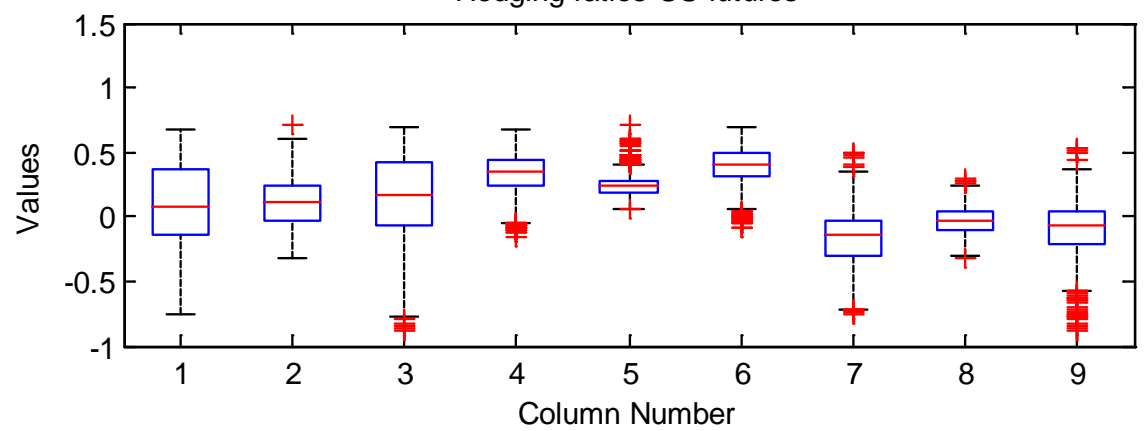

Figure A.10. Hedging ratios. Equity + Bond (0.33) / 10+-year maturity- Out-of-Sample
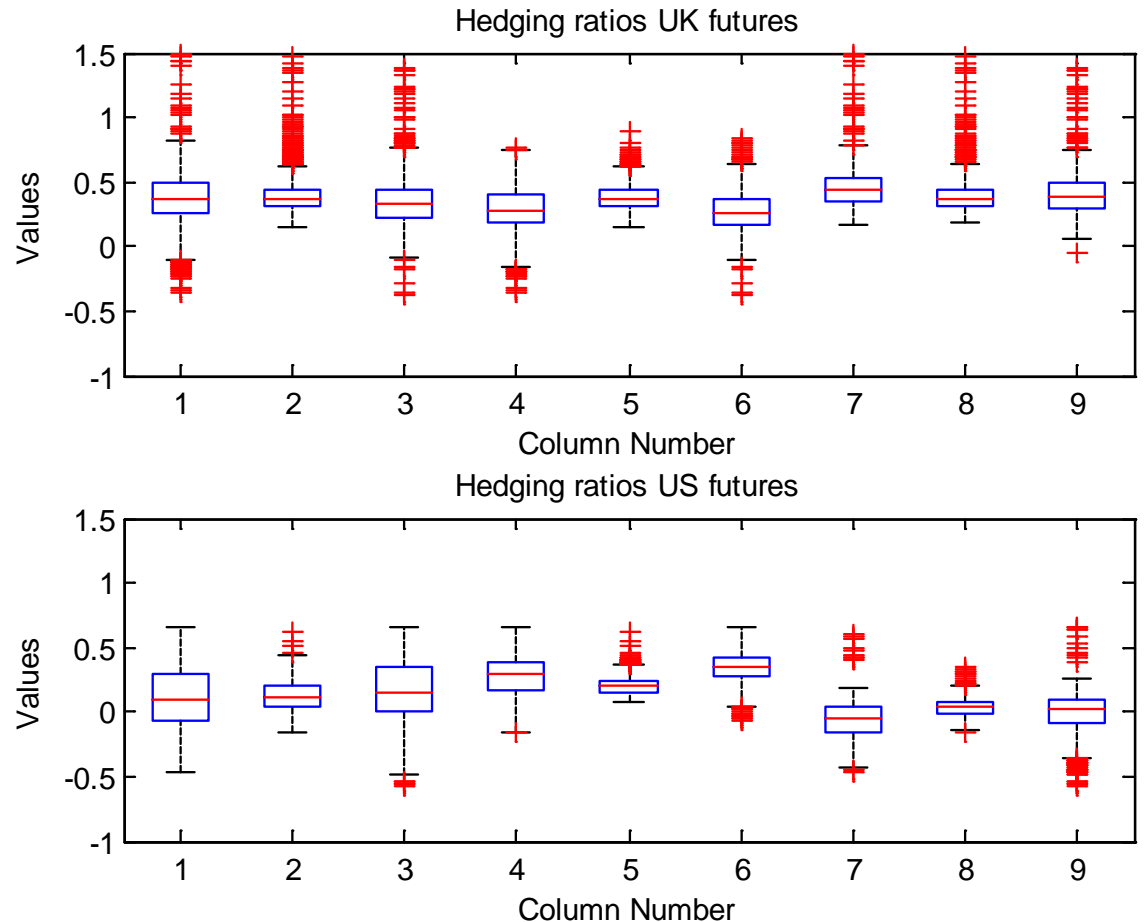
Figure A.11. Hedging ratios. Equity + Bond (0.6/0.20/0.20) / 1-3-year maturity- Out-ofSample
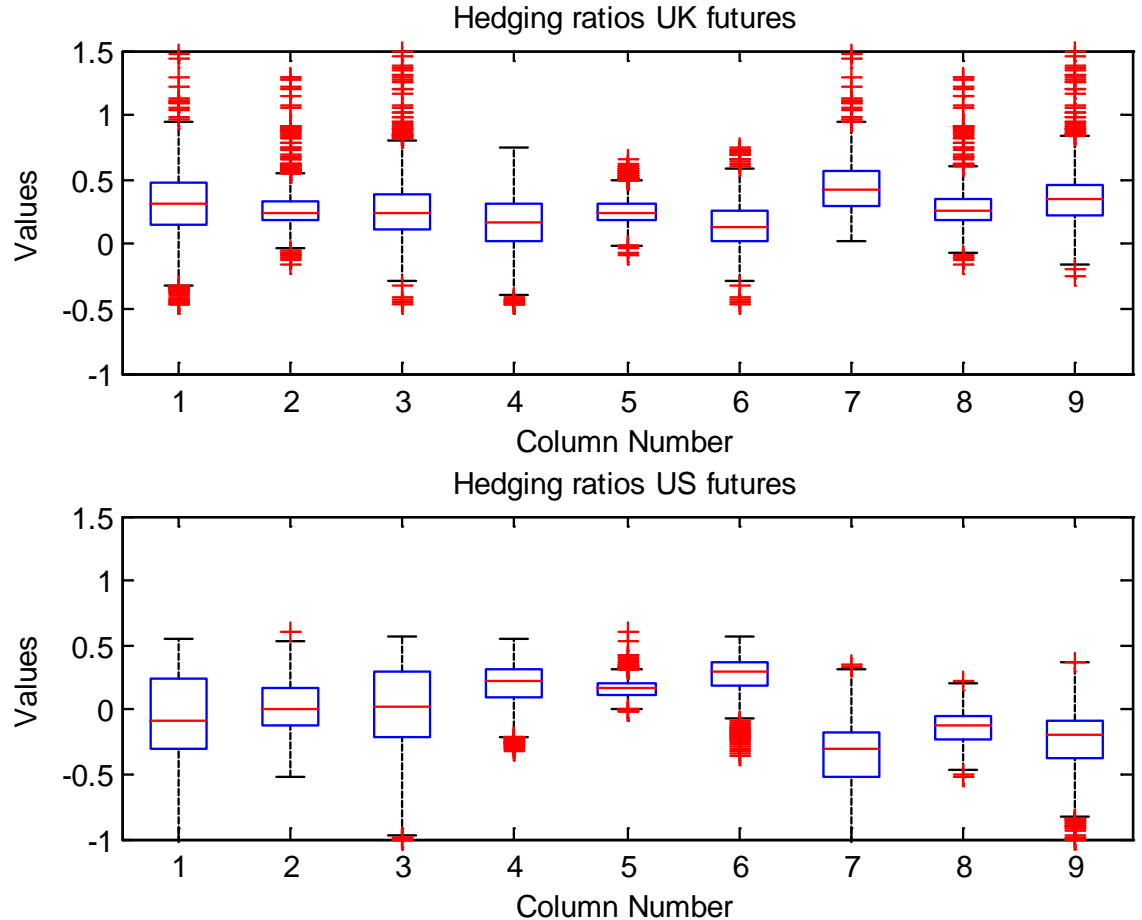

Figure A.12. Hedging ratios. Equity + Bond (0.6/0.20/0.20) / 10+year maturity - Out-ofSample

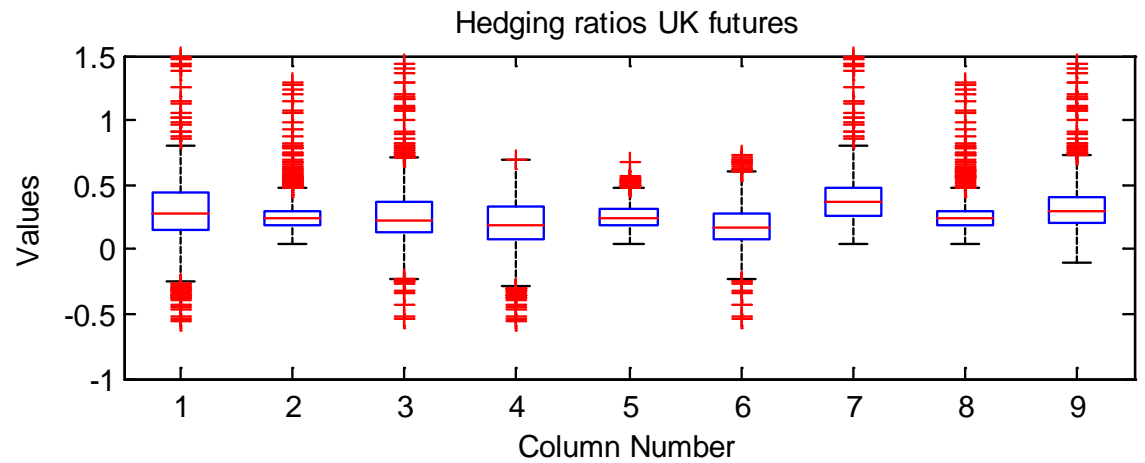

Hedging ratios US futures

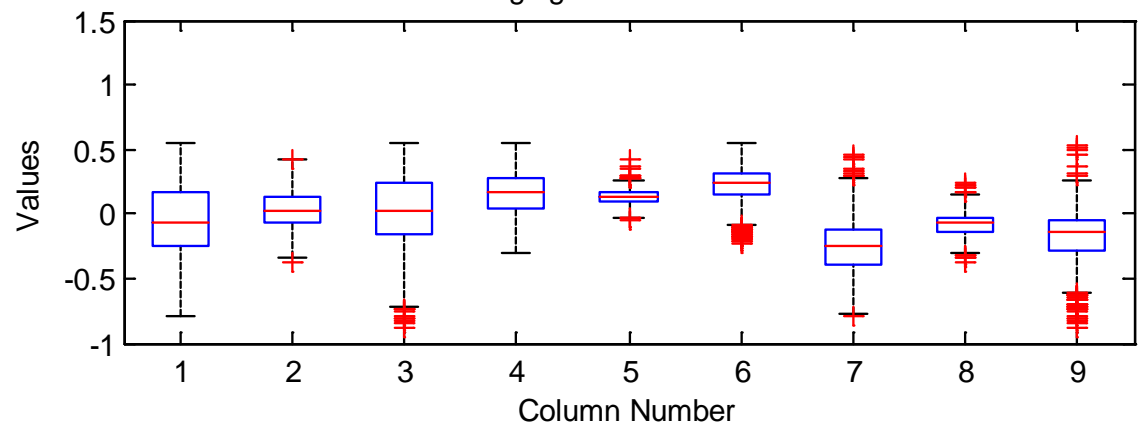

